UNIVERSIDADE DE SÃO PAULO

Instituto de Física e Química de São Carlos

\title{
CONTRIBUIÇÕES ÀS TÉCNICAS DE ESPECTROSCOPIAS FOTOTÉRMICAS \\ E APLICAÇÕES A MATERIAIS POLIMÉRICOS
}

Washington Luiz de Barros Melo

$$
\text { OK }
$$

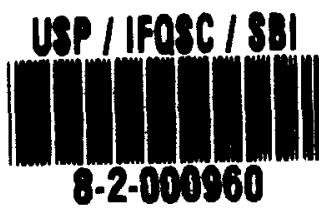

Tese apresentada ao Instituto de Física e Química de São Carlos, para a obtenção do título de: Doutor em Física

Orientador: Prof. Dr. Roberto Mendonça Faria

Departamento de Física e Ciência dos Materiais São Carlos - 1992 


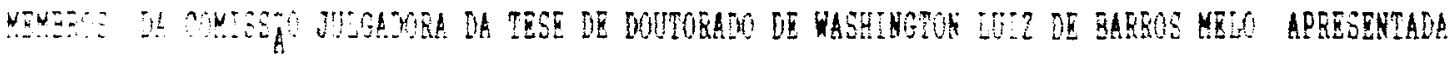

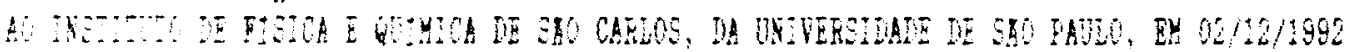

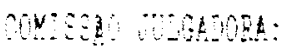

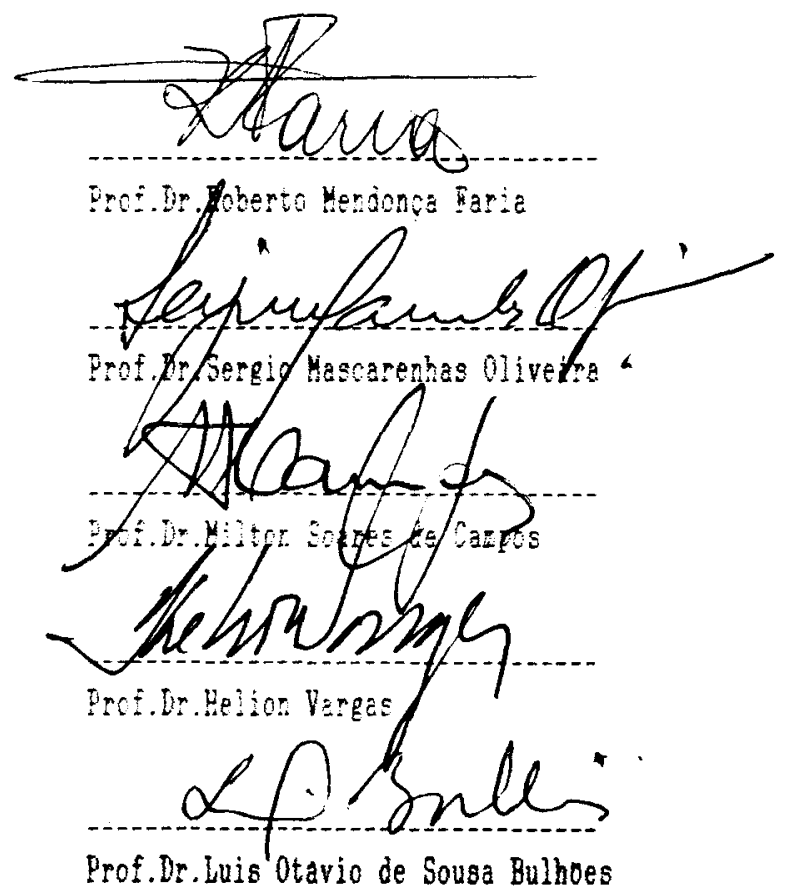




\section{ÍNDICE GERAL}

Índice de Assuntos $\quad$ ii

Índice de Figuras $\quad$ vi

Índice de Tabela $\quad$ ix

Agradecimentos $\quad$ x

RESUMO X xii

$\begin{array}{lll}\text { ABSTRACT } & \text { xiii }\end{array}$ 
Capítulo I - TÉCNICAS ESPECTROSCÓPICAS: FOTOACÚSTICA E FOTOPIROELÉ TRICA EM SÓLIDOS

1.1 - Histórico e Princípio Básico da Fotoacústica

$\begin{array}{ll}\text { 1.1.1 - Modelo RG } & 6\end{array}$

1.1.2 - Considerações sobre a Espectroscopia Fotoacústica 9

1.2 - Histórico e Princípio Básico da Fotopiroelétrica 11

$\begin{array}{lr}\text { 1.2.1 - Modelo PPES } & 12\end{array}$

1.2.2 - Considerações sobre a Técnica Fotopiroelétrica 15

1.3 - Referências 16

Capítulo II - INSTRUMENTAÇÃO: ESPECTRÔMETRO FOTOTÉRMICO, DESENVOL VIMENTO DE CÂMARAS FOTOACÚSTICA E FOTOPIROELÉTRICA

$\begin{array}{ll}2.1 \text { - Introdução } & 19\end{array}$

$\begin{array}{ll}2.2 \text { - O Espectrômetro } & 19\end{array}$

2.3 - Câmaras Fotoacústicas $\quad 23$

2.3.1 - Câmara FA1 24

2.3.2 - Câmara FA2 25

2.3.2 - Câmara FA3 26 
2.4 - Canara Fotopiroelétrica

2.4.1 - Câmara PPE1

2.4.2 - Câmara PPE2

2.5 - Câmara Combinada

2.6 - Considerações sobre as Câmaras FA e PPE 35

2.7 - Referências

Capítulo III - MODELO PARA ESPECTROSCOPIA FOTOPIROELÉTRICA POR REFLEX̃̃O

3.1 - Introdução

3.2 - Modelo Teórico 39

3.3 - Considerações sobre o modelo Fotopiroelétrico por Reflexão 44

3.3.1 - Amostra Termicamente Espessa

3.3.2 - Amostra Termicamente Fina

3.4 - Simulação do Modelo

3.5 - Aplicações

3.5.1 - Medidas Espectroscópicas

3.5.2 - Medidas Térmicas 
Capítulo IV - MÉTOdO FOTOACÚSTICO PARA DETERMINAÇÃO DE GRANDEZAS TERMICAS

4.1 - Introdução

62

4.2 - Modelo Fotoacústico para Amostras Transparentes 63

4.3 - Casos Limites $\quad 68$

$\begin{array}{ll}4.4 \text { - Considerações sobre o Modelo } & 70\end{array}$

$\begin{array}{ll}4.5 \text { - Aplicaçōes } & 72\end{array}$

$\begin{array}{ll}4.6 \text { - Referências } & 76\end{array}$

Capítulo V - MÉTODO SEMI-EMPÍRICO PARA A DETERMINAÇÃO DA DIFUSIVIDADE TÉRMICA

5.1 - Introdução $\quad 78$

$\begin{array}{ll}5.2 \text { - Método } & 79\end{array}$

5.3 - Considerações Gerais $\quad 82$

5.4 - Aplicações $\quad 84$

5.5 - Referências $\quad 86$

Capítulo VI - DETERMINAÇÃO DE PARÂMETROS TÉRMICOS E ÓTICOS DO FILME DE POLI(3-BUTIL-TIOFENO) POR ESPECTROSCOPIA FOTOPIROELÉTRICA

$\begin{array}{ll}6.1 \text { - Introdução } & 87\end{array}$

$\begin{array}{lr}6.2 \text { - O Poli(3-Butiltiofeno) } & 89\end{array}$ 
6.3 - Procedimentos Experimentais $\quad 90$

6.3.1 - Medidas PPES do P3BT com Câmara PPE Fechada 90

6.3.2 - Medidas PPES do P3BT com Câmara PPE aberta 93

6.4 - Determinação da Difusividade e Condutividade térmicas 96

$\begin{array}{ll}\text { 6.4.1 - P3BT não dopado } & 98\end{array}$

$\begin{array}{ll}6.4 .2 \text { - P3BT dopado } & 100\end{array}$

6.5 - Determinação das Grandezas Óticas 102

$\begin{array}{ll}6.6 \text { - Referências } & 105\end{array}$

\section{Capítulo VII - CONCLUSÕES}

$\begin{array}{ll}7.1 \text { - Do Modelo PPESR } & 107\end{array}$

7.2 - Modelo Fotoacústico para Amostra Transparentes 108

7.3 - Método Semi-empírico para Determinação da Difusividade Térmica 108

$\begin{array}{ll}7.4 \text { - Estudos do P3BT } & 109\end{array}$

7.5 - Sugestões aos Usuários das Técnicas Fototérmicas 110

$\begin{array}{ll}7.6 \text { - Trabalhos Futuros } & 111\end{array}$ 


\section{fndice de Figuras}

FIG-1.1 Esquema de uma câmara fotoacústica. (b) suporte, (s) amostra, (g) gás, (w) janela transparente, $(M)$ microfone

FIG-1.2 Esquema do sistema fotopiroelétrico. (b) suporte, (p) detetor piroelétrico,

(s) amostra, (g) gás ou outra substância transparente.

FIG-2.1 Esquema em bloco do Espectrômetro Fototérmico

FIG-2.2 Esquema do instrumental usado na obtenção do sinal fototérmico versus frequência de modulação

FIG-2.3 Esquema da câmara fotoacústica FA1

FIG-2.4 Esquema da câmara fotoacústica FA2

FIG-2.5 Esquema da câmara fotoacústica FA3

FIG-2.6 Esquema da câmara fotopiroelétrica PPE1

FIG-2.7 Esquema da câmara fotopiroelétrica PPE2

FIG-2.8 Esquema do dispositivo fotopiroelétrico para a câmara combinada

FIG-3.1 Esquema do sistema PPESR. (b) suporte, (p) detetor, (g) gás ou outro material.

FIG-3.2 Resposta em frequência do sinal PPERS de uma amostra transparente.

FIG-3.3 Curvas da fase para a amostra transparente

FIG-3.4 Resposta com a frequência do sinal PPERS para amostra absorvedora

FIG-3.5 Curva da fase para a amostra absorvedora

FIG-3.6 Curvas de respostas das fases PPESR. Polímero: PVDF, vidro: quartzo, metal: Alumínio 
FIG-3.7 Resposta em frequência do sinal PPESR. $b_{p t}=0,1$

FIG-3.8 Resposta em frequência do sinal PPESR. $b_{p t}=10^{3}$

FIG-3.9 Espectro de absorção do filme de PMMA + rodamina, obtido através do espectrofotômetro Cary 2315

FIG-3.10 Espectro de Rodamina sobre matriz polimérica de PMMA obtido com detetor branco

FIG-3.11 Espectro de rodamina+PMMA obtido por PPESR com pobre contato térmico

FIG-3.12 Espectro de rodamina sobre matriz polimérica de PMMA obtido com detetor preto.

FIG-3.13 Curvas dos sinais fotopiroelétricos versus frequência de modulação (filme de PVDF)

FIG-3.14 Fases dos sinais mostrados na FIG-3.13

FIG-3.15 Curva da variação do sinal fotopiroelétrico da pastilha de silício com a frequência de modulação.

FIG-3.16 Curva da fase dos sinais da FIG-3.15.

FIG-4.1 Esquema do sistema PA para caracterização de amostras transparentes.

(b)suporte absorvedor, (s) amostra transparente, (g) gás, (w) janela

FIG-4.2 Sinal PA normalizado do filme PVDF $\mathrm{x}$ frequência...

FIG-4.3 Fase do sinal PA do filme de PVDF $\mathrm{x}$ freq...

FIG-4.4 Sinal PA normalizado do filme de PMMA $x$ freq.

FIG-4.5 Fase do sinal PA do filme de PMMA $x$ raíz da freq... 
FIG-4.6 Sinal PA normalizado $x$ freq. do filme de PVC...

FIG-4.7 Fase do sinal PA do filme de PVC $\mathrm{x}$ raíz da freq....

FIG-5.1 Curva $\log (\log (S))$ da amostra hipotética com espessura de $1 \mu \mathrm{m}$. A curva cheia é o melhor ajuste pela eq.(5.9).

FIG-5.2 Curva $\log (\log (S))$ da amostra hipotética com espessura $70 \mu \mathrm{m}$. Curva cheia é o melhor ajuste pela eq.(5.9).

FIG-5.3 Curva $\log (\log )$ dos pontos experimentais obtidos pela técnica fotopiroelétrica e o ajuste pela eq.(5.9), para o filme de P3BT.

FIG-5.4 Curva $\log (\log )$ dos pontos experimentais obtidos por fotoacústica - OPC e o ajuste pela equação (5.9), para o filme P3BT.

FIG-6.1 Unidade básica do polímero P3BT 89

FIG-6.2 Espectros normalizados do filme de P3BT em diversas frequências de modulação

FIG-6.3 Fases dos sinais PPES do filme de P3BT em diversas frequências

FIG-6.4 Amplitude normalizada do sinal PPES do filme de P3BT obtido com câmara PPE aberta

FIG-6.5 Fase do sinal PPES do filme de P3BT obtida com câmara aberta

FIG-6.6 Variação da amplitude do sinal PPES do filme de P3BT com a frequência de modulação na região saturada obtida com a câmara aberta

FIG-6.7 Variação da fase PPES do filme de P3BT com a frequência de modulação na região saturada obtida com a câmara aberta 
FIG-6.8 Variação de $V_{n}$ com a frequência de modulação. Linha cheia é o melhor ajuste

FIG-6.9 Variação da fase com a frequência de modulação. Linha cheia é o melhor ajuste

FIG-6.10 Curva da variação da amplitude do sinal PPES do filme P3BT dopado. Curva cheia melhor ajuste

FIG-6.11 Variação da fase do sinal PPES com a frequência de modulação, para o filme de P3BT dopado. Linha cheia é o melhor ajuste 100

FIG-6.12 $\beta_{\mathrm{g}} \mathrm{L}$, versus energia (eV) obtido do espectro de P3BT na frequência de $500 \mathrm{~Hz}$ 


\section{AGRADECIMENTO}

Desejo agradecer a todos que direta $\mathrm{e}$ indiretamente contribuiram para a realização deste trabalho.

Agradeço, especialmente:

ao Prof. Roberto Mendonça Faria pela orientação, pelo otimismo e amizade;

ao Prof. Sergio Mascarenhas pela orientação inicial e pela amizade;

ao Prof. Otaciro R. Nascimento por sua amizade e consideração;

à Profa. R. Sanches pelas discussões sobre o assunto estudado e pela sua amizade; aos colegas e amigos do DEE-UNESP Ilha Solteira pelo apoio que me deram para que

eu continuasse no programa de doutoramento. Agradeço, especialmente, à A. A. Carvalho (Cidão) pelo apoio e incentivo, além da sua amizade;

aos demais professores do Grupo de Eletretos: Lençóis, Chu, Mariangela e ao Prof. Guilherme, por sua amizade e distinção;

aos técnicos dos Laboratórios de Biofísica (Isabel e Roberto) e Eletretos (Níbio e Zé Berto) pela amizade e assessoria técnica;

à Silvio Tonissi Jr pelo seu apoio no interfaceamento e no programa de aquisição de dados, além de sua amizade;

às secretárias Suely (Biofísica), Ivoninha (Eletretos) e Bené por sua amizade e dedicação;

à todos os colegas dos Grupos de Biofísica e Eletretos pela amizade e incentivo. Agradeço, especialmente, a Cristina Lara e a Marinônio Cornélio; 
à A. Pawlicka por ter, gentilmente, formecido as amostras do P3BT, além de seu apoio e amizade;

à todos os técnicos da Oficina Mecânica, especialmente a Carlos, João, Manoel e Ferri pela amizade e consideração. À Manoel pelo ótimo trabalho nas construções das câmaras fotoacústicas e fotopiroelétrica;

aos técnicos da oficina eletrônica pelo seu apoio e a amizade mantida;

à Marcão, do Lab. Luminescência, pelo apoio e consideração.

Agradeço muito especialmente aos meus pais, Heleno e Alice por terem me dado os primeiros passos para a vida. Também a minha família que atualmente é composta por Eleonice (esposa) e filhas: Natália, Lis e Luize por seu amor e compreensão.

Desejo agradecer ao PICD-CAPES pela ajuda financeira e a FAPESP por ter financiado o Projeto de Construção das Câmaras Fototérmicas.

$x i$ 


\section{RESUMO}

A espectroscopia fototérmica tem sido largamente usada na investigação de propriedades térmicas e óticas de materiais sólidos. Neste trabalho, desenvolvemos novas câmaras fototérmicas as quais foram adaptadas para os estudos de materiais poliméricos. Estendemos o modelo desenvolvido por Mandelis para a espectroscopia fotopiroelétrica (PPES), incluindo nele um termo devido à reflexão de luz na interface amostra-detetor. A aplicação da técnica PPES em filmes de Poli(3-Butiltiofeno) não dopado nos permitiu obter sua condutividade e difusividade térmicas, como também seu "gap" de energia. Também aplicamos a técnica fotoacústica, com um flash de laser $\mathrm{He}-\mathrm{Ne}$, ao estudo de filmes de polímeros transparentes. Finalmente, desenvolvemos um método semi-empírico o qual simplifica a análise do sinal fototérmico, quando ele é, principalmente, devido à difusão térmica. 


\begin{abstract}
Photothermal spectroscopies have been largely used in the investigation of thermal and optical properties of solids materials. In this work we developed new photothermal cells which were adapted for the study of polymerics materials. We also extended the model developed by Mandelis for the Photopyroelectric Spectroscopy (PPES), including in it a term due to the reflected light in the sample-detector interface. The application of the PPES tecnique in films of undoped poly(3-butylthiophene) allowed us to obtain its thermal conductivity and diffusivity, as well as its band gap energy. We also applied the photoacoustic technique, with a flash of He-Ne laser to the study of transparent films of polymers. Finally we developed a semi-empiric method which simplifies the analysis of the photothermal signal, when it is mainly due to the thermal diffusion.
\end{abstract}




\section{INTRODUÇÃo}

Em 1880, Alenxader G. Bell descobriu que um feixe de luz, periodicamente interrompido, incidindo sobre a superfície de um sólido em uma câmara fechada gerava uma onda acústica a qual poderia ser audível. Esse efeito foi considerado como uma curiosidade e que não tinha interesse prático e foi esquecido por vários anos.

As técnicas fototérmicas se tornaram a partir da década de 70 grandes ferramentas de pesquisas nas diversas áreas da ciência, com os trabalhos teóricos de A. Rosencwaig e de outros. Com o crescente interesse nas aplicaçōes dessas técnicas, logo surgiram outros trabalhos teóricos que envolviam diferentes modalidades na deteção do sinal acústico e térmico. Em meados dos anos 80, Coufal e Mandelis usaram, pela primeira vez, um filme fino de Poli(vinilideno de flúor), que apresenta propriedades piezo e piroelétrica, como detetor de onda fototérmica, dando origem a uma nova técnica espectroscópica fototérmica. Devido ao seu potencial interdisciplinar, as técnicas fototérmicas vêm sendo aplicadas em diversos problemas em física, química, biologia, medicina e engenharia.

O princípio básico dessas técnicas consiste na conversão de energia luminosa, absorvida por uma amostra em estudo, em calor. Esse calor se propaga ao longo da amostra e provoca sua dilatação. A deteção do sinal pode ser feita por um dispositivo eletroacústico colocado num meio fluido em contato com a amostra, o qual indiretamente acusa a variação de temperatura (Efeito Fotoacústico), que é a base da Espectroscopia Fotoacústica (PAS). Também se pode usar detetores piezoelétricos que detetam alterações nas dimensões da amostra (Efeito Fotoacústico 
por Piezoeletricidade), e mais recentemente tem-se usado detetores piroelétricos que detetam diretamente a variação de temperatura da amostra (Efeito fotopiroelétrico), do qual origina a Espectroscopia Fotopiroelétrica (PPES).

Neste trabalho temos como objetivos o uso e o desenvolvimento de novos modelos e métodos para as técnicas fototérmicas que se apliquem nos estudos de filmes finos políméricos, em especial, a polímeros condutores.

Os modelos teóricos que descrevem as técnicas PAS e PPES são apresentados no capítulo I, onde demos ênfase aos dois mais usados: Modelo RG para a fotoacústica e o Modelo de Mandelis para a fotopiroelétrica.

No capítulo II descrevemos a instrumentação usada neste trabalho e também os desenvolvimentos de câmaras detetoras fotoacústicas e fotopiroelétricas, além de um tipo de câmara híbrida que denominamos de câmara combinada. Esta última envolve a deteção fotoacústica e fotopiroelétrica, simultaneamente.

Um novo modelo para a técnica fotopiroelétrica foi desenvolvido no qual é levado em consideração a reflexão da superfície do detetor, quando esse é uma superfície espelhada. Este modelo é apresentado e discutido no capítulo III. Algumas aplicações são feitas demonstrando a capacidade e utilidade da técnica.

Um simples modelo fotoacústico foi desenvolvido com o fim de caracterizar amostras transparentes, sendo possível determinar facilmente a sua difusividade e a condutividade térmica. Este desenvolvimento é apresentado e discutido no capítulo IV. Alguns polímeros cujas grandezas térmicas são conhecidas na literatura foram usados como amostras testes.

No capítulo V, apresentamos um método semi-empírico que se baseia em outros modelos 
já desenvolvidos, onde a difusão térmica é o fenômeno dominante. Este método tem como princípio o uso do logarítmo, uma função complexa, como ferramenta de ajuste dos pontos experimentais - amplitude versus frequência de modulação.

As técnicas e os métodos foram usados nos estudos do Poli(3-Butiltiofeno), P3BT, que é um polímero condutor. Estes tipos de polímeros apresentam coloração escura, quando na forma de filme, o que dificulta o estudo de suas propriedades óticas por técnicas espectroscópicas convencionais. Assim, as técnicas fototérmicas tornam-se adequadas para auxiliar nos estudos desse novos materiais.

No capítulo VI, apresentamos estudos feitos com o P3BT usando a técnica fotopiroelétrica a qual é apropriada para filmes finos. Além das grandezas óticas, coeficiente de absorção e "gap" ótico, também determinamos a difusividade e condutividade térmicas da amostra em dois estados: não dopado e dopado. Demonstramos que é possível monitorar o nível de dopagem através desta técnica. Este estudo é inédito na área de polímeros condutores.

No capítulo VII, apresentamos as conclusōes desse trabalho, um roteiro de sugestōes para iniciantes nas técnicas fototérmicas e também sugestões para trabalhos futuros. 


\section{CAPITULO I}

\section{TÉCNICAS ESPECTROSCÓPICAS: FOTOACÚSTICA E FOTOPIROELÉTRICA EM SÓLIDOS}

\section{1 - HISTÓRICO E PRINCÍPIO BÁSICO DA FOTOACÚSTICA}

A Espectroscopia Fotoacústica (PAS), apesar de ter pouco mais de um século, só na década de 70 é que se tornou uma ferramenta espectroscópica importante [1-3]. É uma técnica simples que permite obter espectros de absorção (nas regiões de UV-VIS-IV) de uma larga variedade de materiais, tais como: sólidos, semi-sólidos, pós, géis, filmes, e tantos outros.

O princípio físico da PAS é o Efeito Fotoacústico. Este efeito foi descoberto no século XIX e foi relatado pela primeira vez em 1880 por Alexander Graham Bell. Além deste pesquisador, também John Tyndall e Wilhelm Röntgen estudaram o efeito. $\mathrm{O}$ efeito ocorre quando um gás no interior de uma câmara fechada é iluminado com luz periodicamente interrompida. A energia absorvida pelo gás é convertida em energia cinética das moléculas do gás, dando origem a flutuação da pressão dentro da câmara, a qual foi detetada em 1881 como som audível [4].

Durante aproximadamente 50 anos o efeito fotoacústico ficou esquecido, não havendo registro científico de progressos no seu estudo. Com a descoberta do microfone foi natural a sua utilização como detetor do efeito fotoacústico. Nas décadas de 40 a 70 o efeito foi usado como técnica de análise de gases, entretanto, estudos fotoacústicos de líquidos e sólidos só ocorreram 
a partir de 1970 [4].

Em PAS de sólido, a amostra é colocada dentro de uma cámara contendo um gás e um microfone. A amostra é iluminada com luz monocromática modulada. A luz absorvida pela amostra é convertida, parcial ou completamente, em calor através de processo de conversão não radiativo no interior da amostra. Consequentemente, o sinal fotoacústico pode ser originado por diferentes mecanismos, os quais são [5]:

expansão térmica - a amostra periodicamente aquecida se expande e se contrai gerando uma onda acústica;

nexão termoelástica - um gradiente de temperatura surgindo ao longo da espessura faz com que a expansão térmica seja diferente em diferentes pontos perpendiculares ao gradiente;

difusão têrmica através da amostra - o fluxo periódico de calor da amostra na vizinhança do gás gera flutuações de pressão no gás.

Para amostras sólidas as contribuiçōes da expansão térmica e flexão termoelástica são desprezíveis comparado com a difusão térmica. Assim sendo, a partir da década de 70 surgiram diversos modelos teóricos [6-11] para a PAS. Os mais famosos são o de A. Rosencwaig e A. Gersho [6], conhecido como Modelo RG, e o de F. A. McDonald e G. C. Wetsel Jr. [7] ou Modelo MW.

Dependendo da situação física o modelo RG satifaz a maioria dos casos, enquanto o modelo MW é aplicado em muitos casos de interesses físicos. Por isso, nos limitaremos a apresentar os princípios básicos do modelo RG já que é largamente usado. 


\subsection{1 - MODELO RG}

A fonte principal de sinal acústico é o fluxo periódico de calor da amostra para o gás quando esta é periodicamente aquecida pela luz. A luz absorvida pela amostra é, parcial ou totalmente, convertida em calor por processo de desexcitação não radiativa dentro da amostra. Pensando, assim, RG desenvolveram um modelo unidimensional do fluxo de calor na câmara, resultante da absorção de energia luminosa [6].

Supondo que a luz monocromática seja sinusoidal

$$
I=\frac{1}{2} I_{0}(1+\cos \omega t)
$$

onde $I_{o} e ́$ a intensidade da luz incidente e $\omega$ é a frequência angular de modulação, então, a densidade de calor produzido devido à absorção da luz em algum ponto $\mathrm{x}$ no interior da amostra é dada por

$$
\frac{1}{2} \beta_{s} \eta_{s} I_{0} \exp \left(\beta_{s} x\right)(1+\cos \omega t)
$$

sendo $\beta_{\mathrm{s}}$ - coeficiente de absorção ótica da amostra $\left(\mathrm{cm}^{-1}\right)$ e $\eta_{\mathrm{s}}$ - eficiência de conversão da luz absorvida em calor pelo amostra.

A FIG-1.1 mostra um esquema de uma câmara fotoacústica. Considerando que a amostra está na forma de disco com diâmetro $\mathrm{D}$ e espessura $\mathrm{L}_{\mathbf{s}}$ montada de maneira que sua superfície frontal esteja exposta ao gás dentro da câmara e sua superfície traseira esteja sobre um suporte mau condutor térmico. Supondo que o gás e o suporte não absorvem luz, então temos três regiões de distribuição de calor através da câmara. 


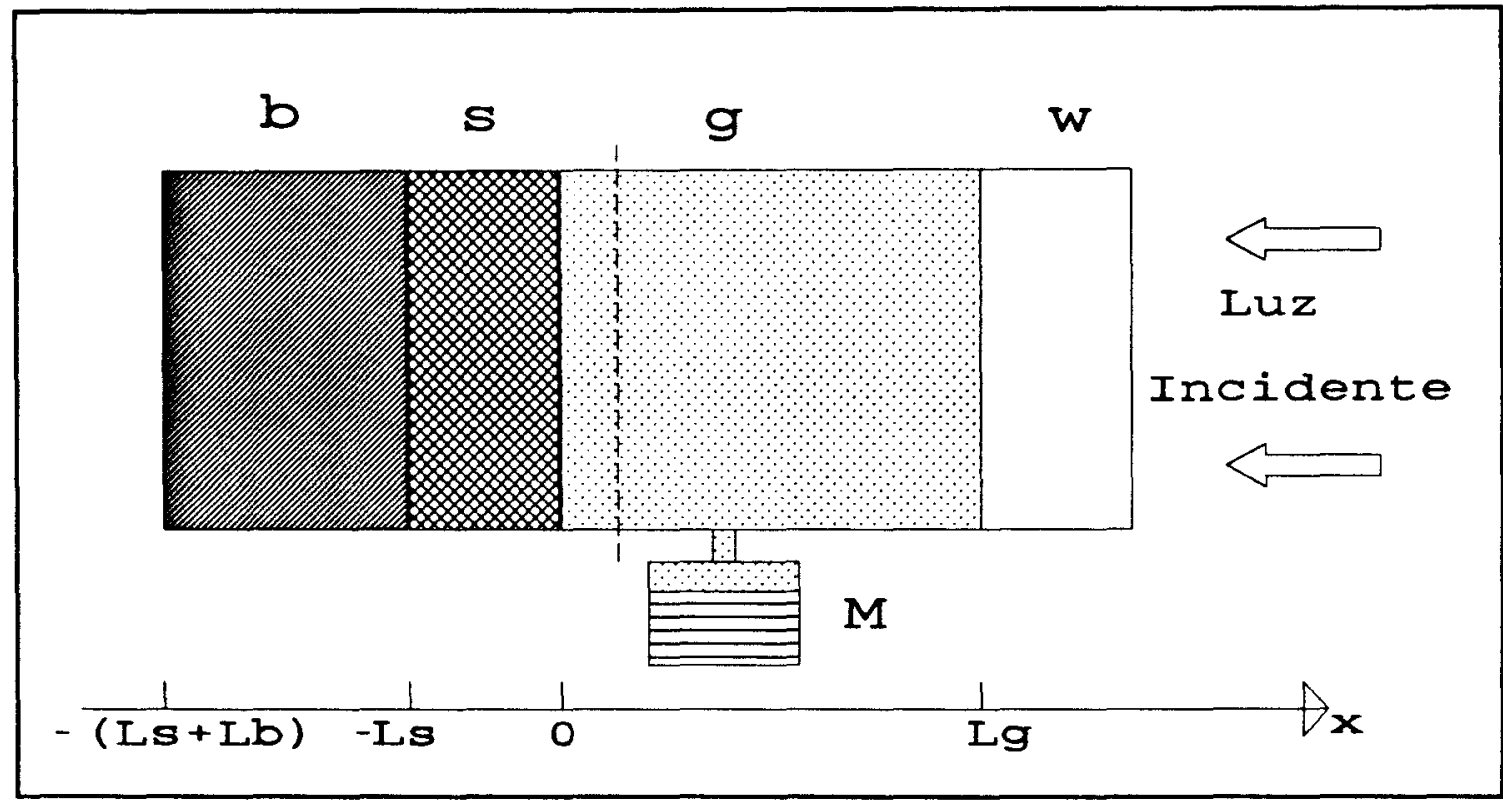

FIG-1.1 - Esquema de uma cámara fotoacústica. (b) suporte, (s) amostra, (g) gás; (w) janela transparente, (M) microfone.

Portanto, as equações de difusão de calor no interior da câmara são:

$1-$ para $0 \leq \mathrm{x} \leq \mathrm{L}_{\mathrm{g}}$

$$
\frac{\partial^{2} T_{g}}{\partial x^{2}}-\sigma_{g}^{2} T_{g}=0
$$

2 - Para $-\mathrm{L}_{\mathbf{a}} \leq \mathrm{x} \leq 0$

$$
\frac{\partial^{2} T_{s}}{\partial x^{2}}-\sigma_{s}^{2} T_{s}=-\left[\frac{\beta_{s} I_{o} \eta_{s}}{2 k_{s}}\right] e^{\beta \beta_{s} x}\left[1+e^{j \omega t}\right]
$$

3 - Para $-\left(\mathrm{L}_{\mathrm{a}}+\mathrm{L}_{\mathrm{b}}\right) \leq \mathrm{x} \leq-\mathrm{L}_{\mathrm{s}}$

$$
\frac{\partial^{2} T_{b}}{\partial x^{2}}-\sigma_{b}^{2} T_{b}=0
$$


Aplicando-se as condições de contorno - de temperatura e continuidade do fluxo de calor - e supondo que o gás se comporta idealmente numa fina camada próxima à superfície da amostra e no restante adiabaticamente, obtém-se que a variação de pressão é dada por $[4,6]$ :

$$
\begin{aligned}
\Delta P & =\frac{\beta_{s} I_{0} \gamma P_{0}}{2 \sqrt{2} k_{s} L_{g} a_{g} T_{0}\left(\beta_{s}^{2}-\sigma_{s}^{2}\right)}\left[\left(I_{s}-1\right)\left(b_{b s}+1\right) e^{\sigma_{s} I_{s}}-\left(I_{s}+1\right)\left(b_{b s}-1\right) e^{-\sigma_{s} I_{s}}+\right. \\
& \left.+2\left(b_{b s}-I_{s}\right) e^{-\beta_{s} L_{s}}\right]+\left[\left(b_{g s}+1\right)\left(b_{b s}+1\right) e^{\left.\sigma_{s} I_{s}-\left(b_{g s}-1\right)\left(b_{b s}-1\right) e^{-\sigma_{s} I_{s}}\right]}\right.
\end{aligned}
$$

sendo $\gamma$ a razão dos calores específicos, $\mathrm{P}_{\mathrm{o}}$ e $\mathrm{T}_{\mathrm{o}}$ a pressão e temperatura ambiente. Os demais coeficientes são:

$\mathrm{k}_{\mathrm{i}}$ - condutividade térmica do material i (cal/cm.seg. $\left.{ }^{\circ} \mathrm{C}\right)$

$\rho_{\mathrm{i}}$ - densidade do material i $\left(\mathrm{g} / \mathrm{cm}^{3}\right)$

$\mathrm{c}_{\mathrm{i}}$ - calor específico do material i $\left(\mathrm{cal} / \mathrm{g}{ }^{\circ} \mathrm{C}\right)$

$\alpha_{\mathrm{i}}=\mathrm{k}_{\mathrm{i}} / \rho_{\mathrm{i}} \mathrm{c}_{\mathrm{i}}-$ difusividade térmica do material i $\left(\mathrm{cm}^{2} / \mathrm{seg}\right)$

$\mathrm{e}_{\mathrm{i}}=\left(\mathrm{k}_{\mathrm{j}} \rho_{\mathrm{i}} \mathrm{c}_{\mathrm{j}}\right)^{1 / 2}$ - efusividade térmica do material i $\left(\mathrm{cal} / \mathrm{cm}^{2}{ }^{\circ} \mathrm{C}\right.$ seg. $\left.{ }^{1 / 2}\right)$

$a_{i}=\left(\omega / 2 \alpha_{i}\right)^{1 / 2}$ - coeficiente de difusão térmica do material i $\left(\mathrm{cm}^{-1}\right)$

$\mu_{\mathrm{i}}=1 / \mathrm{a}_{\mathrm{i}}$ - comprimento de difusão térmica do material i $(\mathrm{cm})$

$\beta_{\mathrm{i}}$ - coeficiente de absorção ótica do material i $\left(\mathrm{cm}^{-1}\right)$

$\sigma_{\mathrm{i}}=(1+\mathrm{j}) \mathrm{a}_{\mathrm{i}}$ - coeficiente complexo de difusão térmica do material $\mathrm{i}$

$b_{i \neq i}=\left(k_{i} \sigma_{i}\right) /\left(k_{\ngtr i} \sigma_{\neq i}\right)$ - parâmetro de acoplamento térmico entre os materiais i e $\neq i$

$\mathrm{r}_{\mathrm{i}}=\beta_{\mathrm{i}} / \sigma_{\mathrm{i}}-$ parâmetro ótico-térmico

$\mathrm{i}=\mathbf{s , g}, \mathrm{b}, \ldots$ 
Nota-se na equação (1.6) que a amplitude do sinal fotoacústico além de depender das grandezas óticas e térmicas também depende da frequência de modulação. Assim, além de possibilitar estudos espectroscópicos, também podemos obter propriedades térmicas da amostra, como por exemplo: difusividade térmica, condutividade térmica, efusividade térmica, e calor específico [12-17]. Esta dependência com a frequência possibilita fazer estudos de profundidade na amostra [4,18-21]. Este processo é chamado de microscopia fotoacústica.

\subsection{2 - CONSIDERAÇÕES SOBRE A ESPECTROSCOPIA FOTOACÚSTICA}

A expressão para a PAS, obtida no modelo RG, é governada, principalmente, pelo primeiro comprimento de difusão $\left(\mu_{\S}\right)$, pelo coeficiente de absorção ótica $\left(\beta_{\mathfrak{s}}\right)$ e pela espessura da amostra $\left(\mathrm{L}_{2}\right)$. Uma interpretação do efeito é dada como segue [22].

Considerando que a distribuição de calor é governada por $\beta_{\mathrm{s}} \exp \left(-\beta_{\mathrm{a}} \mathrm{L}\right)$ onde $\mathrm{L}$ é a distância da superfície iluminada a um ponto no interior da amostra. Quando a absorção da amostra cresce, o sinal PA cresce porque: (i) a distribuição inicial de calor move-se para o interior da região entre o primeiro comprimento de difusão térmica - $\mu_{z}$ numa dada frequência de modulação - e a superfície frontal, (ii) a distribuição move-se em direção à superfície iluminada.

Ambas as situações continuam a ocorrer quando a transmissão ótica se aproxima de zero, e até que a distribuição inicial de calor esteja completamente no interior da região limitada por $\mu_{\mathrm{s}}$ e a superfície frontal, onde $\beta_{\mathrm{s}} \equiv \mathrm{a}_{\mathrm{a}}$, dando início a saturação fotoacústica.

Quando $\beta$, continua a crescer o aumento de sinal é somente devido ao mecanismo (ii), 
e à medida que a distribuição se aproxima da superfície iluminada, uma completa saturação do sinal finalmente ocorre tornando-se independente de $\beta_{\text {. }}$. Aumentando a frequência de modulação, isto é diminuindo $\mu_{v}$, a saturação fotoacústica ocorre para valores de $\beta_{\mathrm{a}}$ maiores. Isto acontece devido ao deslocamento de $\mu_{\mathrm{s}}$ em direção à superfície iluminada.

Isto indica que a técnica fotoacústica ainda continua obtendo informação espectroscópica, ao passo que a técnica espectroscópica por transmissão já alcançou a saturação.

Variando a frequência de modulação é possível passar da situação termicamente fina $\left(\mu_{\mathrm{a}}>\mathrm{L}_{\mathrm{a}}\right)$ para termicamente espessa $\left(\mu_{\mathrm{a}}<\mathrm{L}_{\mathrm{a}}\right)$. A frequência que produz a situação $\mu_{\mathrm{a}}=\mathrm{L}_{\mathrm{a}}$ é chamada de frequência crítica e é definida por

$$
f_{c r} \equiv \frac{\alpha_{s}}{\pi L_{s}^{2}}
$$

onde $\mathbf{L}_{\mathbf{s}}$ é a espessura da amostra. A frequência que corresponde ao inverso da constante de tempo térmica é denominada de frequência característica e é dada por

$$
f_{c} \equiv \frac{\alpha_{s}}{L_{s}^{2}}
$$

Além da técnica fotoacústica, outras técnicas fototérmicas também dão informações óticas e térmicas sobre a amostra. Estas técnicas podem ser úteis em situações particulares, devido às limitações instrumentais, aspectos geométricos e físicos.

Dentre as técnicas fototérmicas temos usado a técnica espectroscópica fotopiroelétrica, a qual descreveremos resumidamente seu histórico e princípio básico. 


\section{2 - HISTÓRICO E PRINCfPIO BÁSICO DA FOTOPIROELÉTRICA}

A espectroscopia fotopiroelétrica (PPES) surgiu no meado da década de 80, a partir dos trabalhos de Coufal e Mandelis [23-25]. Coufal usou filme fino de PVDF - Poli(Fluoreto de Vinilideno), na conformação $\beta$-ferroelétrica devidamente polarizado, como detetor piroelétrico para estudar filmes finos de PMMA - Poli(Metil-metaacrilato) dopado com $\mathrm{Nd}_{2} \mathrm{O}_{3}$ (Óxido de Neodímio). A amostra ficava em contato com a superfície deste detetor. Mandelis demonstrou o potencial, a simplicidade e a sensibilidade da técnica no estudo de cinética de reação do monóxido de cobre com ácido clorídrico, como também obteve o espectro de absorção ótica de uma pasta de $\mathrm{Ho}_{2} \mathrm{O}_{3}$ e água na região UV-VIS[25]. A partir desses trabalhos a PPES passou a ser considerada mais uma técnica espectroscopicamente poderosa e os fundamentos teóricos passaram a ser estabelecidos [26].

O princípio básico desta técnica é similar ao da fotoacústica, diferenciando-se no modo de geração do sinal elétrico. O sinal elétrico obtido é devido ao efeito piroelétrico no detetor, no qual a polarização elétrica varia com a temperatura. O efeito fotopiroelétrico ocorre quando a luz modulada incidindo sobre a amostra é absorvida. O processo de desexcitação não radiativa ocorrido dentro da amostra causa flutuação de sua temperatura e através da difusão de calor a temperatura do detetor piroelétrico flutua. Assim, uma voltagem piroelétrica é gerada no detetor, a qual é expressa por

$$
V=\left[\frac{p}{\epsilon \epsilon_{o}}\right] L_{p} \Delta T
$$

onde $\mathbf{p}$ é o coeficiente piroelétrico do detetor, $\mathbf{L}_{\mathbf{p}}$ é a espessura do detetor, $\epsilon$ é a constante dielétrica, $\epsilon_{o}$ é a permissividade do vácuo e $\Delta T$ é a variação da temperatura no detetor 
piroelétrico.

Em 1985 Mandelis et al [26] desenvolveram um modelo para PPES baseado na difusão de calor. Este modelo tem sido usado com sucesso por diversos pesquisadores [27-34]. Em seguida apresentaremos as idéias centrais do modelo na condição em que o detetor seja termicamente espesso.

\subsection{1 - MODELO PPES}

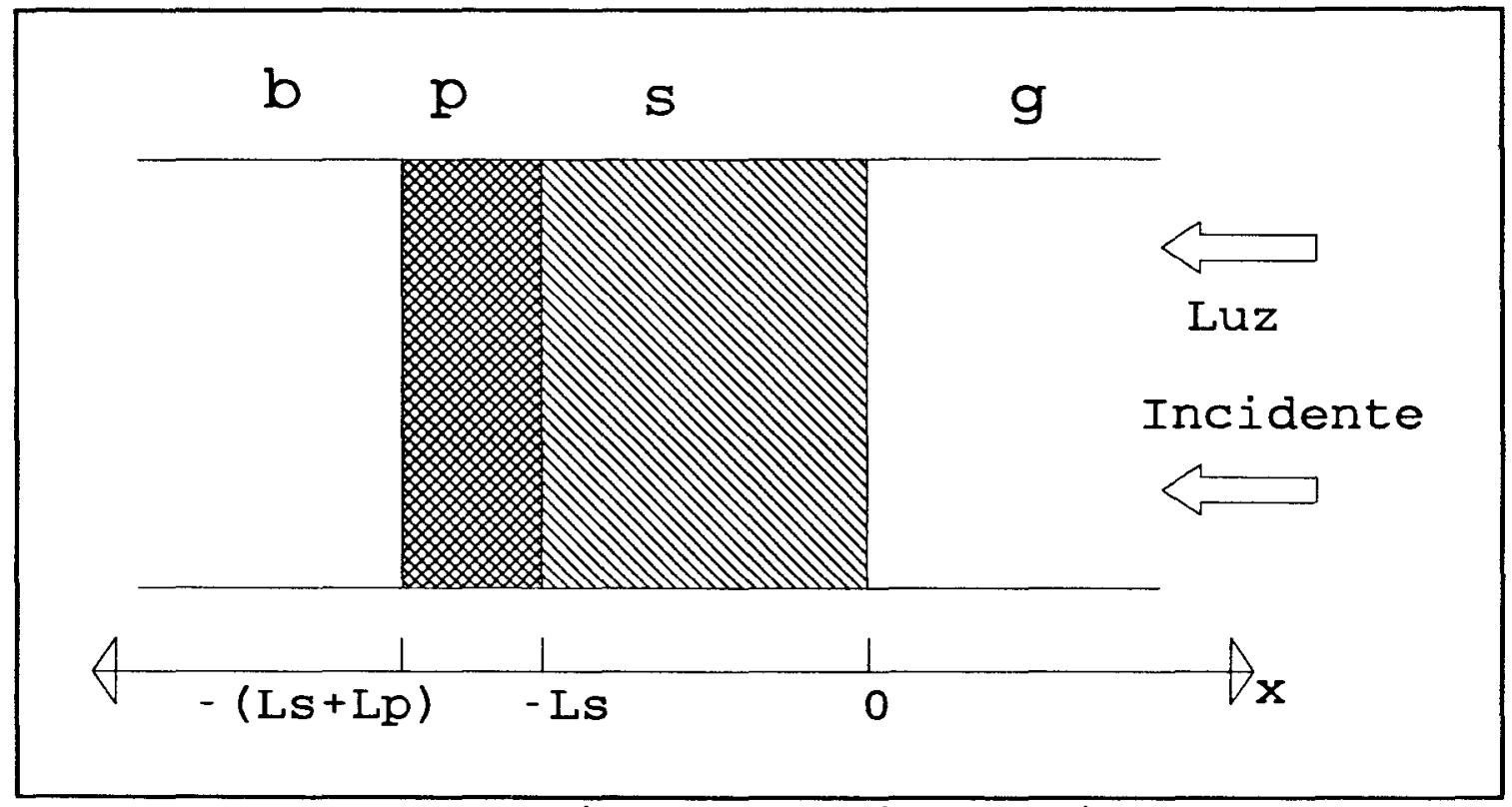

FIG-1.2 - Esquema do sistema fotopiroelétrico. (b) suporte, (p) detetor piroelétrico, (s) amostra, (g) gás ou outra subtância transparente.

Numa geometria unidimensional, a FIG-1.2 mostra o esboço do sistema fotopiroelétrico.

A amostra de espessura $L_{s}$ é iluminada por luz monocromática de comprimento de onda $\lambda$, cuja intensidade é modulada em uma frequência $\omega$. A amostra tem coeficiente de absorção $\beta_{8}$ e está em contato com o detetor piroelétrico. $O$ conjunto amostra-detetor está apoiado sobre um suporte espesso. 
Como pode ser visto na FIG-1.2, a câmara fotopiroelétrica é aberta e a incidência de luz é assumida iluminar a amostra uniformemente. A voltagem piroelétrica média é dada por

$$
V(\omega)=\left[\frac{p L_{p} \theta_{p}(\omega)}{\epsilon \epsilon_{0}}\right] e^{j \omega t}
$$

onde

$$
\theta(\omega)=\frac{1}{L_{p}} \int_{\text {espessura } L_{p}} T_{p}(\omega, x) d x
$$

sendo $\mathrm{T}_{\mathrm{p}}(\omega, \mathrm{x})$ a temperatura no interior do detetor. Considerando que a difusão de calor seja o mecanismo dominante na transferência de calor, as equações de difusão nas quatro regiões são:

$$
1-x \geq 0
$$

$$
\frac{\partial^{2} T_{g}}{\partial x^{2}}-\sigma_{g}^{2} T_{g}=0
$$

$2-\mathrm{L}_{\mathrm{s}} \leq \mathrm{x} \leq 0$

$$
\begin{gathered}
\frac{\partial^{2} T_{s}}{\partial x^{2}}-\sigma_{s}^{2} T_{s}=-\left[\frac{I_{o} \beta_{s} \eta_{s}}{2 k_{s}}\right] e^{\beta_{s} x} \\
3--\left(L_{p}+L_{s}\right) \leq x \leq-L_{s} \\
\frac{\partial^{2} T_{p}}{\partial x^{2}}-\sigma_{p}^{2} T_{p}=-\left[\frac{I_{o} \beta_{p} \eta_{p}}{2 k_{p}} e^{-\beta_{s} L_{s}}\right] e^{\beta_{p}\left(x+L_{s}\right)}
\end{gathered}
$$




$$
4-x \leq-\left(L_{p}+L_{1}\right)
$$

$$
\frac{\partial^{2} T_{b}}{\partial x^{2}}-\sigma_{b}^{2} T_{b}=0
$$

A quantidade de interesse é $T_{p}(\omega, x)$. Após intenso trabalho algébrico chega-se a uma expressão para a temperatura em função dos parâmetros físicos dos meios envolvidos. Esta expressão não é prática devido a sua extensão [26], entretanto, supondo que o detetor seja termicamente espesso e oticamente opaco, isto é, $\mu_{\mathrm{p}}<\mathrm{L}_{\mathrm{p}}, 1 / \beta_{\mathrm{p}}<<\mathrm{L}_{\mathrm{p}}$ e $1 / \beta_{\mathrm{p}}<\mu_{\mathrm{p}}$ obtém-se que $\exp \left(-\beta_{\mathrm{p}} L_{\mathrm{p}}\right) \cong 0, \exp \left(-\sigma_{\mathrm{p}} \mathrm{L}_{\mathrm{p}}\right) \cong 0$ e $\mathrm{r}_{\mathrm{p}}>1$, então, a equação da voltagem piroelétrica fica:

$$
\begin{gathered}
V=A\left[\frac{\beta_{s} \eta_{s}}{k_{s}\left(\beta_{s}^{2}-\sigma_{s}^{2}\right) \sigma_{p}}\right]\left\{2\left(b_{s g} r_{s}+1\right)-\left[\left(r_{s}+1\right)\left(b_{s g}+1\right) e^{\sigma s L_{s}}+\left(r_{s}-1\right)\left(b_{s g}-1\right) e^{-\sigma L_{s}}\right]\right. \\
\left.e^{\left.-\beta L_{s}\right\}}+\left[\frac{\eta_{p} e^{-\beta_{s} L_{s}}}{k_{p} \beta_{p} \sigma_{p}}\right]\left\{\left(b_{s g}+1\right)\left(b_{p s} r_{p}+1\right) e^{\sigma L_{s}}+\left(b_{p s} r_{p}-1\right)\left(b_{s g}-1\right) e^{-\sigma L_{s}}\right\}\right] \div \\
\div\left[\left(b_{s g}+1\right)\left(b_{p s}+1\right) e^{\sigma L_{s}}+\left(b_{s g}-1\right)\left(b_{p s}-1\right) e^{-\sigma_{s} L_{s}}\right]
\end{gathered}
$$

sendo $A=\left[p I_{d} / \epsilon \epsilon_{\mathrm{o}}\right]$

Esta equação demonstra que o sinal fotopiroelétrico depende dos parâmetros óticos e térmicos da amostra e do detetor. 


\subsection{2 - CONSIDERAÇÕES SOBRE A TÉCNICA FOTOPIROELÉTRICA}

Considerando que a superfície do detetor seja preta para maximizar o sinal elétrico, o segundo termo da equação (1.16), que contém parâmetros do detetor, é dominante sobre o primeiro quando $\beta_{z}$ é pequeno. Isto significa que na região espectral de transmissão, a luz que atravessa a amostra atinge diretamente a superfície do detetor, o qual é responsável pelo alto sinal gerado.

Quando $\beta_{\mathbf{z}}$ cresce tornando a amostra absorvedora, o primeiro termo passa a ser significativo. Nesta situação, a incidência de luz direta sobre o detetor é cada vez menor, logo o sinal elétrico diminui. Assim, o espectro obtido por esta técnica é similar àquele obtido por transmitância num espectrofotômetro convencional.

O primeiro termo da equação (1.16) tem um comportamento muito sensível à frequência de modulação. Quando em baixa frequência, a curva espectral da amostra seria similar ao espectro de absorção. Quando em alta frequência, o espectro seria semelhante ao de transmissão. Portanto, há uma inversão espectral quando a amostra passa de termicamente fina para espessa.

Quando a amostra se torna semi-opaca, menos luz atinge diretamente o detetor, e o sinal elétrico gerado é devido ao calor que se difunde através da amostra. Se a amostra for termicamente fina, um aumento de $\beta_{\mathrm{a}}$ faz crescer o calor que atinge o detetor gerando um sinal elétrico proporcional a $\beta_{\mathrm{s}}$. Se a amostra é termicamente espessa, o sinal elétrico obtido é pequeno. Logo, o espectro é similar ao de transmissão, já que o maior sinal gerado é devido a incidência direta sobre o detetor. A condição de sinal fotopiroelétrico saturado é alcançada da mesma forma como ocorre na fotoacústica.

A grande vantagem desta técnica está na sua simplicidade, na detecção direta da variação 
de temperatura, e principalmente na alta relação sinal/ruído. $O$ espectro obtido é de qualidade similar ao fotoacústico. A PPES é uma medida direta enquanto que a fotoacústica é indireta [25].

Embora o princípio fototérmico para PAS e PPES seja o mesmo e os resultados obtidos serem similares, em determinadas aplicações a PPES é mais adaptável, solucionando as restrinções práticas naturalmente impostas à PAS [31].

\section{3 - REFERÊNCIAS}

1 - Rosencwaig, A. - Opt. Commun. - 7, 305(1973)

2 - Rosencwaig, A. - Physics Today/ september, 23(1975)

3 - Rosencwaig, A. - Science - 188, 36(1975)

4 - Rosencwaig, A. - Photoacoustics and photoacoustics spectroscopy - John Wiley \& Sons Cap.2 - 7(1980)

5 - Rousset, G.; Lepoutre, F.; Bertrand, L. - J. Appl. Phys. - 54, 2383(1983)

6 - Rosencwaig, A. - J. Appl. Phys. - 47, 64(1975)

7 - McDonald, F. A.; Weltsel Jr., G. C. - J. Appl. Phys. 49, p.2313(1978)

8 - McDonald, F. A. - Appl. Phys. Lett. 36, 123(1980)

9 - Mandelis, A.; Royce, B. S. - J. Appl. Phys. 50, 7138(1979)

10 - Mandelis, A; Royce, B. S. - J. Opt. Am. 70, 474(1980)

11 - So. C. H.; Kim, H. C. - J. Phys. E:Sci. Instrum - 22, 626(1989)

12 - Pessoa Jr., O.; Cesar, C. L.; Paiel, N. A.; Vargas, H.; Ghizoni, C. C.; Miranda, L. C. M. - J. Appl.Phys., 59, 1316(1986) 
13 - Mansanares, A. M.; Baesso, M. L.; da Silva, E. C.; Gandra, F. C. G.; Vargas, H. - Phys. Rev. B, - 40, 7912(1989)

14 - Perondi, L. F.; Miranda, L. C. M. - J. Appl. Phys. 62, 2955(1987)

15 - Bento, A. C.; Vargas, H.; Aguiar, M. M. F.; Miranda, L. C. M. - Phys. Chem. of Glasses, 28, 127(1987)

16 - Madusoodanan, K. N.; Thomas, M. R.; Philip, J. - J. Appl. Phys. 62, 1162(1987)

17 - Lachaine, A.; Poulet, P. - Appl. Phys. Lett. 45 953(1984)

18 - Michaelian, K. H. - Appl. Spectroscopy, 43, 185(1989)

19 - Marek, W. U.; Koenig, J. L. - Appl. Spectroscopy, 40, 994(1986)

20 - Nery, J. W.; Pessoa Jr., O.; Vargas, H.; Reis, F. A. M.; Gabrielli, A. C.; Miranda, L.

C. M.; Vinha, C. A. - Analyst., 112, 1487(1987)

21 - Cesar, C. L.; Vargas, H.; Pelzl, J.; Miranda, L. C. M. - J. Appl. Phys., 55, 3460(1984)

22 - McClelland J. F.; Kniseley, R. N. - Appl. Phys., 57, 4485(1987)

23 - Coufal, H. - Appl. Phys. Lett., 44, 59(1984)

24 - Coufal, H. - Appl. Phys. Lett., 45, 516(1984)

25 - Mandelis, A. - Chem. Phys. Lett., 4, 388(1984)

26 - Mandelis, A.; Zver, M. M. - J. Appl. Phys. - 57, 4421(1985)

27 - Mandelis, A.; Lo, W.; Wagner, R. E. - Appl. Phys. A, 44, 123(1987)

28 - Mandelis, A.; Wagnes, R. E.; Ghandi, K.; Baltman, R. - Phys. Rev. B, 8, 5254(1989)

29 - Christofides, C.; Mandelis, A.; Ghandi, K.; Wagner, R. E. - Rev. Sci. Instrum., 61, 2360(1990)

30 - Marinelli, M.; Murtas, F.; Mecozzi, M. G.; Zammit, U. Pizzoferrato, r.; Scudieri, f.; 
Martelucci, S.; Marinelli, M. - Appl. Phys. A - 51, 387(1990)

31 - Ghizoni, C. C.; Miranda, L. C. M. - Phys. Rev. B, 12, 8392(1985)

32 - Mieszkowski, M.; Leung, F. K.; Mandelis, A. - Rev. Sci. Instrum., 60, 306(1989)

33 - Mieszkowski, M; Mandelis, A. - J. Opt. Soc. Am. A - 4, 552(1990)

34 - Melo, W. L. B.; Pawlicka, A.; Sanches, R.;Mascarenhas, S.; Faria, R. M. - J. Appl.

Phys. (submetido). 


\section{CAPítuLO II \\ INSTRUMENTAÇÃO: ESPECTRÓMETRO FOTOTÉRMICO \\ DESENVOLVIMENTO DE CÂMARAS FOTOACÚSTICA E FOTOPIROELÉTRICA}

\section{1 - INTRODUÇÃO}

Um equipamento como um espectrômetro fototérmico ou fotoacústico é de grande importância em um laboratório de pesquisa devido sua capacidade na determinação das propriedades térmicas (difusividade, condutividade) e óticos (coeficiente de absorção e gap ótico) de amostras opacas. Além disso, seu custo e manutenção é, em geral, baixo, podendo ser construído com componentes óticos convencionais.

A intenção de estudarmos propriedades óticas e térmicas de materiais poliméricos nos conduziu à montagem de um espectrômetro fototérmico, no qual a maioria das peças componentes foram projetadas e construídas no DFCM.

\section{2 - O ESPECTRÔMETRO}

A FIG-2.1 mostra o diagrama esquemático do espectrômetro fototérmico, que basicamente é composto por:

1 - fonte de luz;

2 - modulador mecânico ou chopper;

3 - monocromador;

4 - detetor; 
5 - sistema de aquisição.

A fonte de luz branca de alta potência (ORIEL 450W) produz uma forte radiação nas regiōes espectrais: ultravioleta próximo, visível e infravermelho próximo.

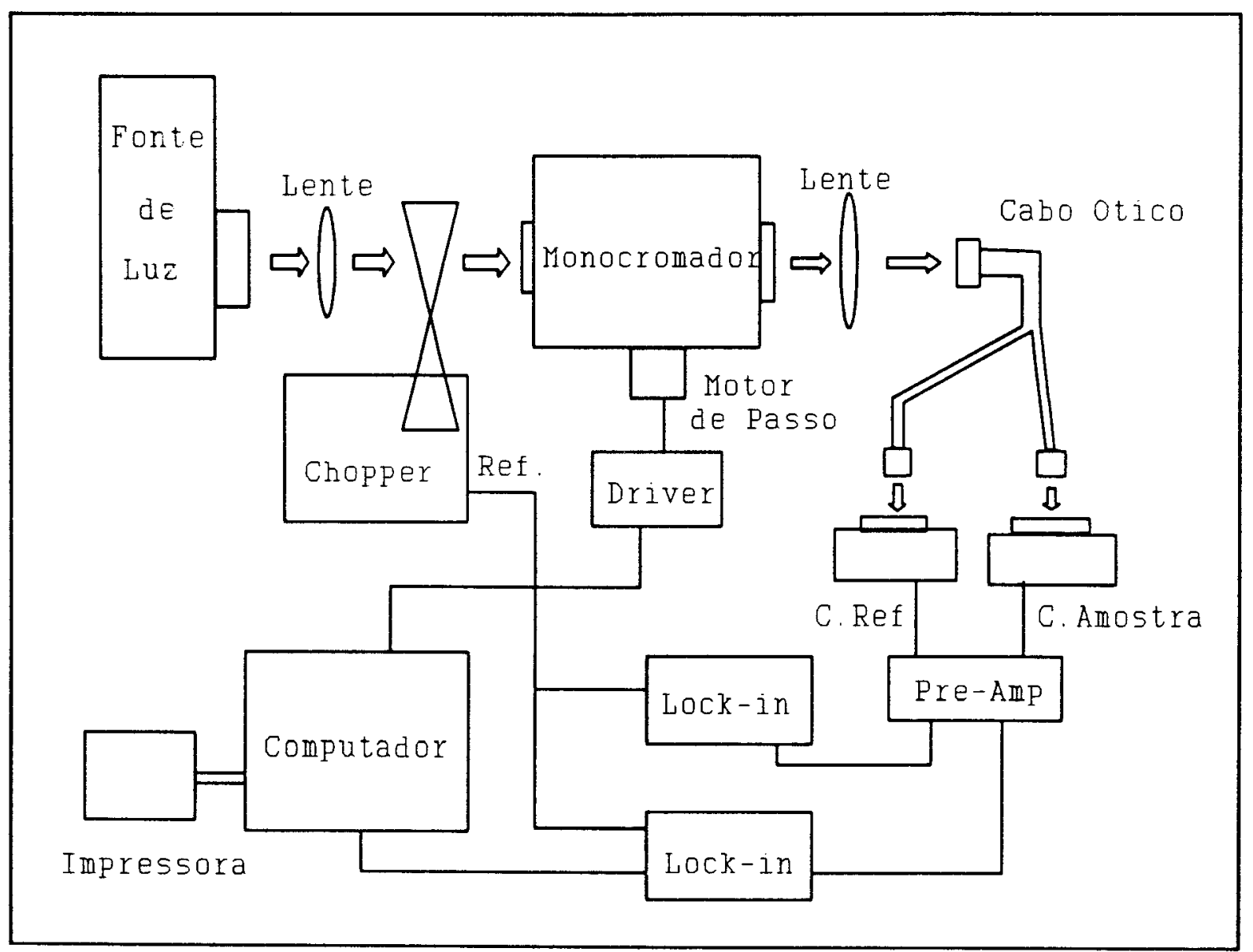

FIG-2.1 - Esquema em bloco do Espectrômetro Fototérmico.

A luz é colimada por uma lente e passa, em seguida, através das fendas de um modulador mecânico de velocidade variável (chopper PAR194A com intervalos de frequências de 3-154 e 10-514 Hz). Este modulador serve para converter o feixe de luz contínua em pulsante. A luz colimada e pulsante incide sobre a fenda de entrada do monocromador (Jarrell- 
Ash mod.82-497) equipado com três redes de difração: no infravermelho próximo, viśvel e ultravioleta. O monocromador separa em componentes a luz branca, as quais aparecem na fenda de saída do monocromador a medida que a rede de difração é girada. Este movimento é obtido através de um motor de passo (Astrosyn - Minebea Co. Ltd. tipo 23PM-C406) conectado ao mecanismo de giro da rede.

A luz emergente da fenda de saída do monocromador é novamente colimada na entrada de um cabo ótico (ORIEL) por uma lente. A luz monocromática é conduzida através do cabo ótico até as câmaras detetoras. Desse modo, além de simplificar o caminho ótico também obtemos um ou mais canais de feixes de luzes. Para isso é bastante trocar um cabo ótico mono por bi ou tri-furcada.

Os sinais elétricos gerados nas câmaras fotoacústicas ou fotopiroelétrica são enviados a um pré-amplificador, construído no laboratório. Este pré-amplificador tem as funções de amplificar os sinais das câmaras e fornecer um pequeno ganho $(\cong 4)$. Dependendo do nível de sinal, o uso desse dispositivo pode ser dispensado.

Os sinais elétricos alimentam as entradas de dois Lock-ins (SR530-Stanford e PAR-EGG 5210) cuja função é filtrar os ruídos nos sinais. Os lock-ins estão conectados entre si e a um microcomputador.

O microcomputador é compatível ao IBM PC-xt com processador aritmético, um disco rígido de 20Mbytes e unidade de disco flexível. Os sinais são enviados pelo SR530 através da interface RS232.

Um programa de aquisição de dados faz o microcomputador controlar todas as operações do espectrômetro: lê os sinais, realiza os cálculos, controla o movimento do motor de passo, e 
mostra na tela, em tempo real, o espectro da amostra que estiver sendo estudada. Os dados aquisicionados são armazenados em disco no formato ASCII e em colunas de pontos com todas as informações sobre as medidas. Isto facilita o posterior tratamento dos dados espectrais.

A FIG-2.2 mostra o esquema instrumental usado para obter os sinais fototérmicos versus variação de frequência de modulação.

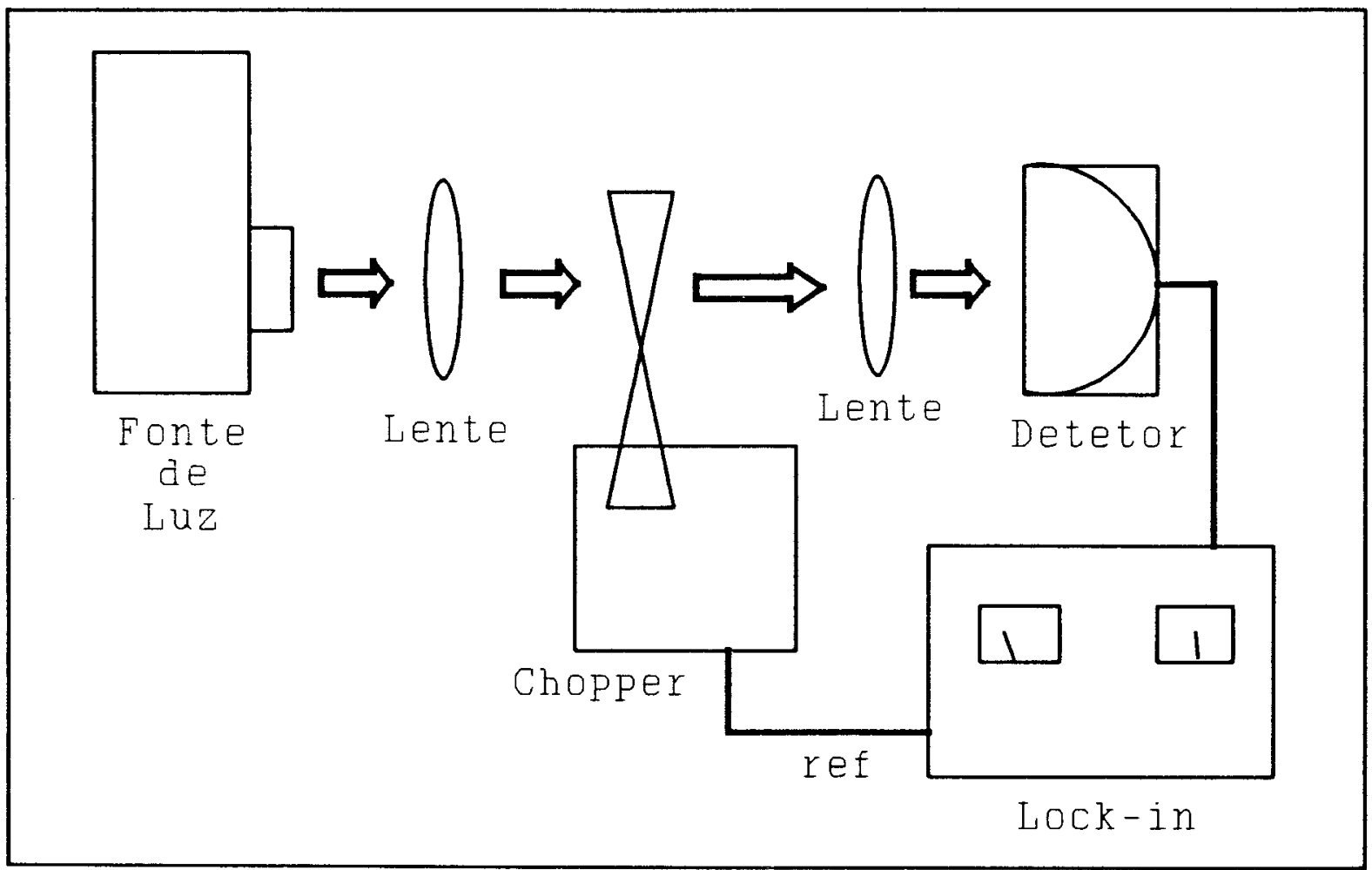

FIG-2.2 - Esquema do instrumental usado na obtenção do sinal fototérmico versus frequência de modulação.

Esse consiste de:

1 - uma fonte de luz, seja branca ou monocromática. A luz branca foi obtida através de uma lâmpada halogênica. Também usamos laser de He-Ne como fonte de luz neste trabalho;

2 - lentes para colimação;

3 - um modulador mecânico ou chopper, já descrito anteriormente; 
4 - câmaras detetoras, as quais poderiam ser fotoacústica ou fotopiroelétrica.

As câmaras fotoacústicas e fotopiroelétricas serão descritas em detalhes nas seç̧ões seguintes.

\section{3 - CÂMARAS FOTOACÚSTICAS}

O desenvolvimento de câmaras fotoacústicas vem sendo realizado por diversos pesquisadores e em sua maioria usam microfones de eletreto como sensor acústico [1-11].

Alguns trabalhos têm analizado as características de uma câmara fotoacústica [12,13]. Estas características se baseiam no comprimento de difusão térmica do gás $\left(\mu_{\mathrm{g}}\right)$, no tipo de gás e nas dimensões da câmara.

No projeto de uma câmara fotoacústica fechada devemos ter os seguintes cuidados:

1 - o volume interno da câmara deve ser o menor possível. Para a câmara onde $\mathrm{L}_{\mathrm{g}}>\mu_{\mathrm{g}}$, o sinal fotoacústico aumenta quando diminui este comprimento $\left(\mathrm{L}_{\mathrm{g}}\right)$. Para câmara com $\mathrm{L}_{\mathrm{g}}<\mu_{\mathrm{g}}$, o sinal fotoacústico decresce com o decréscimo de $\mathrm{L}_{\mathrm{g}}$. Quando a razão $\mathrm{L}_{\mathrm{g}} / \mu_{\mathrm{g}}=1,4$ o sinal fotoacústico é máximo e independente da composição do gás e da frequência de modulação [12]. McDonald [13] sugere que na otimização de uma câmara fotoacústica com geometria cilíndrica, as dimensões sejam as seguintes: o raio (r) e o comprimento $\left(\mathrm{L}_{\mathrm{g}}\right)$ seja o menor possível, mas com $\mathrm{L}_{\mathrm{g}}>2 \mu_{\mathrm{g}}$ e $\mathrm{r}>2 \mathrm{~L}_{\mathrm{g}}$ (na frequência de modulação mais baixa);

2 - a câmara não deve apresentar aberturas que facilitem alguma perda de pressão e entrada de ruído do ambiente;

3 - o microfone deve ser posicionado o mais próximo possível da amostra; 
4 - a massa da cámara deve ser grande para difundir o calor por ela absorvido e não gerar sinal fotoacústico;

5 - a superfície interna deve ser metálica, bem limpa e polida;

6 - o suporte de amostra não deve ser bom condutor de calor;

7 - o interior da câmara deve ser isolado acusticamente de fontes de rúdos externos. O sinal fotoacústico é várias ordens de grandezas menor do que o ruído do ambiente.

Com base nestes itens, desenvolvemos algumas câmaras fotoacústicas e aqui apresentaremos 3 delas. Com essas câmaras temos conseguido obter sinais fotoacústicos de amostras com coeficiente de absorção muito pequeno [14].

\subsection{1 - Câmara FA 1}

Projetamos uma câmara de único corpo dividida em dois ambientes (FIG-2.3): da amostra e do microfone. Essa câmara tem mostrado ter alto sinal com corpo negro, aproximadamente $2 \mathrm{mV}$ com microfone comercial sem pré-amplificador e na frequência de modulação de $3 \mathrm{~Hz}$. Apresenta baixo ruído $(<<1 \mu \mathrm{V})$, além de ser mecanicamente resistente. A amostra é colocada pela abertura inferior do "compartimento da amostra" e a entrada de luz é feita pela janela superior. $\mathrm{O}$ suporte de amostra é feito de lucite ou acríli-

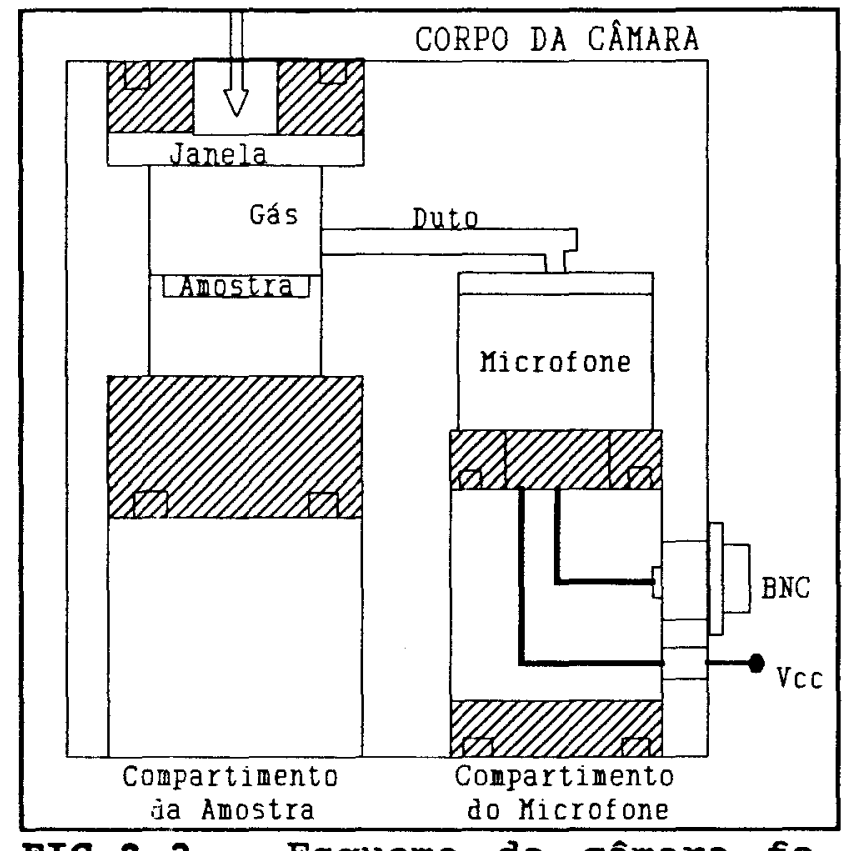

FIG-2.3 - Esquema da câmara fotoacústica FAl. 
co para que deixe passar a luz que atravessa a amostra. Para evidenciar alguns detalhes nas câmaras, as figuras estão fora de escala.

Essa câmara, apesar de sua boa operação, apresenta inconvenientes no momento da substituição da amostra. Há sempre a necessidade de remover a câmara de sua posição no espectrômetro e no momento de fechá-la, a pressão interna, nem sempre será a mesma. Para evitar estes problemas desenvolvemos uma outra câmara também de único corpo.

\subsection{2 - Câmara FA 2}

Essa câmara tem o mesmo princípio da anterior só que elimina os incovenientes na manipulação da amostra (FIG-2.4). Nessa câmara a amostra é colocada num suporte que é introduzido numa abertura lateral com a ajuda de uma haste. Com o movimento de 90 graus na alavanca, na parte inferior da câmara, o suporte é elevado até o ambiente da amostra. O elevador fica pressionando o conjunto suporte-haste, para vedar a câmara. A pressão é fornecida por uma mola que a mantém sempre constante. Todas as câmaras

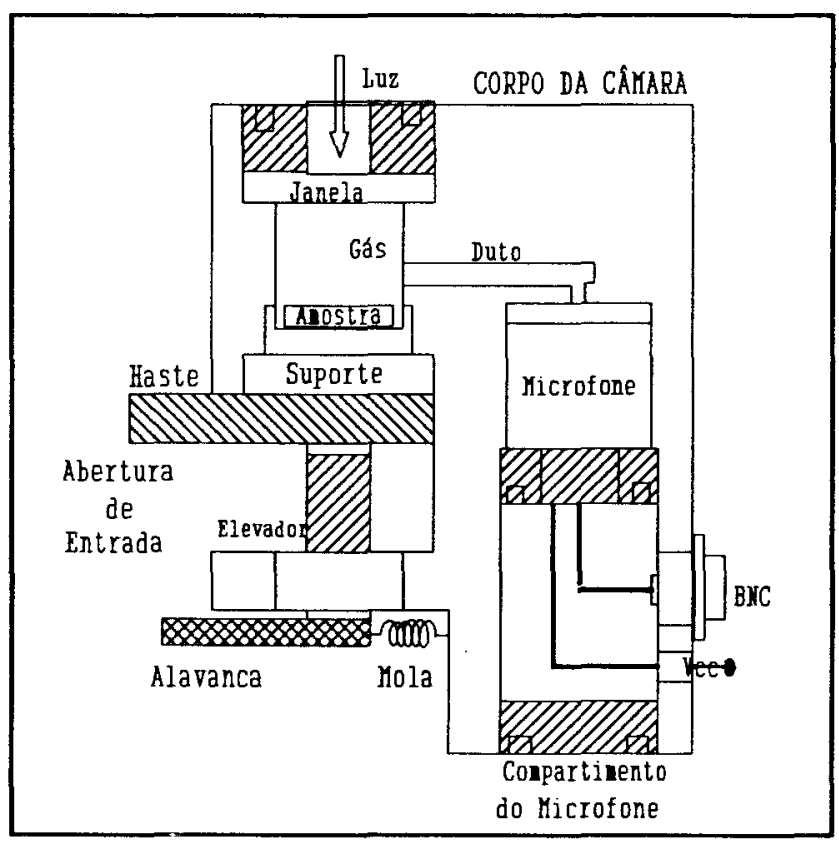

FIG-2.4 - Esquema da câmara fotoacústica FA2. operam com alimenteção de 1,5 a $9 \mathrm{~V}$, dependendo das especificaçōes do microfone usado. 


\subsection{3 - Cámara FA 3}

Essa câmara está mostrada na FIG-

2.5, é uma versão da câmara OPC - Open Photoacoustic Cell [15]. A grande diferença entre essa câmara e as anteriores é que a amostra é colocada sobre o orifício do duto de ar. Dessa forma, o volume de ar é minimizado e obtemos alta relação sinal/ruído. Essa câmara se compõe, basicamente, das seguites parte:

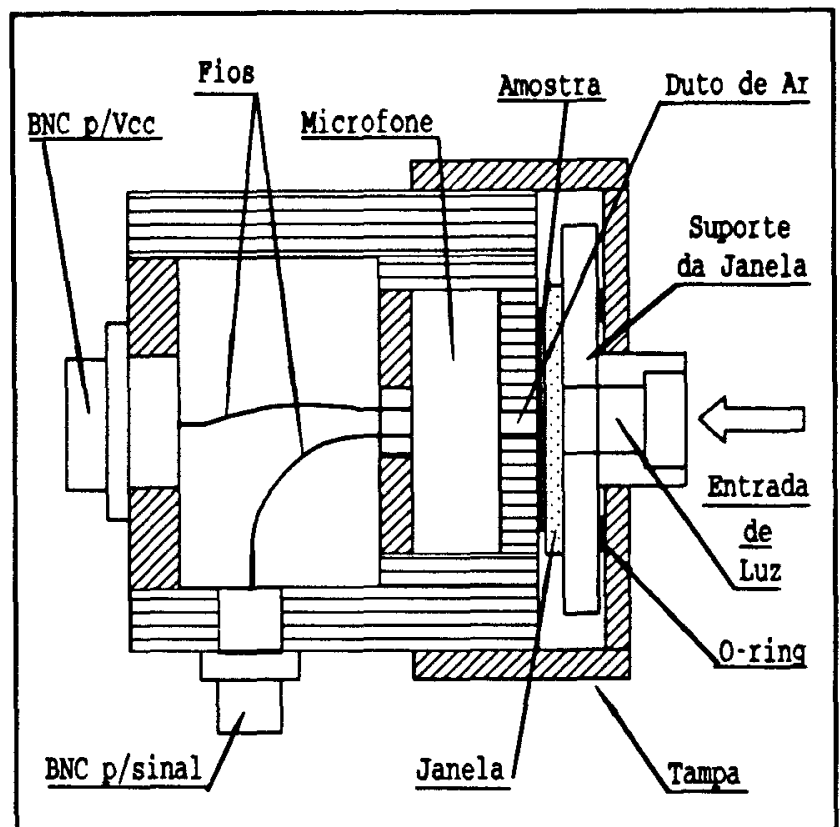

1 - corpo metálico;

FIG-2.5 - Esquema da cámara FA3.

2 - microfone;

3 - tampa.

O corpo metálico serve de abrigo para o microfone e também de suporte de amostra. Um pequeno orifício na parte frontal serve de passagem da onda acústica para o interior do microfone.

O microfone de eletreto é o dispositivo usado em todas as câmaras FA descritas acima. Ele é encontrado comercialmente e sua sensibilidade é $\cong 10 \mathrm{mV} / \mathrm{pas}$.

A tampa serve para dar resistência mecânica e auxiliar sua vedação, a qual também é obtida com auxílio de uma camada fina de graxa de vácuo. Se a amostra for suficientemente rígida, então o uso dessa tampa é dispensável e a vedação é obtida com a amostra e a graxa. Na tampa há uma peça em forma de T que serve de suporte da janela. Essa peça evita que a tampa 
arraste a amostra, sobre a superfície frontal do corpo metálico, no momento de rosqueá-la. Isto evita danos na amostra, principalmente, quando na forma de filme.

\section{4 - CÂMARA FOTOPIROELÉTRICA}

A técnica fotoacústica é capaz de obter espectros de amostras difíceis ou impossíveis de estudar por outras técnicas convencionais. Apesar de sua crescente popularidade, essa técnica sofre algumas limitações impostas pelas suas próprias características:

1 - o uso de microfone como sensor torna sensível a ressonância da câmara fotoacústica[6], a qual distorce o espectro obtido. Este problema pode ser evitado usando câmara fotoacústica com frequência ressonante fora da região de interesse;

2 - a necessidade da presença de um gás para conduzir o sinal acústico para o microfone;

3 - complicações com o sinal fotoacústico com relação a amostra em pó com tamanho das partículas menores do que o comprimento de difusão térmica [13];

4 - sensitividade à ruído e vibrações ambiental. Esses ruídos levaram os pesquisadores a montar seus instrumentos em pesadas mesas óticas suspensas em colchões de ar para melhorar a relação sinal/ruído, encarecendo muito o sistema.

As dificuldades acima mencionadas levaram a busca de métodos alternativos, em especial para o estudo de amostras opacas.

Uma técnica que soluciona alguns dos problemas acima é a Espectroscopia Fotopiroelétrica. Essa técnica tem se mostrado promissora no estudo de filmes finos, filmes semicondutores, 
e outros. Apresenta a vantagem de ser imune a ruído mecânico externo, não necessitando de pesada montagem instrumental. Também, dependendo da frequência de modulação, essa técnica pode dar informação da geometria da amostra, tal como espessura e pode ser obtido o espectro similar a absorção ou a transmissão [16].

Alguns pesquisadores [21-23] utilizaram o filme de PVDF como sensor piezoelétrico. Comumente, sensores piezoelétricos são feitos de cerâmicas piezoelétricas (por exemplo o PZT Titanato Zirconato de Chumbo [17-19]) que exibem respostas em frequências muito mais altas do que os microfones. O filme de PVDF tem distintas vantagens sobre o PZT, sendo a mais importante o seu altíssimo patamar de frequência entre DC e dezenas de $\mathrm{MHz}$ [15]. Além da propriedade piezoelétrica, o PVDF exibe forte propriedade piroelétrica, logo ele pode ser usado como detetor de radiação térmica [23-26].

A grande novidade desta técnica é o uso do filme polimérico PVDF-Poli(Vinilideno de Flúor) como detetor piroelétrico em espectroscopia [17]. O uso do PVDF como detetor piroelétrico está se tornando comum devido a seus fatores térmicos e mecânicos. Resumidamente, vamos descrever a propriedade piroelétrica do PVDF.

O PVDF apresenta 4 formas estruturais, mas a sua conformação $\beta$ é a que apresenta elevadas atividades: piezo e piroelétrica. $\mathrm{Na}$ forma- $\beta$, filmes de PVDF apresentam coeficiente piroelétrico da ordem de $4 \mathrm{nC} / \mathrm{cm}^{2} \mathrm{~K}$, após terem sido polarizado em campo elétrico de $1 \mathrm{MV} / \mathrm{cm}$ em $100^{\circ} \mathrm{C}$. Este efeito é causado por uma polarização surgida da orientação dos dipolos elétricos no interior do polímero [28].

Em estudos feitos, foi mostrado que a polarização induzida no PVDF não é homogênea, porém mais forte no eletrodo positivo, que somente no limite de campo alto e longo tempo de 
polarização é que a polarização se estende uniformemente através da amostra [27]. Isto leva a crer que o efeito piroelétrico é uma resposta da polarização próxima à superfície do filme, a qual torna-se de maior importância.

O uso do PVDF como detetor piroelétrico faz da técnica fotopiroelétrica um método termométrico ou calorimétrico. Para um calorímetro ser útil como termômetro sensível, a capacidade térmica deve ser baixa, isto é, ter uma pequena massa e ser feito de um material com calor específico baixo. O coeficiente piroelétrico do detetor deve ser grande, e sua constante dielétrica pequena. Além das propriedades do material, a geometria do calorímetro é importante. Sua área de acoplamento amostra-detetor deve ser grande para facilitar o contato térmico e deve ser fina, em espessura, para alcançar rápida resposta térmica [17].

Assim, uma combinação das propriedades do material é representada pela Figura de Mérito Piroelétrica (FMP) [29]

$$
F M P \approx \frac{p}{\epsilon_{0} \epsilon C}
$$

onde $\mathrm{p}$ é o coeficiente piroelétrico, $\epsilon$ é a constante dielétrica, $\epsilon_{\mathrm{o}}$ é a permissividade do vácuo $\mathrm{e}$ C é o calor específico. O PVDF tem figura de mérito de 9,7 em comparação com $\mathrm{Li}_{2} \mathrm{SO}_{4} \mathrm{H}_{2} \mathrm{O}$ que é de 15,2 e o PZT com 0,02. Isto torna o PVDF um dos primeiros candidatos a um termômetro piroelétrico que pode ser conectado a qualquer tipo de amostra.

Ao contrário dos materiais piroelétricos cristalinos e cerâmicos, o PVDF pode ser obtido em folha de várias espessuras, desde alguns micra até algumas poucas centenas de micra, como também em diversos comprimentos e larguras. Isto permite construir sensores de diversos formatos e espessuras, de acordo com a necessidade experimental. Cristais e cerâmicas são 
frágeis e difíceis de polir mecanicamente em elementos finos, por estas razões, os pesquisadores têm preferido os polímeros piroelétricos aos cristais e cerâmicas.

Um dado importante a respeito de um detetor é sua responsividade e detetividade. A responsividade é definida como o sinal gerado, seja corrente ou voltagem, pela potência da radiação incidente [25]. A detetividade depende do nível de ruído. Pode ser definida como a relação sinal/ruído pela potência radiante incidente [25]. A sensibilidade típica do PVDF é da ordem de $100 \mathrm{mV} / \mathrm{K}$ [17].

Um material com grande coeficiente piroelétrico, uma pequena capacidade térmica e uma pequena constante dielétrica é adequado para um detetor com alta responsividade. A responsividade para baixa frequência é proporcional a p/€ enquanto que para alta frequência é proporcional a p. Isto implica que materiais piroelétricos com baixas constantes dielétricas, tais como os polímeros, podem dar melhor performance em baixa frequência.

Optamos em nossas câmaras para a utilização do PVDF como detetor piroelétrico.

Diversas câmaras foram desenvolvidas e os melhoramentos foram realizados progressivamente. Dentre as câmaras, vamos descrever uma das versões que vem sendo usada e obtendo sucesso. Além dessa, descreveremos outras que demonstram a versatilidade do PVDF.

\subsection{1 - Câmara PPE 1}

A câmara piroelétrica está esquematizada na FIG-2.6 e é composta de:

1 - um filme de PVDF que é usado como sensor piroelétrico. Esse filme tem as dimensões: $15 \mathrm{~mm}$ de comprimento, $4 \mathrm{~mm}$ de largura e 20 ou $40 \mu \mathrm{m}$ de espessura;

2 - dois discos de lucite com diâmetro de $30 \mathrm{~mm}$. Esses discos servem de 
suporte para o filme de PVDF. Um dos discos (superior) tem um orifício central cujo diâmetro é de $\cong 8 \mathrm{~mm}$, quatro orifícios menores posicionados próximos à borda são usados para passar 4 parafusos, os quais servem para manter preso os dois discos.

3 - Um segundo disco (inferior) que tem o mesmo diâmetro, mas no centro há um pino cujo diâmetro é de $\cong 7,96 \mathrm{~mm}$. Este pino central tem aproximada-

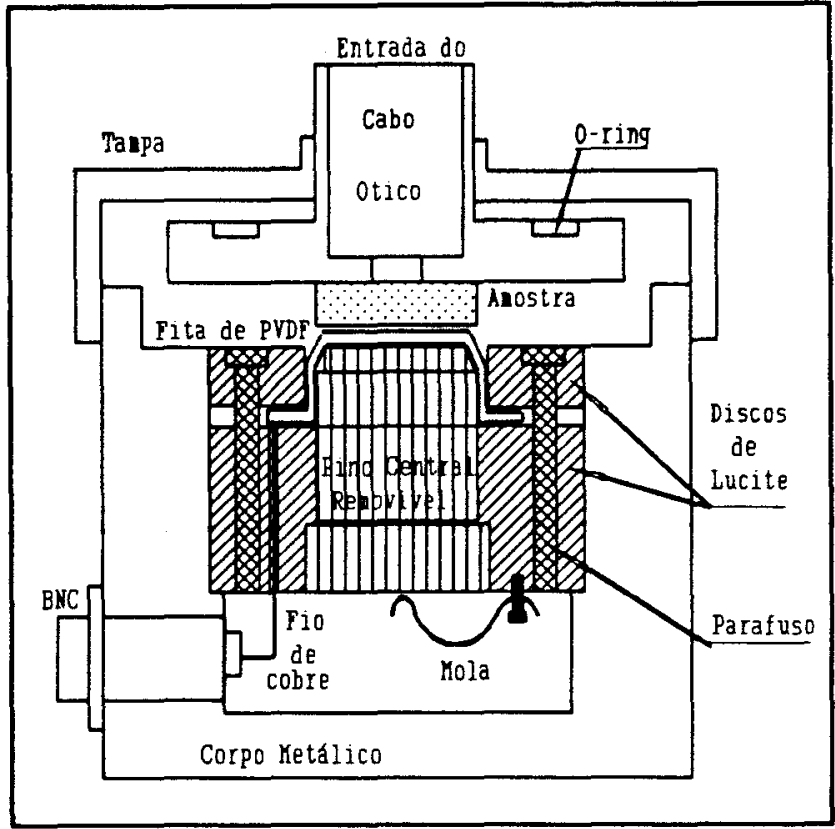

FIG-2.6 - Esquema da camara fotopiroelétrica PPE 1.

mente a mesma altura do disco superior e se encaixa em seu orifício central. A extremidade superior do pino central tem superfície plana cuja borda foi cortada fazendo um angulo de $\cong 60$ graus com a horizontal. Esse corte altera o formato da borda de circular para quadrado. Também 4 parafusos são usados para fixar os discos entre si.

Próximo ao pino central há um pequeno orifício que serve de passagem para o fio que faz o contato elétrico do filme de PVDF;

4 - Contatos elétricos são obtidos usando um fino fio de cobre esmaltado, um anel de alumínio de $\cong 10 \mu \mathrm{m}$ de espessura e uma fita do mesmo alumínio cujo comprimento é de $\cong 50 \mathrm{~mm}$ e $3 \mathrm{~mm}$ de largura. O anel de alumínio se encaixa no pino central, e sua utilidade é aumentar a área de contato sob o filme de PVDF. O fio de cobre esmaltado, após passar pelo orifício no disco inferior, faz contato com o anel. A outra extremidade é conectada ao pino central do conector BNC. A fita de alumínio é introduzida por entre os discos ao longo do 
diâmetro. Essa fita é conectada com a superfície superior do filme de PVDF. A outra extremidade da fita serve de contato elétrico com o corpo metálico da cámara;

5 - um filme de PVDF é montado entre os discos e passa pela superfície plana do pino central. O filme desce pelos lados do pino e suas extremidades ficam presas por entre os discos. Dessa forma o filme é moldado pelo pino central. Assim, a área quadrada na extremidade desse pino é coberta pelo filme. Portanto, essa é a área útil do sensor piroelétrico, sobre a qual é colocada a amostra.

O conjunto montado é introduzido num corpo de alumínio no qual se encontra o conector BNC. A fita de alumínio é conectada ao corpo o qual serve de blindagem eletromagnética. Em seguida, uma tampa com um orifício para a passagem de luz, é usada para fechar a câmara. Uma peça na forma de $\mathrm{T}$ completa a tampa.

\subsection{2 - Câmara PPE 2}

Essa câmara tem o formato diferente da anterior, a FIG-2.7 mostra o esquema. Ela consiste de:

1 - um disco de fibra de vidro de $2 \mathrm{~mm}$ de espessura com lâmina de cobre em ambas as faces (material para circuito impresso). Neste disco há duas fendas estreitas e paralelas, cortadas com um pequeno grau de inclinação. Da face superior do disco é retirada a cobertura de cobre e é deixado um retângulo entre as fendas;

2 - uma fita do filme de PVDF é colado sobre a face superior do disco de fibra e suas extremidades passam por cada fenda para a face inferior do disco. Essas extremidades são coladas à face inferior do disco e fazem contatos elétricos com a superfície cobreada. Também 
é tomado o cuidado para não curto-circuitar o filme de PVDF;

3 - um disco de alumínio de mesmo diâmetro é usado como suporte para o disco de fibra. Esse disco é preso à face inferior do disco de fibra por 4 parafusos. Dessa forma um contato elétrico com o corpo da câmara é obtido;

4 - uma das extremidades de um fio isolado passa por um orifício nos discos e é

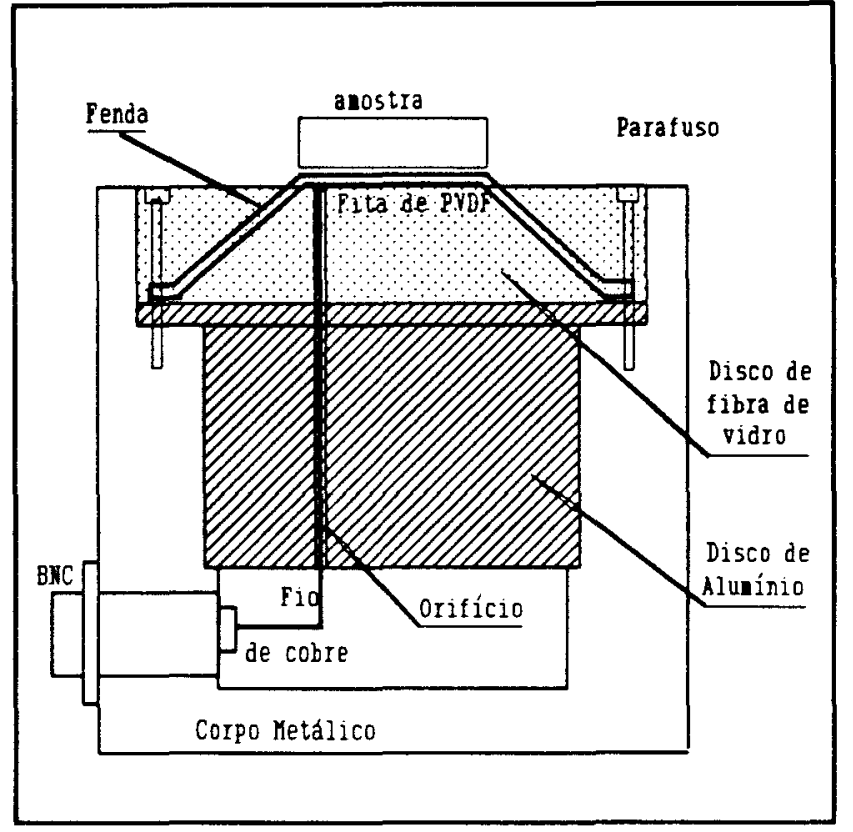

FIG-2.7 - Esquema da câmara fotopiroelétrica PPE2.

soldado à camada de cobre na face superior (a solda não é vista na FIG-2.7). A outra extremidade é ligada a um conector BNC, o qual se encontra num corpo de alumínio semelhante ao da câmara anterior.

Esse tipo de câmara possibilita obter um detetor com área útil variável, sendo apenas limitada pelo tamanho da fenda.

\section{5 - CÂMARA COMBINADA}

A denominação de câmara combinada é devido a deteção simultânea dos efeitos fotoacústico e fotopiroelétrico. Esse tipo de câmara é composta por uma câmara fotoacústica e dispositivo detetor fotopiroelétrico. A FIG-2.8 mostra o dispositivo.

Esse dispositivo consiste de:

1 - um suporte de amostra onde em sua superfície se encontra um filme de PVDF. No 
seu centro há um parafuso, o qual serve para fazer contato elétrico com um dos lados do filme de PVDF. Este parafuso está ligado a um conector BNC por um fio de cobre. O outro lado do filme de PVDF entra em contato com o corpo metálico da câmara fotoacústica, quando o dispositivo é introduzido nela, completando o circuito elétrico. A câmara fotoacústica usada nesta combinação é a

FA-2.

Esse tipo de câmara tem utilidade nos

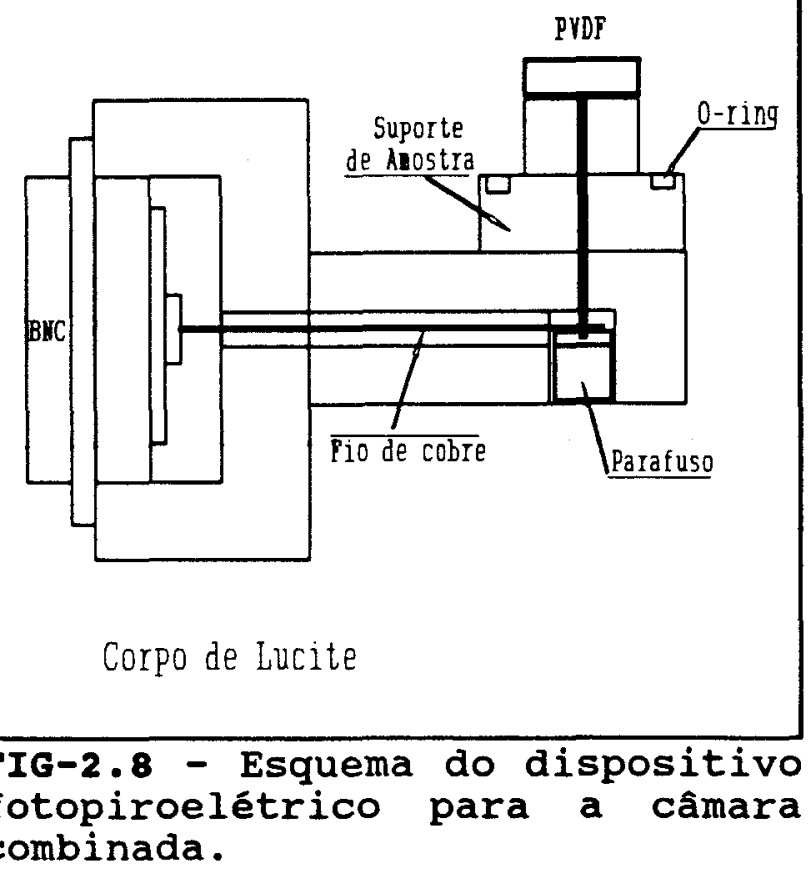

estudos que envolve reações fotoquímicas, tal como fotossíntese. Com ela é possível obter o sinal fototérmico da superfície e do interior da amostra, simultaneamente.

Temos estudado a degradação do pó do óxido de neodímio $\left(\mathrm{Nd}_{2} \mathrm{O}_{3}\right)$ quando exposto à luz e verificamos grandes mudanças no seu espectro de absorção no visível. Essa pesquisa pode ser realizada na câmara combinada para verificar se há liberação de oxigênio ou só uma mudança estrutural ao longo do tempo.

Através do efeito fotoacústico verificaria a variação de pressão e pelo efeito fotopiroelétrico detetaria a variação da temperatura durante o processo químico. 


\section{6 - CONSIDERAÇÕES SOBRE AS CÂMARAS FA e PPE}

O maior problema na montagem das câmaras fotoacústicas foi conseguir microfones razoáveis. Era necessário comprar lotes de 20 microfones para selecionar 2 com boas respostas. Mesmo assim, foi conseguido um sinal fotoacústico 5 vezes maior quando se usou um microfone de US\$2,00 trazido dos Estados Unidos.

O lado positivo é que as câmaras são duráveis, práticas e dão sinais bastante reprodutíveis.

As câmaras fotopiroelétricas mostraram uma durabilidade menor. É que a metalização de Al no filme de PVDF se torna quebradiça com o passar do tempo e há, consequentemente, uma perda considerável do sinal. Este era um dos grandes problemas das primeiras câmaras desenvolvidas, mas na câmara PPE2 o filme de PVDF fica praticamente esticado o que ameniza esse efeito.

Inicialmente usamos a técnica de moldar o filme de PVDF ao pino central, mas era ineficiente e anti-econômica, pois havia muitas perdas deste filme. $O$ uso de pequena fita de PVDF resolveu todos os problemas de moldagem e de economia.

Aparte destes problemas, as câmaras são excelentes. A câmara PPE2 é extremamente versátil pois possibilita usar o detetor de qualquer tamanho, isto é, dependendo do tamanho das fendas. As câmaras fotopiroelétricas fornecem os sinais elétricos muito estáveis não importando se elas estão ou não tampadas. 


\section{7 -REFERENCIAS}

1 - Rosencwaig, A. - Rev. Sci. Instrum., 48, 1133(1977).

2 - Rosencwaig, A. - Physics Today/ september, 23(1975).

3 - Diószeghy, T.; Miklós, A.; Kelemen, A.; Lörincz, A. - J. Appl. Phys., 58, 2105(1985).

4 - Louis, G.; Lepoutre, F.; Monchalin, J. P. - Can. J. Phys., 64, 1111(1986).

5 - Guthrie, R. W.; Medina,D. F.- J. Appl. Phys. 57, 4485(1985)

6 - Fernelius, N. C. - Applied Optics, 18, 1784(1979).

7 - Perondi, L. F.; Miranda, L. C. M. - J. Appl. Phys.,62, 2955(1987).

8 - Mansanares, A. M.; Bento, A. C.; Vargas, H.; Leite, N. F.; Miranda, L. C. M. - Phys. Rev. B, 42, 4477(1990)

9 - Cesar, C. L.; Lima, C. A. S.; Leite, N. F.; Vargas, H.; Rubira, A. F.; Galembeck, F. J. Appl. Phys., 57, 4431(1985).

10 - Zammit, U.; Marinelli, M.; Pizzoferrato, R.; Scudieri, F.; Martelllucci - J. Phys. E: Sci. Instrum., 21, 935(1988).

11 - Monchalin, J. P.; Bertrand, L.; Rousset, G.; Lepoutre, F. - J. Appl. Phys. 56, 190(1984).

12 - Aamodt, L. C.; Murphy, J. C.; Parker, J. G. - J. Appl. Phys., 48, 927(1977).

13 - McDonald, F. A. - Can. J. Phys. 64, 1023(1986).

14 - Albuquerque,E. J. - Dissertação de Mestrado - IFQSC-USP(1992).

15 - Marquezini, M. V.; Cella, N.; Mansanares, A. M.; Vargas, H. e Miranda, L. C. M. Meas. Sci. Technol. - 2, 396(1991).

16 - Mandelis, A. - Chem. Phys. Lett., 108, 388(1984).

17 - Coufal, H. - Appl. Phys. Lett., 44, 59(1984). 
18 - Rosencwaig, A.; Busse, G. - Appl. Phys. Lett., 36, 725(1980).

19 - Sawada, H.; Shimizu, H.; Oda, S. - Japan. J. Appl. Phys. 20, L25(1981).

20 - Tam, A. C.; Patel, C. K. N. - Appl. Opt., 18, 3348(1979).

21 - Tam, A. C.; Coufal, H. - Appl. Phys. Lett., 42, 33(1983).

22 - Coufal, H. - IBM Research Report RJ 4023(45181)(1983).

23 - Putley, E. H. - Ferroelectrics, 33, 207(1981).

24 - Mader, G.; Meixner, H. - Sensors and Actuators, A21-A23, 503(1990).

25 - Porter, S. G. - Ferroelectrics, 33, 193(1981).

26 - Coufal, H. J.; Grygier, R. K.; Horne, D. E.; Fromm, J. E. - J. Vac. Sci. Technol. A, 5, 2875(1987).

27 - Das-Gupta, D. K. - Ferroelectrics - 33, 75(1981).

28 - Sussner, H.; Horne, D. E.; Yoon, D. Y. - Appl. Phys. Lett., 32, 137(1978).

29 - Peralta, S. B.; Ghandi, K.; Mandelis, A. - Rev. Sci. Instrum., 61, 1038(1990). 


\section{CAPITULO III}

\section{MODELO PARA ESPECTROSCOPIA FOTOPIROELÉTRICA POR REFLEXÃO}

\section{1 - INTRODUÇÃO}

No desenvolvimento do modelo de Mandelis [1] foi considerado um detetor piroelétrico cuja superfície é totalmente absorvedora. Como detetor ele usou um filme de PVDF, de conformação $\beta$, eletricamente polarizado e com eletrodos de metal evaporado em ambas as faces. Essas camadas metálicas formam superfícies espelhadas, as quais, em sua maioria, têm alto fator de reflectância. Os metais usualmente empregados são: alumínio, ouro, prata, níquel entre outros [2]. Estas superfícies dão ao detetor piroelétrico a característica refletora, que não é um dos requisitos apropriados na construção desse tipo de detetor.

Mandelis et al [3-5] sugerem depositar sobre a superfície metálica frontal do detetor, uma camada de material preto para maximizar o sinal. Consequentemente, a deposição de uma fina camada de tinta preta, causa alteração na curva de resposta do sinal piroelétrico versus frequência de modulação [6]. Para eliminar essa fonte de erro, passamos a usar o detetor piroelétrico - filme de PVDF - sem a camada de tinta preta.

O uso do detetor piroelétrico com superfície frontal refletora não é usual. Quando uma amostra não opaca é colocada sobre essa superfície, surge uma nova situação espectroscópica, que passamos a denominar de Espectroscopia Fotopiroelétrica por Reflexão, ou abreviadamente PPESR. 


\section{2 - MODELO TEÓRICO}

O modelo teórico que passamos a desenvolver é um tratamento unidimensional, visto que a propagação longitudinal não deve contribuir, substancialmente, para a geração da voltagem piroelétrica. Dessa forma, supomos que a luz incidente será parte absorvida pela amostra e parte refletida pela superfície do detetor. Consideramos ainda que uma pequena fração da luz incidente é transmitida através do detetor, e que difere de zero, contribui para o sinal fotopiroelétrico. Uma parte da luz refletida é reabsorvida pela amostra e este fenômeno produz um sinal cujo espectro se assemelha àquele obtido por técnica fotoacústica [7].

A FIG-3.1 apresenta o esquema do sistema fotopiroelétrico por reflexão.

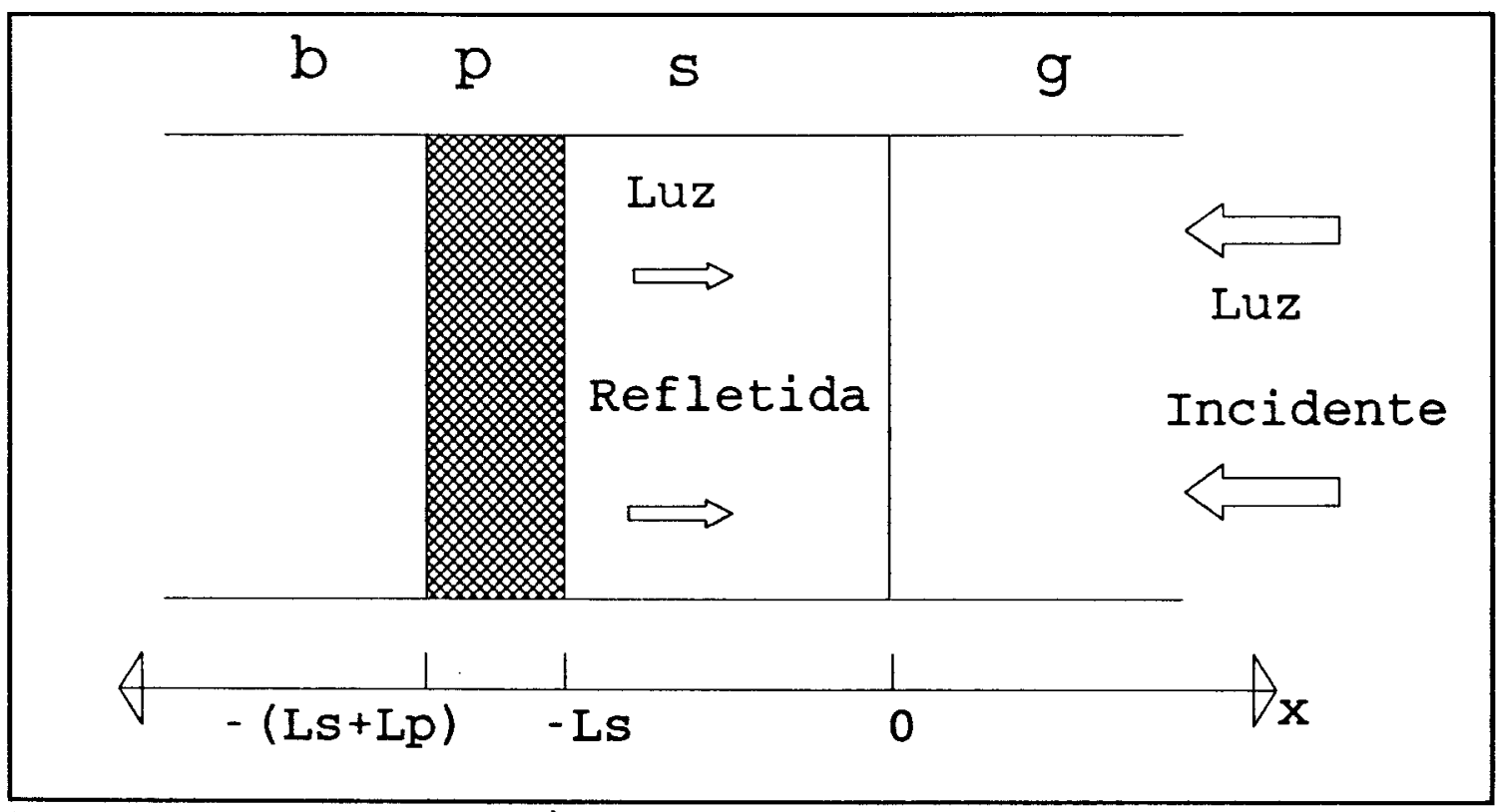

FIG-3.1 - Esquema do sistema PPESR. (b) suporte, (p) detetor, (g) gás ou outro material.

O modelo desenvolvido abaixo segue o mesmo princípio do modelo de PPES de Mandelis [1]. Supomos que o fenômeno dominante no transporte de calor seja a difusão térmica, e que o detetor seja termicamente espesso $\left(\exp \left(-\sigma_{\mathrm{p}} \mathrm{L}_{\mathrm{p}}\right)=0\right)$. Desprezamos as multiplas reflexões 
nas superfícies da amostra e só a reflexão na fronteira amostra-detetor é considerada relevante.

As equações de difusão térmica no sistema da FIG-3.1 são:

$$
\begin{aligned}
& \text { para } x \geq 0 \\
& \frac{\partial^{2} T_{g}}{\partial x^{2}}-\sigma_{g}^{2} T_{g}=0 \\
& \text { para }-L_{s} \leq x \leq 0 \\
& \frac{\partial^{2} T_{s}}{\partial x^{2}}-\sigma_{s}^{2} T_{s}=-\left[\frac{\eta_{s} \beta_{s} I_{0}}{2 k_{s}}\right] e^{\beta_{s} x}-\left[\frac{\eta_{s} \beta_{s} R I_{o}}{2 k_{s}} e^{-\beta_{s} L_{s}}\right] e^{-\beta_{s} x} \\
& \text { para }-\left(L_{s}+L_{p}\right) \leq x \leq-L_{s} \\
& \frac{\partial^{2} T_{p}}{\partial x^{2}}-\sigma_{p}^{2} T_{p}=-\left[\frac{\eta_{p} \beta_{p} I_{p}}{2 k_{p}}\right] e^{\beta_{p}\left(x+L_{s}\right)}
\end{aligned}
$$

A intensidade de luz que é transmitida através do detetor, $\mathbf{I}_{\mathbf{p}}$, é dada pela expressão

$$
I_{p}=(1-R) I_{0} e^{-\beta_{s} L_{s}}
$$

onde $\mathbf{R}$ é $\mathbf{o}$ fator de reflexão.

As soluções das equações de difusão são:

$$
T_{g}=C_{0} e^{-\sigma_{g} x}
$$




$$
\begin{gathered}
T_{s}=\left[\frac{\eta_{s} \beta_{s} I_{0}}{2 k_{s}\left(\sigma_{s}^{2}-\beta_{s}^{2}\right)}\right]\left(e^{\beta_{s} x}+R e^{-\beta_{s}\left(L_{s}+x\right)}\right)+C_{1} e^{\sigma_{s} x}+C_{2} e^{-\sigma_{s} x(3.6)} \\
T_{p}=\left[\frac{\eta_{p} \beta_{p} I_{p}}{2 k_{p}\left(\sigma_{p}^{2}-\beta_{p}^{2}\right)}\right] e^{\beta_{p}\left(x+L_{s}\right)}+C_{3} e^{\sigma_{p} x}+C_{4} e^{-\sigma_{p} x}
\end{gathered}
$$

Consideramos que o detetor seja termicamente espesso, então, $\mathbf{C}_{\mathbf{4}}=\mathbf{0}$. Definimos:

$$
\begin{gathered}
E=\frac{\eta_{s} \beta_{s} I_{0}}{2 k_{s}\left(\beta_{s}^{2}-\sigma_{s}^{2}\right)} \\
F=\frac{\eta_{p} \beta_{p} I_{p}}{2 k_{p}\left(\beta_{p}^{2}-\sigma_{p}^{2}\right)} \\
A=R e^{-\beta_{s} L_{s}}
\end{gathered}
$$

e, ainda $X=\exp \left(\sigma_{\mathfrak{a}} \mathbf{L}_{\mathfrak{s}}\right), Y=\exp \left(\sigma_{\mathbf{a}} L_{2}\right)$.

Aplicando as condiçōes de contorno e continuidade

$$
T_{i}=T_{* i}
$$

e

$$
k_{i} \frac{\partial T_{i}}{\partial x}=k_{\neq i} \frac{\partial T_{* i}}{\partial x}
$$

obtemos o sistema de equações: 


$$
\left[\begin{array}{cccc}
1 & -1 & -1 & 0 \\
1 & b_{s g} & -b_{s g} & 0 \\
0 & X^{-1} & X & -Y^{-1} \\
0 & X^{-1} & -X & -b_{p s} Y^{-1}
\end{array}\right]\left[\begin{array}{l}
C_{0} \\
C_{1} \\
C_{2} \\
C_{3}
\end{array}\right]=\left[\begin{array}{c}
-E(1+A) \\
b_{s g} I_{s} E(1-A) \\
E\left(e^{\left.-\beta_{s} I_{s}+A e^{\beta s I_{s}}\right)-F}\right. \\
E I_{s}\left(e^{\left.-\beta, I_{s}-A e^{\beta I_{s}}\right)-b_{p s} I_{p} F}\right.
\end{array}\right]
$$

Desejamos determinar $\mathrm{T}_{\mathrm{p}}$ para obter a voltagem piroelétrica. Para isto, é necessário determinar o coeficiente $\mathrm{C}_{3}$. Resolvendo-se o sistema de equações encontramos,

$$
\begin{aligned}
C_{3}=\left[E \left\{2\left(b_{s g} I_{s}+1\right)-\left[\left(r_{s}+1\right)\left(b_{s g}+1\right) X+\left(I_{s}-1\right)\left(b_{s g}-1\right) X^{-1}\right] e^{\left.-\beta_{s} I_{s}\right\}}\right.\right. \\
+F\left\{\left(b_{p s} I_{p}+1\right)\left(b_{s g}+1\right) X+\left(b_{p s} I_{p}-1\right)\left(b_{s g}-1\right) X^{-1}\right\}_{+} \\
+E A\left\{2\left(1-b_{s g} I_{s}\right)+\left[\left(r_{s}-1\right)\left(b_{s g}+1\right) X+\left(r_{s}+1\right)\left(b_{s g}-1\right) X^{-1}\right] e^{\left.\beta_{s} I_{s}\right] \div}\right. \\
\quad \div Y^{-1}\left[X^{-1}\left(b_{s g}-1\right)\left(b_{p s}-1\right)+X\left(b_{s g}+1\right)\left(b_{p s}+1\right)\right]
\end{aligned}
$$

A voltagem piroelétrica média é dada por,

$$
V=\left[\frac{p}{\epsilon \epsilon_{o}}\right] \int_{-\left(L_{p}+L_{s}\right)}^{-L_{s}} T_{p}(x) d x
$$

onde $\mathbf{T}_{\mathrm{p}}(\mathbf{x})$ é a temperatura ao longo do detetor, e $\mathbf{p}$ é o coeficiente piroelétrico.

Aplicando-se a equação (3.7) em (3.15) e resolvendo a integral obtemos 


$$
V=\left[\frac{p}{\epsilon \epsilon_{0}}\right]\left[-\frac{F}{\beta_{p}}\left(1-e^{-\beta_{p} L_{D}}\right)+\frac{C_{3}}{\sigma_{p}} e^{-\sigma_{p} L_{s}}\left(1-e^{-\sigma_{p} L_{p}}\right)\right]
$$

Considerando que o detetor tem baixa absorção (caso observado para o PVDF), temos que $\beta_{\mathrm{p}} \mathrm{L}_{\mathrm{p}}<<1$, e sendo também termicamente espesso - isto é, e $\exp \left(-\sigma_{\mathrm{p}} \mathrm{L}_{\mathrm{p}}\right)<<1$ - então, a voltagem piroelétrica é simplificada, resultando em,

$$
V=\left[\frac{p}{\epsilon \epsilon_{0}}\right] \frac{C_{3}}{\sigma_{p}} e^{-\sigma_{p} L_{s}}
$$

Assim, a expressão resultante para a voltagem fotopiroelétrica é dada pela equação (3.18)

$$
\begin{gathered}
V=\left(\frac{p}{2 \epsilon \epsilon_{0}}\right)\left[[ \frac { \eta _ { s } \beta _ { s } I _ { 0 } } { \sigma _ { p } k _ { s } ( \beta _ { s } ^ { 2 } - \sigma _ { s } ^ { 2 } ) } ] \left\{2\left(b_{s g} I_{s}+1\right)-\left[\left(I_{s}+1\right)\left(b_{s g}+1\right) e^{\sigma_{s} L_{s}}\right.\right.\right. \\
\left.\left.+\left(r_{s}-1\right)\left(b_{s g}-1\right) e^{-\sigma_{s} L_{s}}\right] e^{-\beta_{s} L_{s}}\right\}+\left[\frac{\eta_{p} I_{0}(1-R) e^{-\beta_{s} I_{s}}}{k_{p} \sigma_{p} \beta_{p}}\right]\left[\left(b_{p s} I_{p}+1\right)\left(b_{s g}+1\right)\right. \\
\left.\cdot e^{\sigma_{s} I_{s}}+\left(b_{p s} I_{p}-1\right)\left(b_{s g}-1\right) e^{-\sigma_{s} I_{s}}\right]+\left[\frac{\eta_{s} \beta_{s} I_{0} R}{k_{s}\left(\beta_{s}^{2}-\sigma_{s}^{2}\right) \sigma_{p}}\right]\left\{2\left(1-b_{s g} I_{s}\right) e^{-\beta_{s} I_{s}+}\right. \\
\left.\left.+\left[\left(I_{s}-1\right)\left(b_{s g}+1\right) e^{\sigma_{s} L_{s}}+\left(I_{s}+1\right)\left(b_{s g}-1\right) e^{-\sigma_{g} I_{s}}\right]\right\}\right] \div \\
\div\left[\left(b_{s g}+1\right)\left(b_{p s}+1\right) e^{\sigma_{s} I_{s}}+\left(b_{s g}-1\right)\left(b_{p s}-1\right) e^{-\sigma_{g} L_{s}}\right]
\end{gathered}
$$


Podemos observar que a equação (3.18) contém a expressão obtida por Mandelis mais os termos devidos a reflexão. Para $R=0$, a equação (3.18) resulta naquela obtida por Mandelis. Para $R \cong 1$, podemos notar que o termo que depende dos parâmetros do detetor é eliminado, logo, obtemos

$$
\begin{gathered}
V(\beta, \omega)=\left(\frac{p I_{0}}{2 \epsilon \epsilon_{0}}\right)\left[\frac{\eta_{s} \beta_{s}}{k_{s}\left(\beta_{s}^{2}-\sigma_{s}^{2}\right) \sigma_{p}}\right]\left[\left\{2\left(b_{s g} r_{s}+1\right)-\left[\left(r_{s}+1\right)\left(b_{s g}+1\right) e^{\sigma L_{s}}+\left(r_{s}-1\right)\left(b_{s s}-1\right) e^{-\sigma L_{s}}\right]\right.\right. \\
\left.\cdot e^{\left.-\beta L_{s}\right\}+}\left\{2\left(1-b_{s g} r_{s}\right) e^{-\beta_{s} L_{s}}+\left[\left(r_{s}-1\right)\left(b_{s g}+1\right) e^{\sigma s L_{s}}+\left(r_{s}+1\right)\left(b_{s g}-1\right) e^{-\sigma L_{s}}\right]\right\}\right] \div \\
\div\left[\left(b_{s g}+1\right)\left(b_{p s}+1\right) e^{\sigma L_{s}}+\left(b_{s g}-1\right)\left(b_{p s}-1\right) e^{-\sigma L_{s}}\right]
\end{gathered}
$$

O $2^{\circ}$ termo do $2^{\circ}$ membro da equação (3.19) é similar a expressão obtida no modelo RG para espectroscopia fotoacústica [7], isto é, equação (1.6).

\section{3 - CONSIDERAÇÕES SOBRE O MODELO FOTOPIROELÉTRICO POR REFLEXÃO}

Na sequência consideremos dois casos importantes:

3.3.1 - Amostra termicamente espessa $\left(\mu_{1}<<L_{2}\right)$. Para esse caso, consideramos que $\exp \left(-\sigma_{3} L_{2}\right) \cong 0$, a expressão (3.19) é simplificada, resultando em 


$$
V \approx\left(\frac{p I_{0}}{2 \epsilon \epsilon_{0}}\right)\left[\frac{\eta_{s} r_{s}}{k_{s} \sigma_{s} \sigma_{p}\left(r_{s}^{2}-1\right)}\right]\left[\frac{\left(r_{s}-1\right)-\left(r_{s}+1\right) e^{-\beta_{s} L_{s}}}{b_{p s}+1}\right]
$$

sendo que $\left(\mathbf{r}_{\mathbf{s}}-\mathbf{1}\right)$, primeiro termo do segundo colchete, é a contribuição devido à absorção da luz refletida.

Considerando que $\mathrm{r}_{\mathbf{1}}<<1$ e $\mathrm{L}_{\mathbf{a}}<<\beta_{1}^{-1}$ (baixa absorção), obtemos

$$
V \approx 2\left[\frac{p I_{0}}{2 \epsilon \epsilon_{0}}\right]\left(\frac{\eta_{s} \beta_{s}}{2 \sqrt{2} k_{s} a_{s}^{2} a_{p}}\right)\left(\frac{1}{b_{p s}+1}\right) e^{-j \frac{3 \pi}{4}}
$$

Podemos observar na equação (3.21) que a voltagem fotopiroelétrica é proporcional a $\beta_{\mathrm{a}}$ e a dependência com a frequência é $\omega^{-3 / 2}$, visto que $a_{\mathrm{a}} \mathrm{e} a_{\mathrm{p}}$ são proporcionais a $\omega^{-1 / 2}$, como foi mostrado no capítulo I.

Considerando agora $r_{\mathbf{a}}>>1$ e $L_{\mathfrak{a}}>>\beta_{t}^{-1}$, obtemos que

$$
V \approx\left[\frac{p I_{0}}{2 \epsilon \epsilon_{0}}\right]\left(\frac{\eta_{s}}{2 k_{s} a_{s} a_{p}}\right)\left(\frac{1}{b_{p s}+1}\right) e^{-j \frac{\pi}{2}}
$$

Dessa equação podemos verificar que a dependência da amplitude com a frequência é $\omega^{-1}$. Esta expressão não dá informação espectroscopica, já que é uma condição fototermicamente saturada. 
3.3.2 - Amostra termicamente fina $-\left(\mu_{2}>>L_{2}\right)$. Assumindo que $b_{x}>>1$, obtemos a partir da equação (3.19),

$$
V \approx\left(\frac{p I_{0}}{2 \epsilon \epsilon_{0}}\right)\left[\frac{\eta_{s} r_{s}}{k_{s} \sigma_{s} \sigma_{p}\left(r_{s}^{2}-1\right)}\right]\left[\frac{2 r_{s}\left(1-e^{-\beta L_{s}}\right)}{D}\right]
$$

onde $\mathrm{D}=\mathrm{b}_{\mathrm{ps}}+\sigma_{\mathrm{s}} \mathrm{L}_{\mathrm{s}}$

Quando $r_{\mathbf{a}}>>1$, obtemos que

$$
V \approx 2\left(\frac{p I_{0}}{2 \epsilon \epsilon_{0}}\right)\left[\frac{\eta_{s}}{2 k_{s} a_{s} a_{p}}\right]\left[\frac{1-e^{\beta L_{s}}}{|D|}\right] e^{j\left(\frac{\pi}{2}+\phi\right)}
$$

onde $\phi$ representa a fase oriunda de $D$. Nessa expressão, quando $b_{p s}>>\sigma_{g} L_{\mathfrak{s}}$, a voltagem piroelétrica depende de $\beta_{\mathrm{g}} \mathrm{L}_{\mathrm{s}}$ e de $\omega^{-1}, \phi=0$ resultando que a fase é $\pi / 2$. Quando $b_{\mathrm{ps}}<<\sigma_{\mathrm{g}} \mathrm{L}_{\mathrm{s}}$, sua dependência é $\omega^{-3 / 2}$ e a fase tende a $-3 \pi / 4$.

Levando em consideração $\beta_{\mathrm{s}} \mathrm{L}_{\mathrm{z}}<1$, obtemos de (3.24) que

$$
V \approx 2\left(\frac{p I_{0}}{2 \epsilon \epsilon_{0}}\right)\left[\frac{\eta_{s}}{2 k_{s} a_{s} a_{p}}\right]\left[\frac{\beta_{s} L_{s}}{|D|}\right] e^{-j\left(\frac{\pi}{2}+\phi\right)}
$$

Esta expressão nos dá informação espectroscópica e depende diretamente de $\beta_{\mathfrak{z}} \mathrm{L}_{\mathbf{a}}$. 


\section{4 - SIMULAÇÃO DO MODELO}

Vamos analisar o modelo para uma amostra hipotética com $\mathrm{L}_{\mathrm{s}}=15 \mu \mathrm{m}$ (a escolha deste valor foi devido ds limitações computacionais), $\alpha_{1}=10^{-7} \mathrm{~m}^{2} / \mathrm{s}$ (este valor foi escolhido por ser da ordem de grandeza dos materiais poliméricos). Essa amostra tem frequência crítica, $f_{c r}=\cong 140 \mathrm{~Hz}$, e frequência característica, $f_{c} \cong 440 \mathrm{~Hz}$. As FIG-3.2 a FIG-3.7 foram obtidas usando a equação (3.19) sendo que as demais equações acima são os seus casos limites.

A FIG-3.2 mostra o gráfico $\log (\mathrm{V}) \times \log (\mathrm{f})$ que apresenta o comportamento do modelo para amostra de baixo $\beta_{\mathfrak{z}}$ e diferentes $b_{p r}$. A região de altas frequências caracteriza o caso termicamente espesso. Observa-se que a inclinação da reta no gráfico $\log -\log$ independe de $b_{p b}$, mas sua amplitude é maior quanto menor o valor de $b_{p s}$.

Na região de baixas frequências - termicamente fina - a inclinação da reta do gráfico log$\log$ é diferente daquela no caso anterior. Isto é esperado já que a dependência em frequência nos dois casos são diferentes. Podemos observar que para $b_{p s}<1$ a inclinação da reta é diferente das demais, como é previsto na equação (3.23) através dos valores do fator D.

A FIG-3.3 mostra o comportamento da fase. Para a região termicamente espessa a fase mantém-se constante em $-3 \pi / 4$ como obtido na equação (3.21). Na região termicamente fina a fase tende $a-x / 2$. Para $b_{p s}>>1$, o valor $-\pi / 2$ é atingido em frequências maiores que nas curvas obtidas com $b_{p s}<<1$. Acima da frequência crítica encontramos um ponto de mínimo. Isso evidencia que a fase não é uma função só das grandezas térmicas envolvidas - difusividade e condutividade térmicas. Ainda podemos observar que para $b_{p s}$ grande, esse ponto de mínimo se aproxima da frequência característica. 


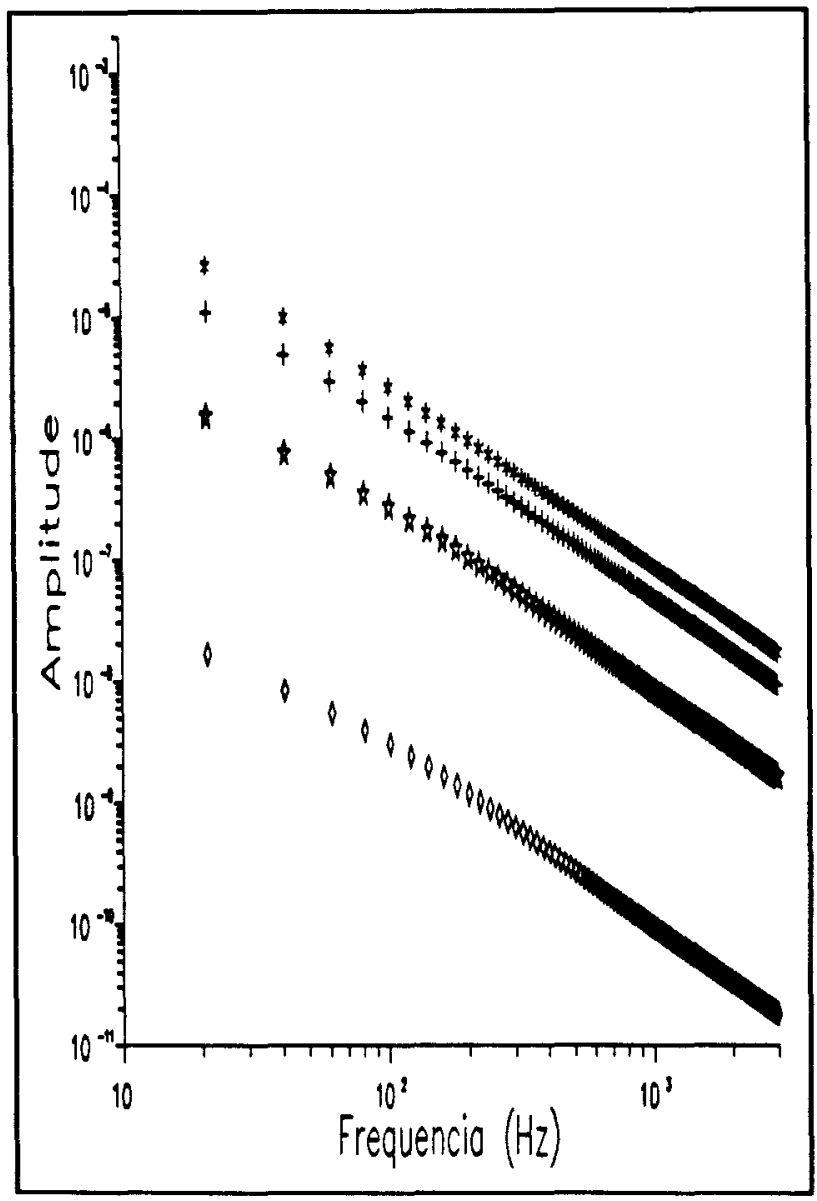

FIG-3.2 - Resposta em frequência do sinal PPESR de uma amostra transparente : $\quad \beta_{\mathrm{s}}=100 \mathrm{~m}^{-1}$; $(\star): b_{p s}=0,1 ;(+): b_{p s}=1 ;(\hbar): b_{p s}=10 ;$ $(\diamond): \mathrm{b}_{\mathrm{ps}}=1000$.

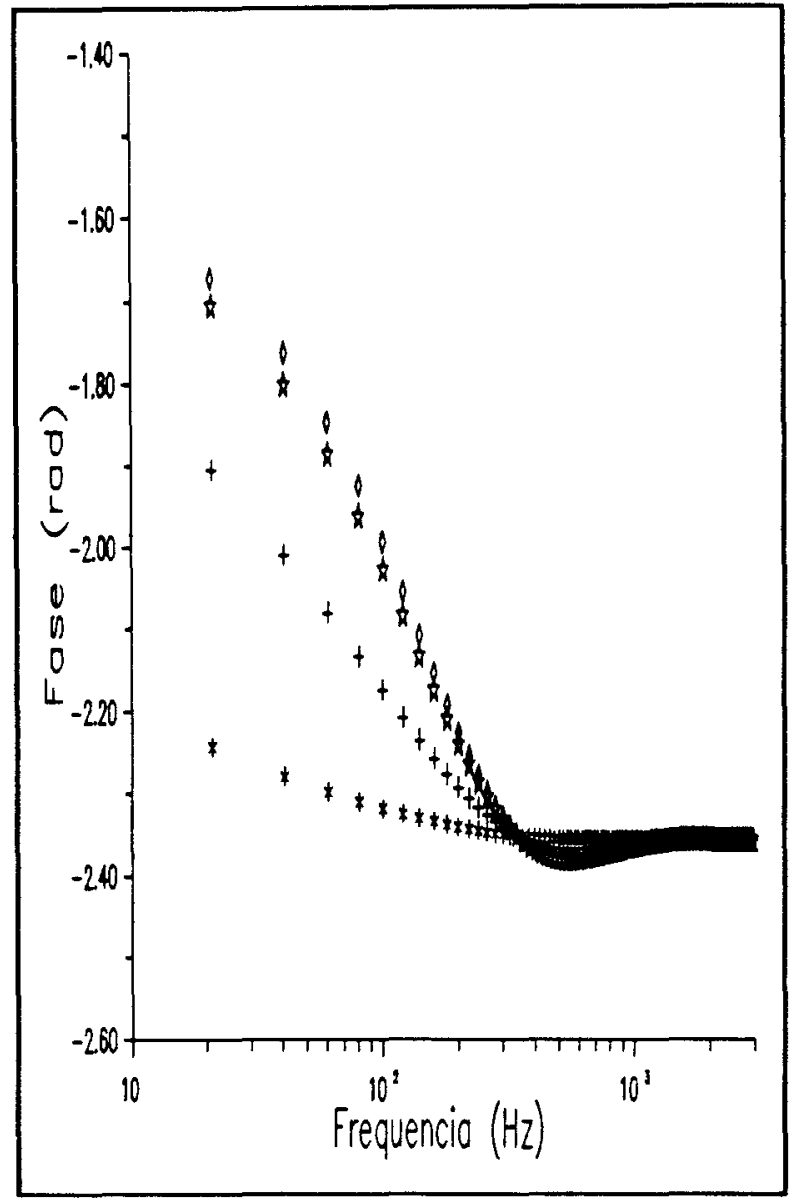

FIG-3.3 - Curvas da fase para a amostra transparente: $\beta_{\mathrm{s}}=100 \mathrm{~m}^{-1}$; $(*): b_{p s}=0,1 ; \quad(+): b_{p s}=1$; $(\star): b_{p s}=10 ;(\diamond): 10^{-3}$

As FIG-3.4 e FIG-3.5 ilustram, respectivamente, o comportamento da amplitude e da fase com a frequência para uma amostra muito absorvedora, e para diferentes $b_{p s}$. Observamos na FIG-3.4 que a variação de $b_{p}$ só desloca o valor da amplitude não alterando sua forma. A curva caracterizada por $b_{p s}<1$, foge ligeiramente do comportamento das demais, na região de baixas frequências. Podemos separar em três regiões: termicamente fina, de transição e termicamente espessa. 


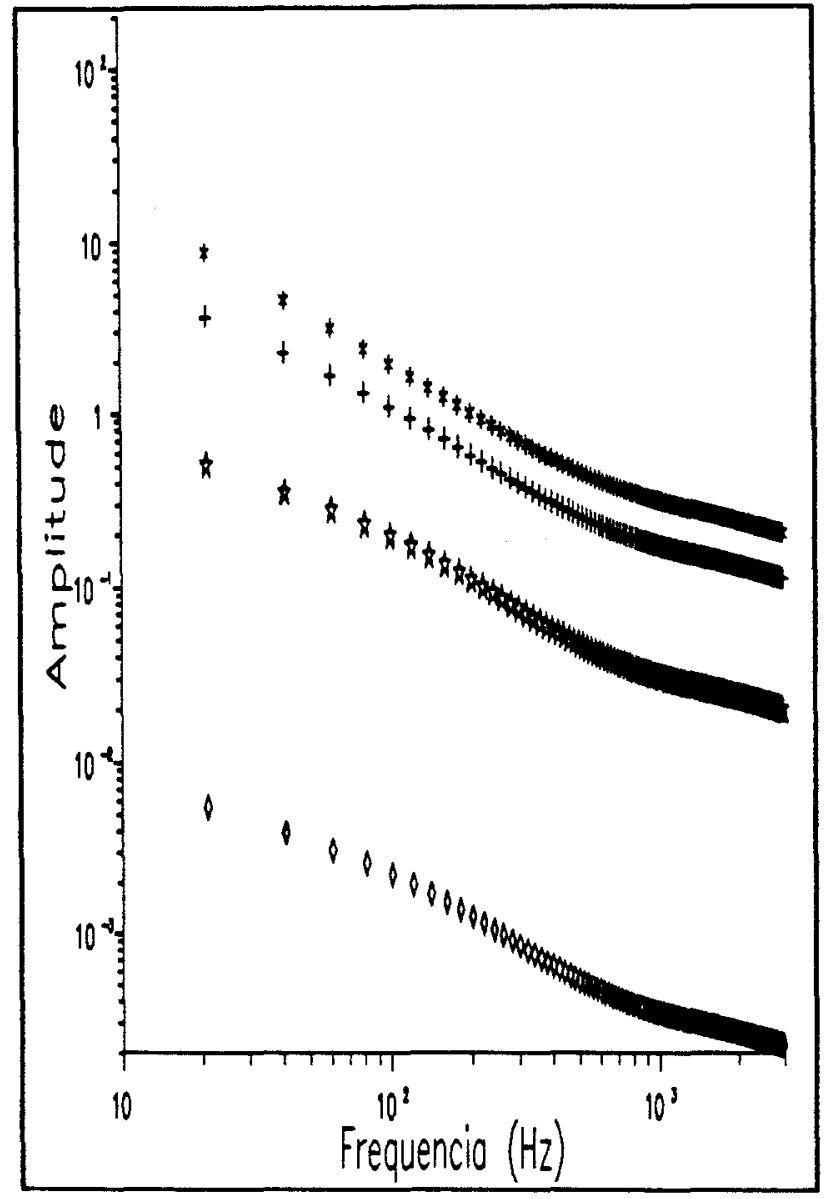

FIG-3.4 - Resposta com a frequência do sinal PPESR para amostra absorvedora: $\beta_{\mathrm{s}}=10^{7} \mathrm{~m}^{-1}$

(*) $\mathrm{b}_{\mathrm{ps}}=.1,(+) \mathrm{b}_{\mathrm{ps}}=1$, (*) $\mathrm{b}_{\mathrm{ps}}=10 \mathrm{e}$

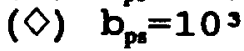

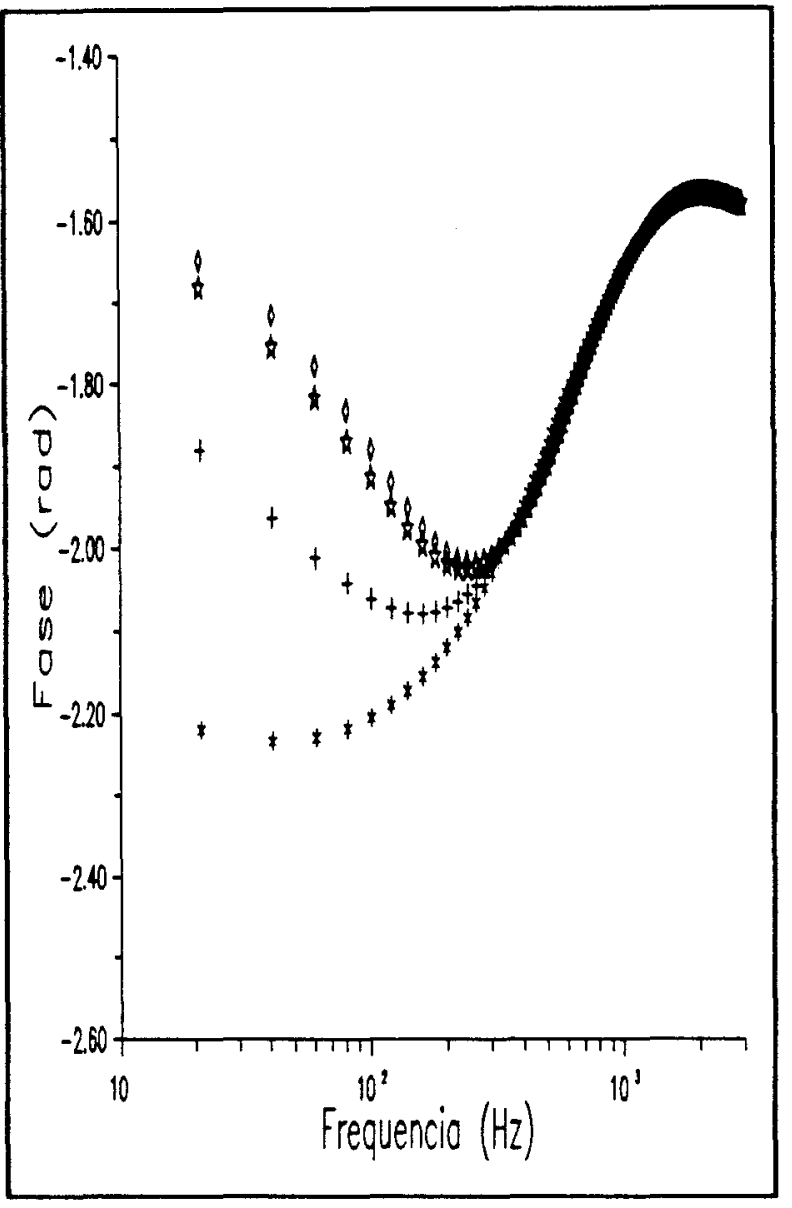

FIG-3.5 - Curva da fase para a amostra absorvedora: $\beta_{\mathrm{s}}=10^{7} \mathrm{~m}^{-1}$ $(*): b_{p t}=0,1 ;(+): b_{p s}=1 ;(t): b_{p t}=10$ e $(\diamond): b_{p s}=10^{3}$.

A FIG-3.5 apresenta as curvas de fase versus frequência. Vemos que o comportamento na região termicamente espessa difere muito daquele observado com os simulados de baixa absorção na FIG-3.3. Como a contribuição da absorção da luz refletida é dominante no regime termicamente espesso, já que ocorre na fronteira amostra-detetor, é esperado que seu valor tenda a $-\pi / 2$, como mostra a equação (3.22). O mínimo na curva ocorre próximo à frequência crítica.

Observamos que nas FIG-3.3 e FIG-3.5 os mínimos ocorrem em frequências diferentes. Em geral, para amostra de baixa absorção a fase também depende de $\beta_{n}$, enquanto para alta 
absorção isso não ocorre. Sendo a frequência crítica $\cong 140$ para a amostra hipotética, então da curva com $b_{p t}=1$ podemos determinar a frequência crítica precisamente. Portanto, conhecendo $o b_{p e}$ e os parâmentos térmicos do detetor podemos determinar a condutividade térmica da amostra.

A FIG-3.6 mostra as curvas de fase para três diferentes classes de materiais. Para obtermos estas curvas, supomos que cada amostra seja absorvedora, $\operatorname{com} \beta_{a}=10^{7} \mathrm{~m}^{-1} \mathrm{e}$ consideramos que o polímero - PVDF tem $\mathrm{L}_{\mathrm{s}}=50 \mu \mathrm{m}, \alpha_{\mathrm{s}}=5,4 \times 10^{-8} \mathrm{~m}^{2} / \mathrm{s}, \mathrm{k}_{\mathrm{s}}=0,13 \mathrm{~W} / \mathrm{mK}$

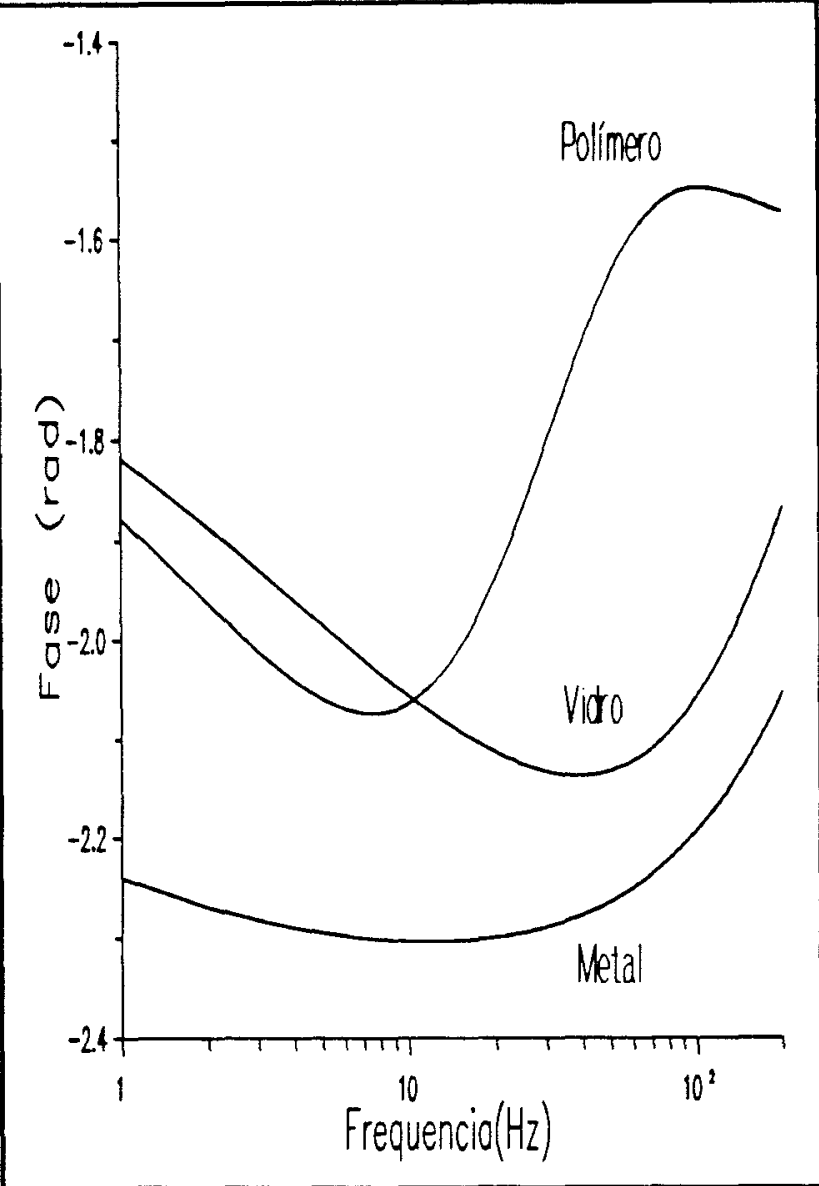

FIG-3.6 - Curvas de respostas das fases PPESR. Polimero:PVDF, vidro: Quartzo e metal:Al. [1] e frequência crítica de $6,87 \mathrm{~Hz}$ e $b_{p s}=1 ; 0$ vidro - quartzo tem $\mathrm{L}_{\mathrm{s}}=50 \mu \mathrm{m}, \alpha_{\mathrm{z}}=44 \times 10^{-8} \mathrm{~m}^{2} / \mathrm{s}$, $\mathrm{k}_{\mathrm{s}}=0,92 \mathrm{~W} / \mathrm{mk}$ [11], tendo frequência crítica de $56 \mathrm{~Hz}$ e $\mathrm{b}_{\mathrm{ps}}=0,4$ e o metal - alumínio tem $\mathrm{L}_{\mathrm{s}}=500 \mu \mathrm{m}, \alpha_{\mathrm{s}}=82 \times 10^{-6} \mathrm{~m}^{2} / \mathrm{s}, \mathrm{k}_{\mathrm{s}}=201 \mathrm{~W} / \mathrm{mK}$ com frequência crítica de $104 \mathrm{~Hz}$ e $\mathrm{b}_{\mathrm{ps}}=0,025$.

Podemos observar que o mínimo de cada curva não ocorre na região de frequência crítica para as amostras, cujas grandezas térmicas são maiores do que as do detetor. Esse é o caso verificado nas curvas obtidas com metal e vidro. Por outro lado, para polímeros o mínimo da curva é, em geral, próximo à frequencia crítica. Enquanto que para outros tipos de amostras, necessitaria de algorítmo de ajustes de curvas elaborado para esse comportamento da fase. 
Podemos observar nas FIG-3.7 e FIG-3.8 os comportamentos dos termos que compõem

a eq.(3.19) originados das luzes incidente e refletida, para as amostras muito absorvedo$\operatorname{ra}\left(\beta_{\mathrm{t}}=10^{7} \mathrm{~m}^{-1}\right)$ e transparente $\left(\beta_{\mathrm{t}}=100 \mathrm{~m}^{-1}\right)$, com $\mathrm{b}_{\mathrm{pt}}=0,1$ e $\mathrm{b}_{\mathrm{pt}}=1000$, respectivamente. Para o caso em que a amostra é muito absorvedora, a separação das curvas começa na região de transição. Nota-se que para altas frequências a contribuição devido ao calor gerado pela absorção da luz incidente decresce mais rápido do que a contribuição devido a luz refletida.

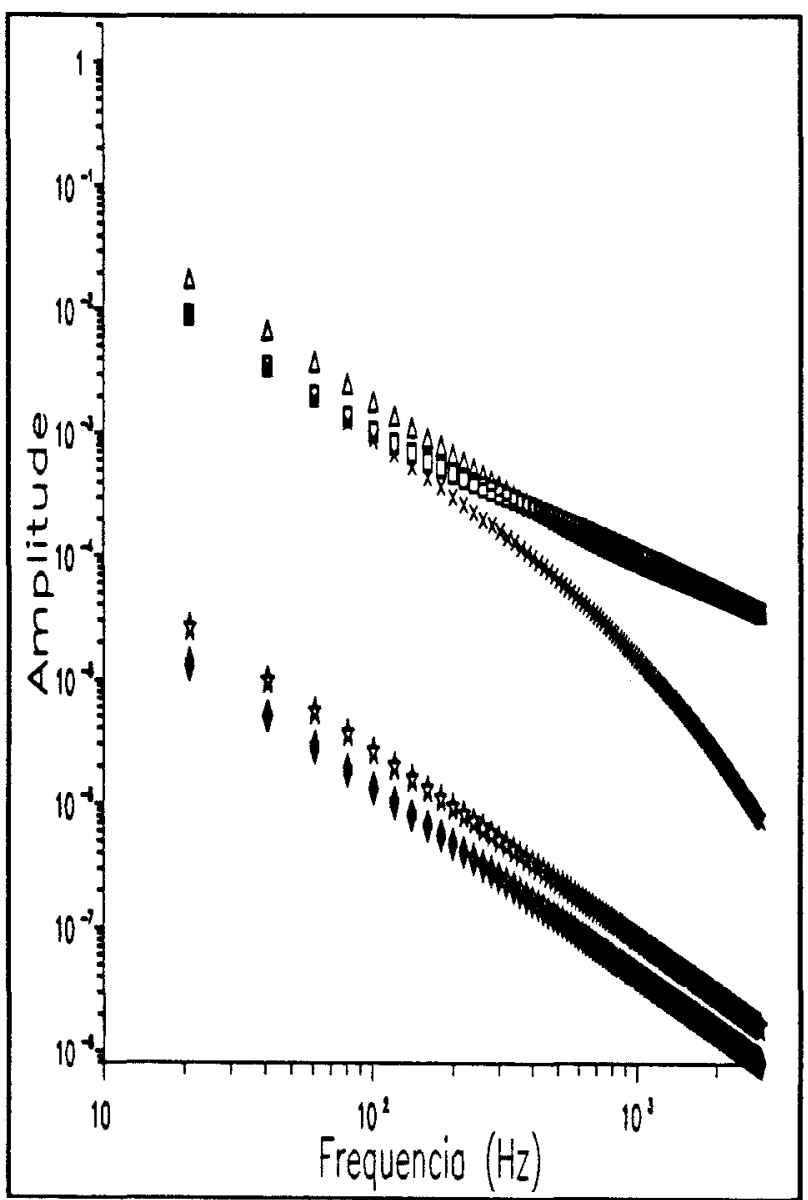

FIG-3.7 - Resposta em frequência do sinal PPESR. $b_{p s}=0,1: \beta_{\mathrm{s}}=100 \mathrm{~m}^{-1}$ $:(*)$ incidente, $(\diamond)$ refletida, (*) resultante. $\beta_{1}=10^{7} \mathrm{~m}^{-1}$ : (x) incidente, resultante.

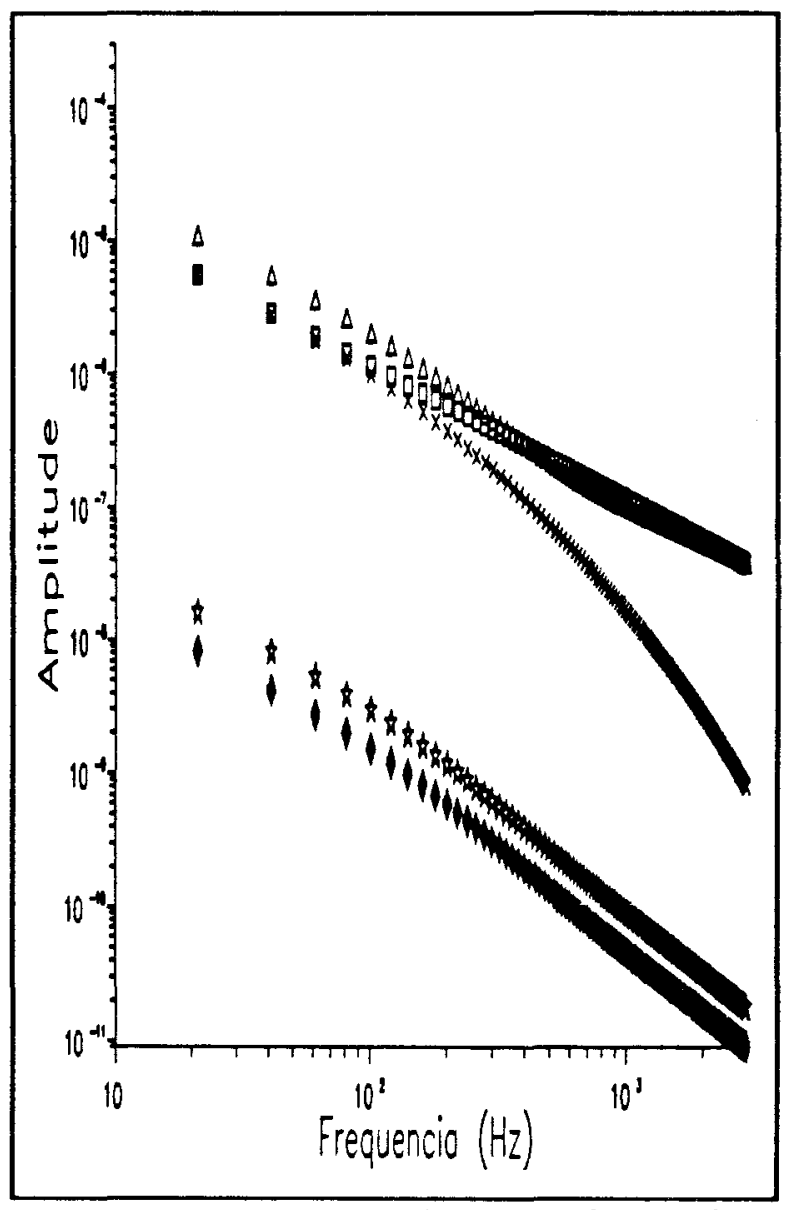

FIG-3.8 - Resposta em frequência do sinal PPESR. $b_{p s}=10^{3}$ : $\beta_{s}=100 \mathrm{~m}^{-1}:(*)$ incidente, refletida, $(\star)$ resultante. $\beta_{\mathrm{s}}=10^{7} \mathrm{~m}^{-1}$ : (x) incidente, ( $\square$ ) refletida, ( $\Delta$ ) resultante. 
Observamos que em baixas frequências, as contribuições são equivalentes. Para amostras de baixa absorção, as contribuições ao sinal são iguais para todo intervalo de frequência. $O$ fator 2 nas equaçōes (3.21), (3.24) e (3.25) surge dos termos semelhantes das contribuições devido a luz incidente e refletida. Coufal já tinha previsto a existência desse fator através de considerações puramente conceituais [8].

O fenômeno descrito neste modelo só é possível quando:

i) a amostra não é totalmente opaca;

ii) a superfície do detetor é bem refletora;

iii) o acoplamento amostra-detetor é excelente.

Apesar destas limitações, este método espectroscópico é equivalente à fotoacústica e à deflexão fototérmica transversa [9]. A voltagem fotopiroelétrica, neste modelo, independe da eficiência quântica do detetor, o que não ocorre no modelo PPES, tornando-se mais simples a análise. Além disso, continua sendo um método com câmara aberta que fornece algumas vantagens sobre as câmaras fechadas.

As aplicações deste modelo serão apresentadas na seção seguinte.

\section{5 - APLICAÇÕES}

Para demonstrar esta técnica espectroscópica usamos um filme de Poli(MetilMetacrilato), PMMA, dopado com rodamina. Usamos o PMMA pelo fato de não absorver na região visível e ser facilmente dissolvido em acetona. A rodamina é um corante que apresenta bandas de absorção sobrepostas formando um simples espectro na região do visível [10], (ver 
FIG-3.9), além de ser facilmente dissolvida em acetona.

Para a variação de frequência de modulação usamos duas amostras: um filme de PVDF e uma pastilha de silício amorfo. $O$ uso do filme de PVDF foi devido as características térmicas serem as mesmas do detetor, além de ser transparente no visível, enquanto que o silício é totalmente opaco nessa região e tem características térmicas diferentes daquelas do detetor.

\subsection{1 - Medidas Espectroscópicas}

Usando um detetor com superfície refletora (detetor branco), com bom acoplamento amostra-detetor, obtemos um espectro

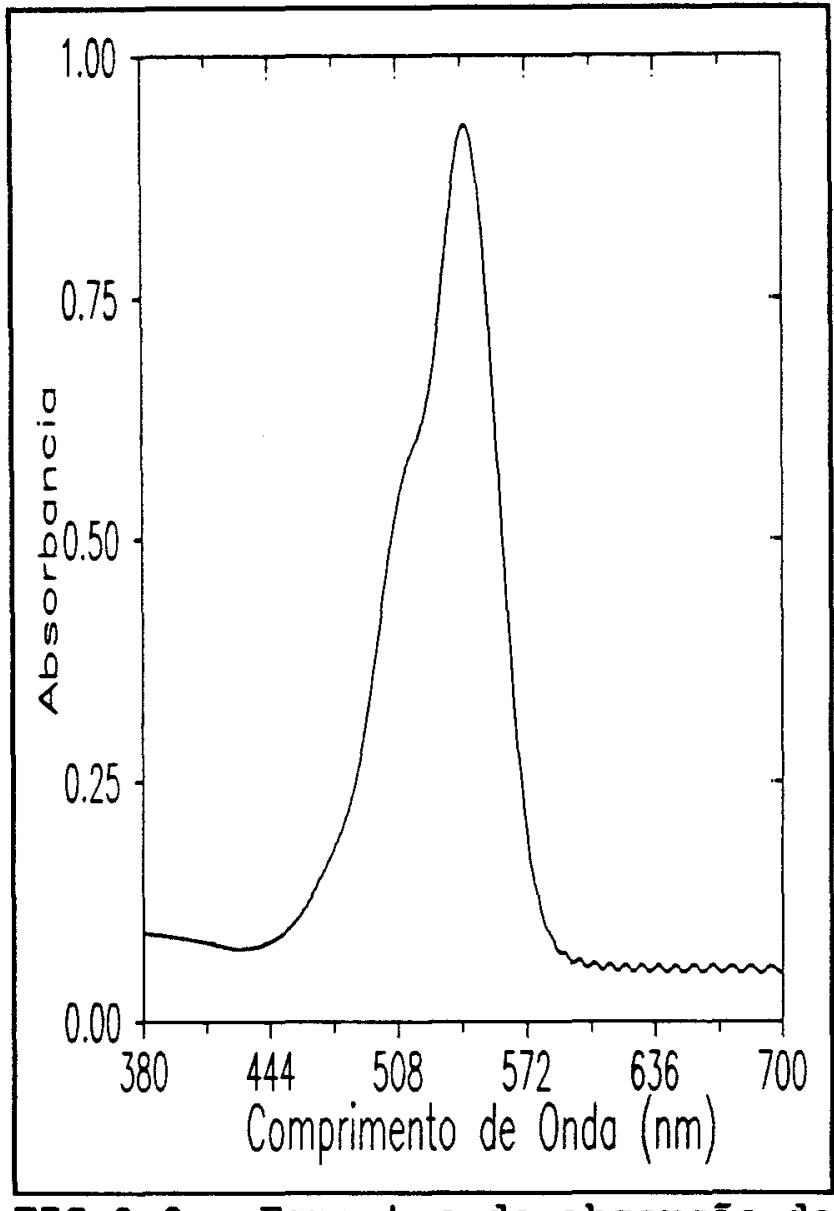

FIG-3.9 - Espectro de absorção do filme de PMMA+rodamina, obtido através do espectrofotômetro Cary 2315.

para o filme PMMA-rodamina (FIG-3.10), semelhante ao espectro obtido através de um equipamento Cary2315, UV-Visível (FIG-3.9). Nesse experimento, usamos o espectrômetro fototérmico com duplo feixe e duas câmaras fotopiroelétricas (ver FIG-2.1): uma para referência e outra para amostra. A frequência de modulação foi fixada em $514 \mathrm{~Hz}$ e a fenda de saída do monocromador deu resolução de $6 \mathrm{~nm}$. O pré-amplificador foi usado para igualar os sinais das câmaras compensando as diferenças entre si. Todos os espectros foram obtidos com as câmaras 
abertas e sem uso de janelas transparentes e os procedimentos de medidas foram os seguintes:

1 - A amostra foi inicialmente colocada sobre a superfície refletora do detetor com auxílio de um fina camada de graxa de vácuo. O espectro foi obtido em tempo real (FIG.3.10).

2 - Em seguida retiramos a graxa de vácuo, empobrecendo assim o acoplamento amostra-detetor, e consequentemente o contato térmico. Obtemos, então, o espectro que se assemelha ao de transmissão ótica mostrado na FIG-3.11.

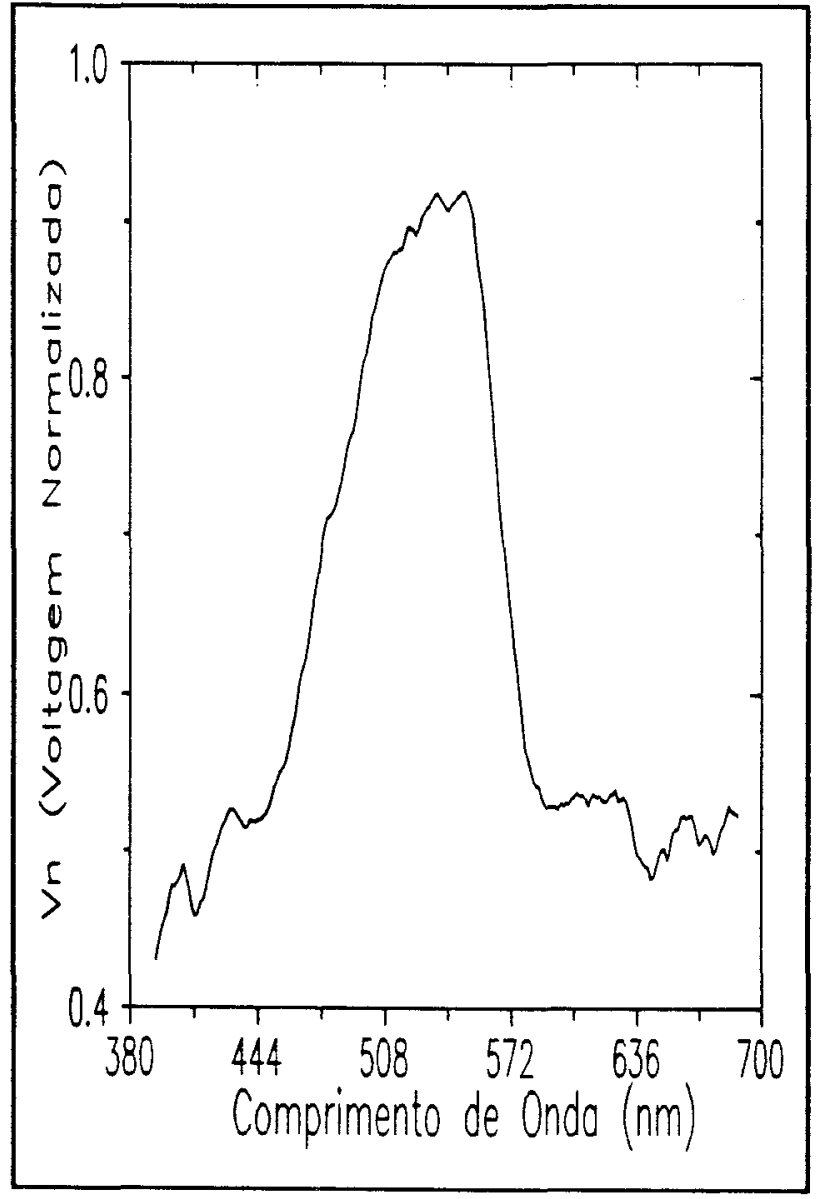

FIG-3.10 - Espectro de Rodamina sobre matriz polimérica de PMMA obtido com detetor branco.

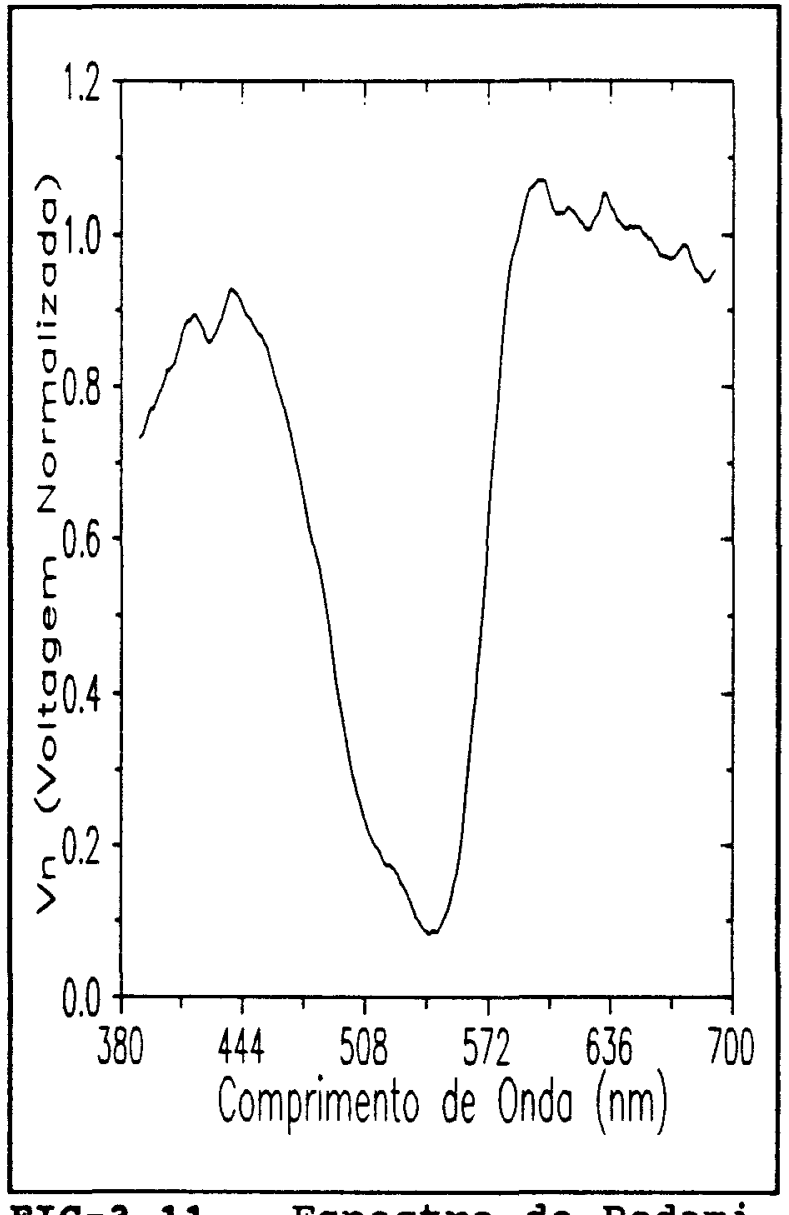

FIG-3.11 - Espectro de Rodamina+PMMA obtido por PPERS com pobre contato térmico. 
Nesse caso, o calor gerado devido à absorção da luz pela amostra não contribuiu para o sinal piroelétrico, já que o contato térmico entre as superfícies amostra-detetor não foi otimizado. O sinal piroelétrico foi gerado pela luz que atravessou a amostra e atingiu diretamente o detetor. Isso é o que ocorre nos espectrofotômetros por transmissão.

Em seguida, realizamos novas medidas espectroscópicas, usando câmaras piroelétricas com superfícies pintadas de preto (detetor preto). As condições experimentais foram as mesmas usadas nas medidas anteriores para os casos de bom e mau acoplamento amostra-

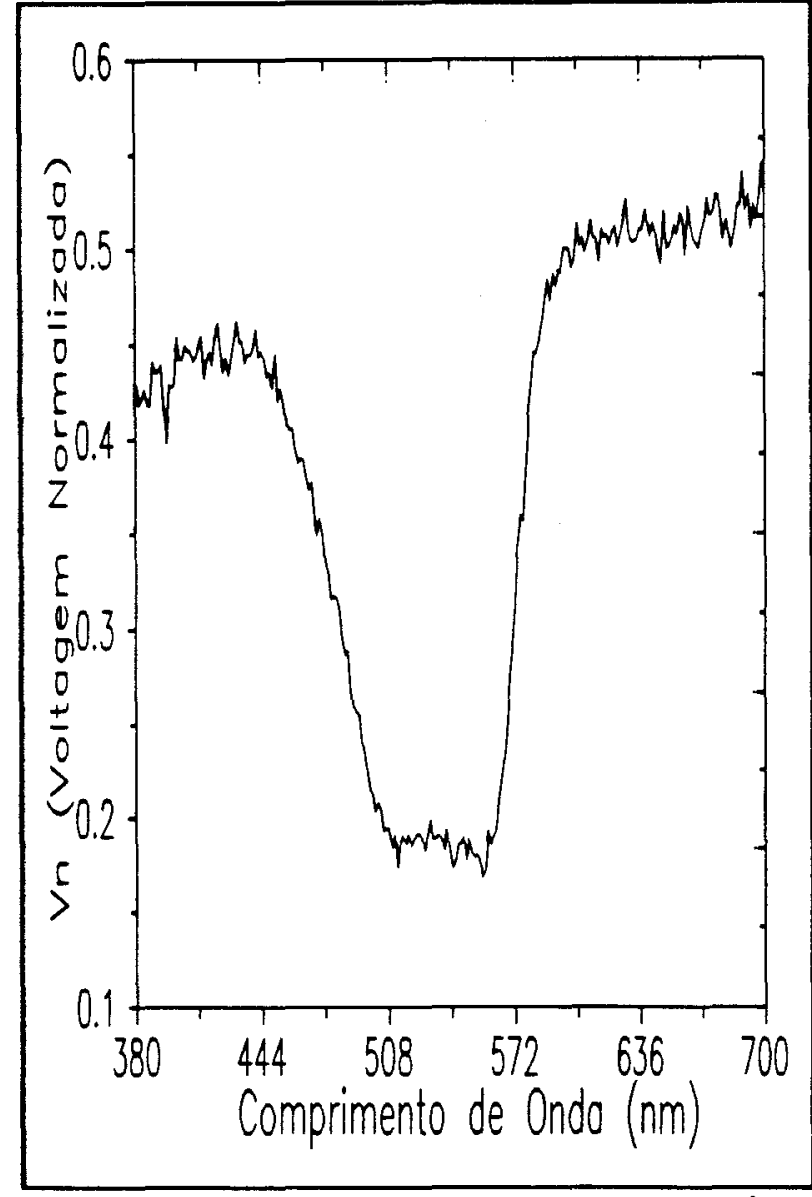

FIG-3.12 - Espectro de Rodamina sobre matriz polimérica de PMMA obtido com detetor preto. detetor.

Quando fizemos um bom contato térmico o espectro obtido se assemelhou ao de transmissão ótica, como está mostrado na FIG-3.12. Quando a graxa de vácuo foi retirada, continuamos obtendo o mesmo tipo de espectro, como era de se esperar.

Portanto, o espectro da FIG-3.10 comprova que a contribuição dominante para o sinal fotopiroelétrico é dada pela luz refletida na superfície do detetor e reabsorvida pela amostra, como prevê o modelo. 


\subsection{2 - Medidas Térmicas}

Apresentamos agora medidas térmicas usando como amostras um filme de PVDF de $50 \mu \mathrm{m}$ e uma pastilha de silício de $940 \mu \mathrm{m}$, com objetivo de verificar o comportamento do sinal fotopiroelétrico com a frequência previsto pelo modelo.

Usamos um filme de PVDF no qual uma das faces foi pintada de preto com uma caneta especial usada para escrever em superfície muito lisa. Essa pintura deixou uma fina camada não muito uniforme de tinta, resultando numa camada semi-transparente. As frequências crítica e característica dessa amostra são $\cong 7 \mathrm{e} \cong 22 \mathrm{~Hz}$, respectivamente.

O acoplamento amostra-detetor foi arranjado de tal maneira que a face não pintada ficou em contato com a superfície refletora do detetor. Para melhor fixação, foi também usado nesse arranjo uma camada fina de graxa de vácuo. Pressionamos levemente a amostra colocando sobre ela uma janela de quartzo pressionada pela tampa da câmara.

Para excitar a amostra usamos o sistema com fonte de luz incandescente (ver FIG-2.2), com a qual obtemos alta relação sinal/ruído. As tensões foram lidas no lock-in, o qual forneceu a intensidade $(\mathrm{R})$, a fase $(\theta)$ e as componentes em fase e em quadratura da amplitude do sinal.

Repetimos os mesmos procedimentos para a mesma amostra, agora colocada sobre o detetor pintado de preto. $O$ detetor foi pintado pelo mesmo processo usado na amostra. Podemos verificar, nas FIG-3.13 e FIG-3.14 que as curvas obtidas com os diferentes detetores são distintas tanto na amplitude quanto na fase.

A sensível diferença de intensidades nas curvas de amplitude, vem do fato que no detetor branco, uma razoável quantidade de luz é refletida para fora da amostra, não sendo convertida em calor. Experiência realizada com luz de laser He-Ne, mostrou que a intensidade de luz 
refletida da superfície do detetor chega a ser próxima de $80 \%$ da intensidade nela incidente.
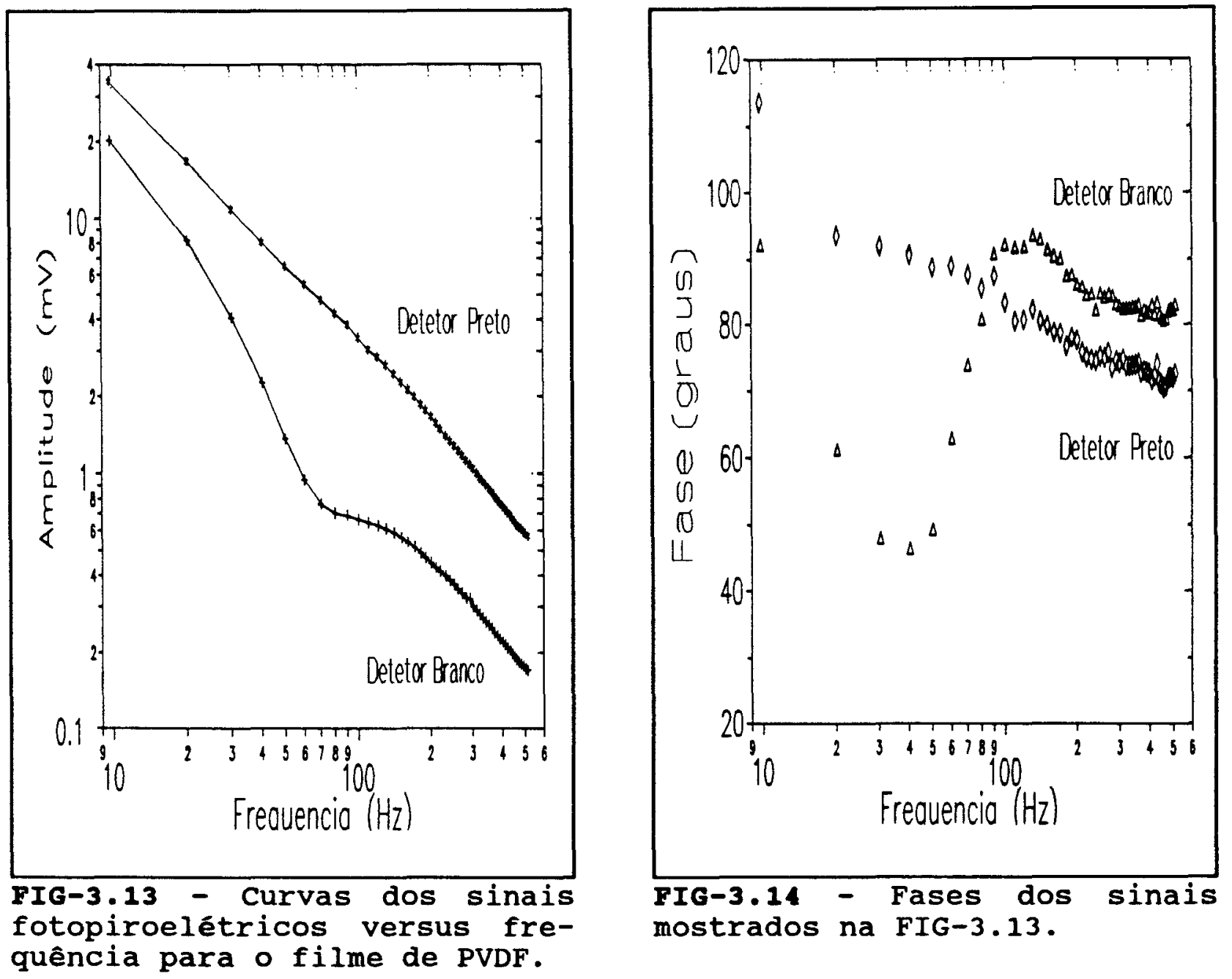

Na curva obtida com detetor branco, podemos ver três regiōes distintas. Na região de baixa frequência, o calor gerado na superfície da amostra é dominante em comparação com aquele gerado na superfície do detetor, enquanto que em alta frequência, isto é, acima de $200 \mathrm{~Hz}$, a contribuição passa a ser dominada pelo calor gerado sobre o detetor. Essa frequência pode ser tomada como limite, acima da qual a amostra se torna $100 \%$ termicamente espessa. Uma terceira 
região, intermediária, é também observada na FIG-3.13 para o detetor branco. Já na curva obtida com o detetor preto, essa região não é verificada. Para frequências acima de $200 \mathrm{~Hz}$, observamos que as curvas são paralela. Isso demonstra o domínio do detetor nesta região.

A FIG-3.14 mostra a variação da fase com o detetor branco e detetor preto. Observamos que há um ponto de mínimo na curva de fase para o detetor branco, como foi previsto pelo modelo. Este ponto deveria ocorrer próximo à frequência crítica, já que se trata de uma amostra polimérica. Entretanto, devido ao fato da amostra só absorver numa fina película da superfície frontal, e não absorver ao longo de sua espessura, a fase se compõe do atraso na propagação do calor através da amostra. Há também a contribuição do tempo de propagação no detetor, isto é, a contribuição para a fase devido ao próprio detetor.

À medida que a frequência de modulação cresce - ainda na região de baixa frequência a fase devido ao calor gerado no detetor passa a ser dominante. Portanto, essas contribuições individuais para a fase desloca o ponto de mínimo para valores de frequências mais altas, além da influência dos contatos térmicos entre as superfícies.

Devido à não uniformidade na superfície preta do detetor, há passagem de luz para a camada espelhada. Por isso, a fase não apresenta um comportamento monótono em baixa frequência.

As FIG-3.15 e FIG-3.16 mostram as curvas para amplitudes e fases dos sinais fotopiroelétrico devido à pastilha de silício com os detetores branco e preto. As frequências crítica e característica dessa amostra são $\cong 32 \mathrm{e} \cong 102 \mathrm{~Hz}$, respectivamente. Portanto, consideramos que a difusividade térmica média é aproximadamente $0,9 \mathrm{~cm}^{2} / \mathrm{s}[11,12]$. 
Podemos observar nessas figuras que as curvas diferem, indicando a influência da superfície do detetor. As curvas obtidas com o detetor branco se assemelham as curvas das FIG3.4 e FIG-3.5, demonstrando a adequação do modelo.

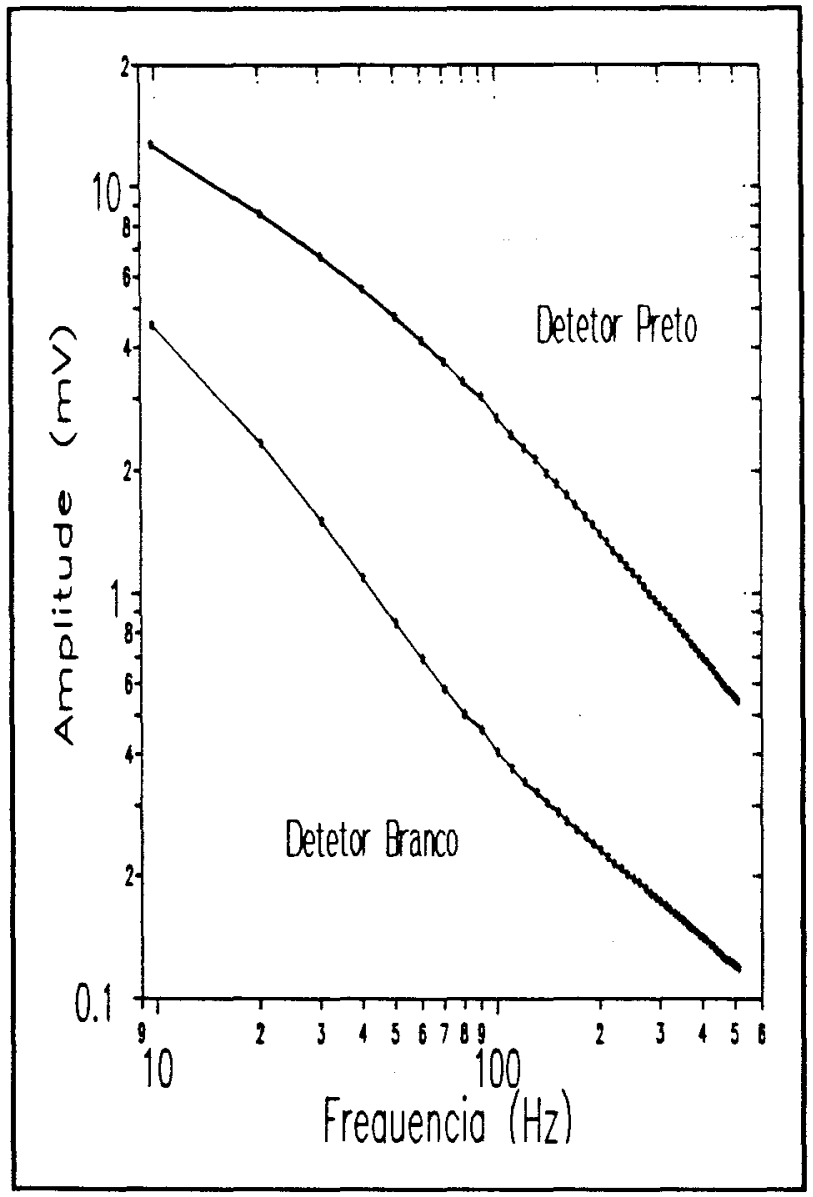

FIG-3.15 - Curva da variação do sinal fotopiroelétrico da pastitha de silicio com a frequência de modulação.

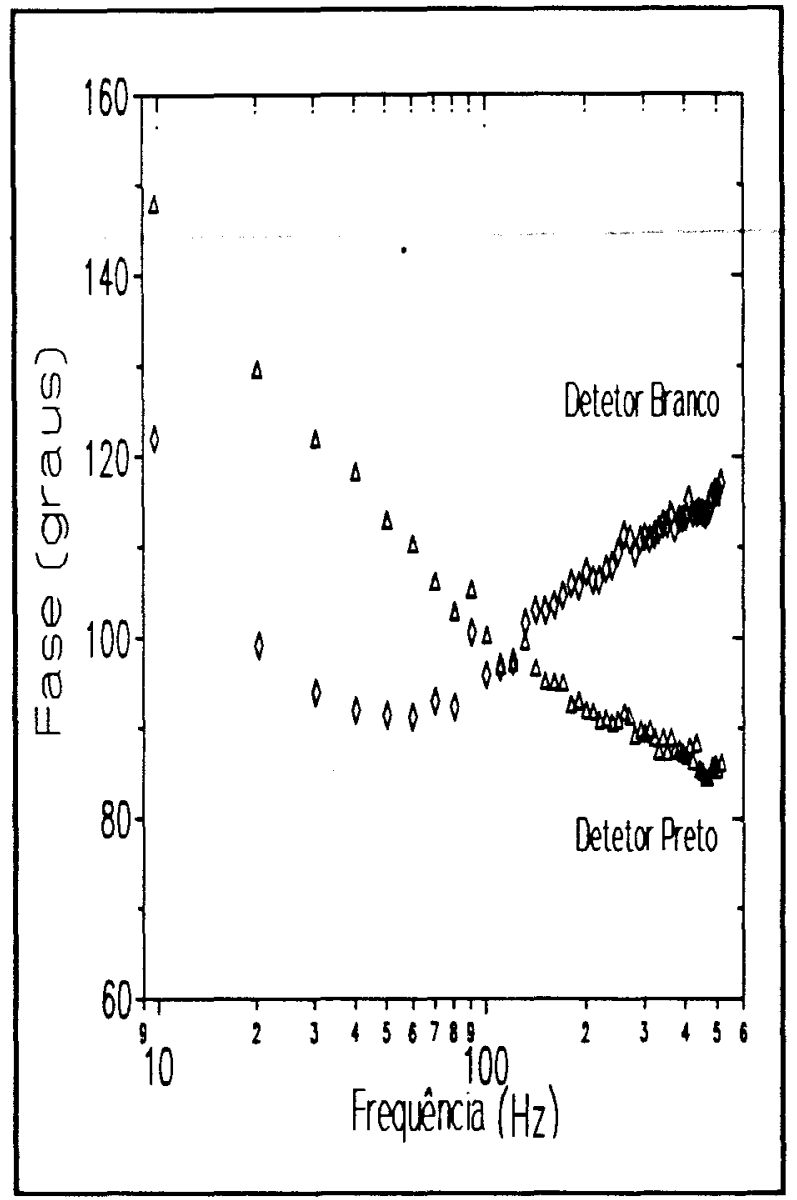

FIG-3.16 - Curva da fase dos sinais da FIG-3.15.

Neste caso, a amostra absorve ao longo de sua espessura. Portanto, a luz refletida será absorvida também na superfície traseira. Por isso, as curvas se comportam de acordo com o modelo. Podemos observar na curva da amplitude as três regiōes prevista pelo modelo e notar que a região de transição fica entre a frequência crítica e a característica. Dessa forma, dois 
pontos da curva podem dar informaçōes para obtermos a difusividade térmica. Essa característica não é observada na curva do detetor preto.

A fase apresenta um vale com ponto de mínimo em tomo de $45 \mathrm{~Hz}$, indicando a região de transição. Este deslocamento pode ser devido ao acoplamento térmico, a resistência térmica de contato [13], ao coeficiente de absorção ótica como pode ser comparado com a FIG-3.5 e FIG-3.6 e/ou, ainda, a instrumentação [4].

O silício é opaco na região visível mas é semi-transparente no infravermelho próximo $(\lambda \cong 1,2 \mu \mathrm{m})$ [4]. Essa radiação ao atravessar a amostra deve ser refletida pela camada de alumínio do detetor.

As curvas, amplitude e fase, obtidas com detetor preto, se comportaram segundo o modelo de Mandelis. A amplitude apresenta uma variação monótona com a frequência, enquanto que a fase apresenta um ponto de transição na região da frequência característica.

Portanto, o uso do modelo do detetor branco mostra-se mais sensível na caracterização térmica de amostras opacas e semi-transparentes, já que obtemos três regiões e dois pontos de informações sobre o comportamento da onda térmica na amostra.

60 


\section{6 - REFERENCIA}

1 - Mandelis, A.;Zver, M. M. - J. Appl. Phys. - 57, 4421(1985).

2 - Coufal, H. J.; Grygier, R. K.; Horne, D. E.; Fromm, J. E. - J. Vac. Sci. Technol.A - 5, 2875(1987).

3 - Christofides, C.; Mandelis, A.; Ghandi, K.; Wagner, R. E. - Rev. Sci. Instrum. - 61, 2360(1989).

4 -Christofides, C.; Ghandi, K.; Mandelis, A. - Meas. Sci. Technol. - 1, 1363(1990).

5 - Coufal, H.; Mandelis, A. - Ferroelectrics - 118, 379(1991).

6 - Blevin, W. R.; Geist, J. - Appl. Optics - 13, 1171(1974).

7 - Rosencwaig, R.; Gersho, A. - J. Appl. Phys. - 47, 64(1976).

8 - Coufal, H. - Appl. Phys. Lett. - 45, 516(1984).

9 - Mandelis, A. - J. Appl. Phys. - 54, 3404(1983).

10 - Rai, V. N. - Applied Optics, 27, 2776(1988).

11 - Rosencwaig, A. - Photoacoustics and Photoacoustics Spectroscopy, Chem. Analysis v57, John Wiley \& Sons, Inc. USA(1980).

12 - Vargas, H. e Miranda, L. C. M. - Phys. Report, 161, 43(1988).

13 - Lima, C. A. S.; Miranda, L.C. M.; Santos, R. - J. Appl. Phys. 52, 137(1981). 


\section{CAPITULO IV}

\section{MÉTODO FOTOACÚSTICO PARA DETERMINAÇÃo DE GRANDEZAS TÉRMICAS}

\section{1 - INTRODUÇÃO}

A técnica fotoacústica (PA) tem se mostrado capaz de fornecer informações óticas e térmicas de substâncias, além de ser não destrutiva. Diversos sistemas e modelos teóricos têm sido desenvolvidos para aumentar esta capacidade [1-5]. Novo tipo de câmara fotoacústica tem sido desenvolvido [6], juntamente com seu modelo teórico, e seu uso vem crescendo muito nos últimos anos [7-10].

Um outro método PA de incidência frontal e traseira[11-12] tem sido bastante usado na caracterização de amostras de sólidos opacos. Esse método consiste na comparação entre os sinais gerados nas superfícies frontal e traseira, pelos feixes incidentes, nas respectivas superfícies. $O$ calor gerado na superfície traseira se difunde através da amostra e a comparação dos sinais leva em conta a difusividade térmica do material. Também as fases desses sinais dão as mesmas informações.

Outras técnicas tais como: fotopiroelétrica e deflexão fototérmica, também nos dão as mesmas informações[13-16]. Algumas com mais dificuldades experimentais do que outras.

Como o princípio básico das técnicas fototérmicas está no calor gerado e propagado através da amostra, propomos um método PA que use câmaras fotoacústicas convencionais fechadas para caracterização de amostras transparentes. 


\section{2 - MÉTODO FOTOACÚSTICO PARA AMOSTRAS TRANSPARENTES.}

Nesse método supomos que a amostra e o gás no interior da câmara não absorvam a luz incidente. A absorção é feita pelo material de suporte de amostra. Uma parte do calor gerado pelo material de suporte se difunde pela amostra até atingir o gás que se encontra na sua superfície frontal. $\mathrm{O}$ gás periodicamente aquecido pulsará sensibilizando o microfone. Portanto, para se obter sinal PA é necessário que haja transmissão de calor através da amostra.

A FIG-4.1 mostra o esquema do sistema PA para este método.

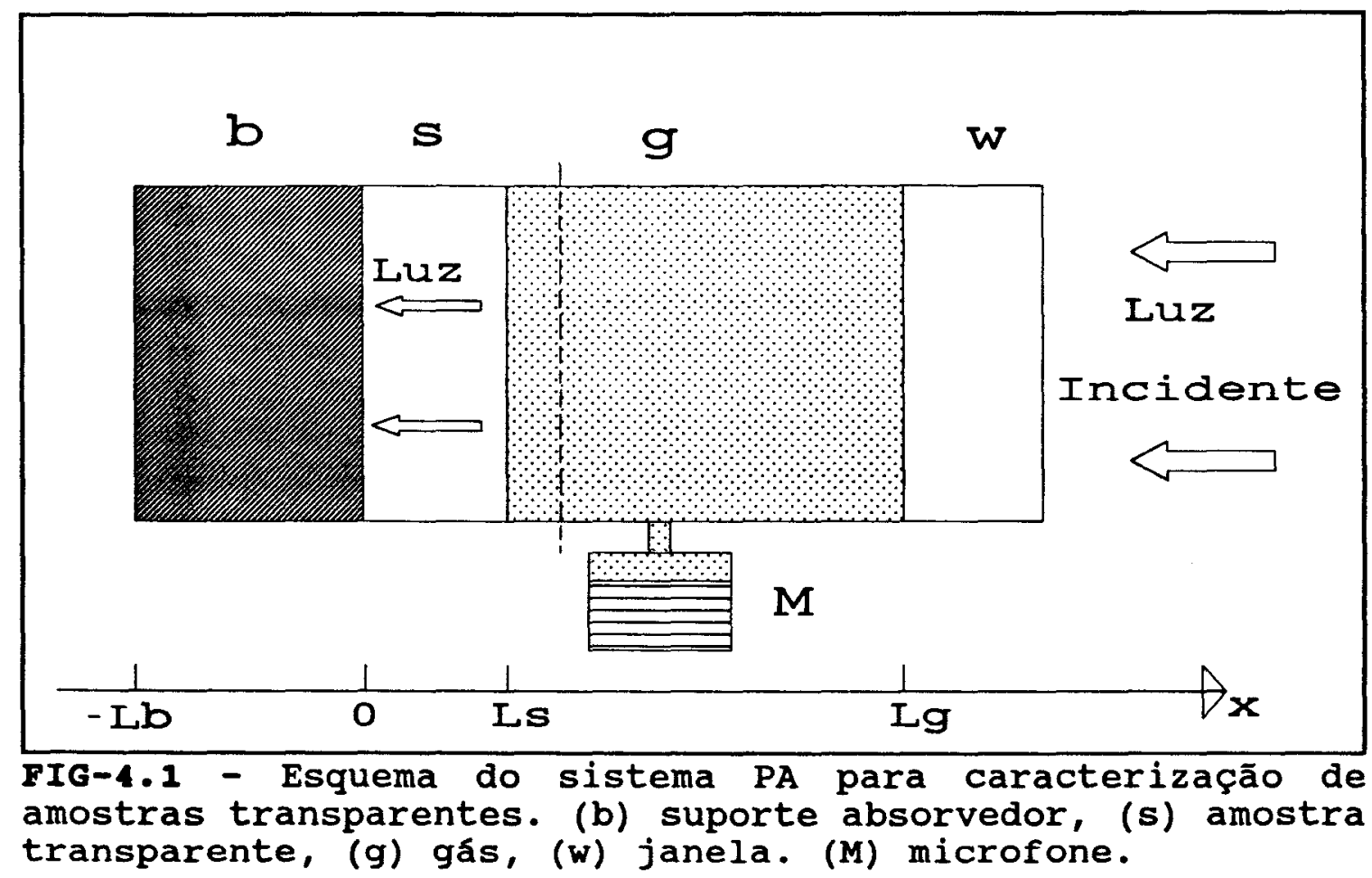

Consideremos que a luz incidente seja modulada e que o fenômeno de transmissão de calor seja dominado pela difusão térmica, cujas equações são: 
para $L_{1} \leq x \leq\left(L_{1}+L_{8}\right)$

$$
\frac{\partial^{2} T_{g}}{\partial x^{2}}-\sigma_{g}^{2} T_{g}=0
$$

para $0 \leq \mathrm{x} \leq \mathrm{L}_{\mathbf{3}}$

$$
\frac{\partial^{2} T_{s}}{\partial x^{2}}-\sigma_{s}^{2} T_{s}=0
$$

para $x \leq 0$

$$
\frac{\partial^{2} T_{b}}{\partial x^{2}}-\sigma_{b}^{2} T_{b}=-\left[\frac{\eta_{b} \beta_{b} I_{0}}{2 k_{b}}\right] e^{\beta_{b} x}
$$

Consideramos que os termos oscilantes nas soluçōes das equações acima são responsáveis pela geração do sinal fotoacústico (PA), então, as soluções de interesse são:

$$
\begin{gathered}
T_{g}=C_{0} e^{-\sigma_{g} x} \\
T_{s}=C_{1} e^{-\sigma_{s} x}+C_{2} e^{\sigma_{g} x} \\
T_{b}=-\left[\frac{\eta_{b} \beta_{b} I_{0}}{2 k_{b}\left(\beta_{b}^{2}-\sigma_{b}^{2}\right)}\right] e^{\beta_{b} x}+C_{3} e^{\sigma_{b} x}+C_{4} e^{-\sigma_{b} x}
\end{gathered}
$$


Considerando $\mathrm{C}_{4}=0$ já que $\mu_{\mathrm{b}}<<\mathrm{L}_{\mathrm{b}}$, isto $\hat{e}$, o comprimento do suporte é muito maior do que o seu comprimento de difusão térmica,temos

$$
T_{b}=\left[\frac{\eta_{b} \beta_{b} I_{0}}{2 k_{b}\left(\beta_{b}^{2}-\sigma_{b}^{2}\right)}\right] e^{\beta_{b} x}+C_{3} e^{\sigma_{b} x}
$$

Aplicamos as condições de contorno e de continuidade nas equações (4.4), (4.5) e (4.7) e definimos

$$
\begin{array}{cc}
E=-\frac{\eta_{b} \beta_{b} I_{0}}{2 k_{b}\left(\beta_{b}^{2}-\sigma_{b}^{2}\right)} & F=I_{b} b_{b s} E \\
X=e^{\sigma_{s} L_{s}} & Y=e^{\sigma_{g} L_{s}}
\end{array}
$$

obtendo o sistema de equações

$$
\left[\begin{array}{cccc}
Y^{-1} & -X^{-1} & -X & 0 \\
-b_{g s} Y^{-1} & X^{-1} & -X & 0 \\
0 & 1 & 1 & -1 \\
0 & -1 & 1 & -b_{b s}
\end{array}\right]\left[\begin{array}{l}
C_{0} \\
C_{1} \\
C_{2} \\
C_{3}
\end{array}\right]=\left[\begin{array}{l}
0 \\
0 \\
E \\
F
\end{array}\right]
$$

Estamos interessados na determinação da temperatura do gás, $\mathrm{T}_{\mathrm{g}}(\mathrm{t})$, e para isto é necessário encontrar a expressão para $\mathbf{C}_{\mathbf{0}}$. Usando o Teorema de Cramer para resolver sistema de equações, obtemos que 


$$
C_{0}=\left[\frac{\eta_{b} r_{b} I_{0}}{k_{b} \sigma_{b}\left(r_{b}+1\right)}\right]\left[\frac{b_{b s} e^{\sigma L_{s}}}{\left(b_{g s}+1\right)\left(b_{b s}+1\right) e^{\sigma L_{s}}-\left(b_{g s}-1\right)\left(b_{b s}-1\right) e^{-\sigma L_{s}}}\right]
$$

Se a onda térmica fica praticamente atenuada a uma distância de $2 \pi \mu_{\mathfrak{z}}$, então a temperatura média no gás dentro desse espaçamento é dada por

$$
\theta=\frac{1}{2 \pi \mu_{g}} \int_{L_{s}}^{2 \pi \mu_{g}+L_{s}} T_{g} d x
$$

Portanto, a temperatura do gás $T_{3}(t)$ é

$$
T_{g}(t)=\frac{1}{2 \sqrt{2} \pi}\left[\frac{\eta_{b} r_{b} I_{0}}{k_{b} \sigma_{b}\left(r_{b}+1\right)}\right]\left[\frac{b_{b s} e^{i\left(\omega t-\frac{\pi}{4}\right)}}{\left(b_{g s}+1\right)\left(b_{b s}+1\right) e^{\sigma_{L} L_{s}}-\left(b_{g s}-1\right)\left(b_{b s}-1\right) e^{-\sigma_{L} L_{s}}}\right]
$$

ou ainda

$$
T_{8}(t)=\frac{\Theta_{0}}{2 \sqrt{2} \pi} e^{i\left(\omega t-\frac{\pi}{4}\right)}
$$


O deslocamento do gás dentro de $2 \pi \mu_{\varepsilon}$ é dado por

$$
\Delta x(t)=2 \pi \mu_{8} \frac{T_{g}(t)}{T_{0}}
$$

onde $\mathrm{T}_{0}$ é a temperatura ambiente.

Consideramos que o gás se comporta adiabaticamente [17], então

$$
\Delta P(t)=\frac{\gamma P_{0}}{L_{g}} \Delta x(t)
$$

onde $\mathrm{P}_{0}$ é a pressão ambiente e $\gamma$ é a razão dos calores específicos.

A variação de pressão que gera o sinal PA é dada pela expressão

$$
\Delta P(t)=A \mu_{g}\left[\frac{\eta_{b} r_{b}}{k_{b} \sigma_{b}\left(r_{b}+1\right)}\right]\left[\frac{b_{b s} e^{i\left(\omega t-\frac{\pi}{4}\right)}}{\left(b_{g s}+1\right)\left(b_{b s}+1\right) e^{\sigma L_{s}}-\left(b_{g s}-1\right)\left(b_{b s}-1\right) e^{-\sigma_{s} L_{s}}}\right]
$$

onde

$$
A=\frac{\gamma \eta_{b} P_{0} I_{0}}{\sqrt{2} L_{g} T_{0}}
$$

A equação (4.16) só fornece informações térmicas sobre a amostra, e também estão envolvidos parâmetros do gás e do suporte. Essa expressão é mais simples do que as obtidas até o momento, isto é, a de RG [17] e outras [1-3], e pode ser aplicada completamente. Vamos 
apresentar alguns casos limites muito úteis.

\section{3 - CASOS LIMITES}

4.3.1 - Quando $\mathrm{r}_{\mathrm{b}}>>1, \mathrm{~b}_{\mathrm{gs}}<<1$ e $\mathrm{b}_{\mathrm{bs}}>1$ a amplitude do sinal PA é

$$
Q=A \mu_{g}\left(\frac{1}{k_{b} \sigma_{b}}\right)\left[\frac{b_{b s}}{\left(b_{b s}+1\right) e^{\sigma_{s} L_{s}}+\left(b_{b s}-1\right) e^{-\sigma_{g} L_{s}}}\right]
$$

4.3.1A - Quando $\left(b_{b s}+1\right) \exp \left(\sigma_{s} L_{s}\right)>\left(b_{b s}-1\right) \exp \left(-\sigma_{g} L_{g}\right)$ ou $\exp \left(-\sigma_{s} L_{2}\right) \cong 0$ (termicamente espessa) então

$$
Q \approx A \mu_{8}\left(\frac{1}{k_{b} \sigma_{b}}\right)\left(\frac{b_{b s}}{b_{b s}+1}\right) e^{-\sigma L_{s}}
$$

enquanto a fase é dada por

$$
\phi=-\sqrt{\frac{L_{s}^{2}}{2 \alpha_{s}}} \sqrt{\omega}-\frac{\pi}{2}
$$

A dependência da amplitude com a frequência é $\omega^{-1}$ já que $\sigma_{\mathrm{i}} \propto \omega^{3 / 2}$ (i=diversos materiais na câmara fotoacústica), enquanto a fase tem o comportamento linear com a raíz quadrada da frequência. 
4.3.1B - Na condição $\exp \left( \pm \sigma_{\mathrm{z}} \mathrm{L}_{\mathrm{a}}\right) \cong 1$, isto é, termicamente fina

$$
Q \approx \frac{A \mu_{g}}{2}\left(\frac{1}{k_{b} \sigma_{b}}\right)
$$

e a fase é $\Phi=-\pi / 2$. A equação (4.21) independe dos parâmetros térmicos da amostra e sua dependência com a frequência é $\omega^{-1}$.

4.3.1C - Para $\exp \left( \pm \sigma_{2} \mathrm{~L}_{\mathrm{s}}\right) \cong\left(1 \pm \sigma_{\mathrm{s}} \mathrm{L}_{\mathfrak{k}}\right)$ (termicamente fina) temos,

$$
Q \approx\left(\frac{A \mu_{g}}{2 k_{b} \sigma_{b}}\right)\left(\frac{b_{b s}}{b_{b s}+\sigma_{s} L_{s}}\right)
$$

A dependência com a frequência pode variar de $\omega^{-1} a \omega^{-3 / 2}$ dependendo da relação entre $b_{b e}$ e $\sigma_{a} L_{a}$. Nesse caso a expressão da fase é mais complexa, pois envolve $b_{b s}$

$$
\Phi=-\left(\frac{a_{s} L_{s}}{b_{b s}+a_{s} L_{s}}\right)-\frac{\pi}{4}
$$

4.3.2 - Quando $\mathrm{r}_{\mathrm{b}}>>1, \mathrm{~b}_{\mathrm{ga}}<<1$ e $\mathrm{b}_{\mathrm{bs}}<<1$ temos

$$
Q \approx\left(\frac{A \mu_{g}}{k_{g} \sigma_{g}}\right)\left(\frac{2 b_{b s}}{\operatorname{senh}\left(\sigma_{s} L_{s}\right)}\right)
$$


4.3.2A - Para $\sigma_{\mathbb{a}} \mathrm{L}_{\mathrm{a}}>>1$ (termicamente espessa), temos

$$
Q \approx\left(\frac{A \mu_{g}}{k_{b} \sigma_{b}}\right) b_{b s} e^{-\sigma L_{s}}
$$

A dependência com a frequência é $\omega^{-1}$ e a expressão da fase é igual ao da equação (20) para o caso $1 \mathrm{~A}$.

4.3.2B - Na condição $\sigma_{\mathrm{a}} \mathrm{L}_{\mathrm{a}}<1$ (termicamente fina), temos

$$
Q \approx\left(\frac{A \mu_{g}}{k_{b} \sigma_{b}}\right)\left(\frac{2 b_{b s}}{\sigma_{s} L_{s}}\right)
$$

A dependência com a frequência é $\omega^{-3 / 2}$, sendo a fase $\Phi=-\pi / 2$.

\section{4 - CONSIDERAÇÕES SOBRE O MÉTODO}

Os casos anteriores demonstram o quanto é simples este método de caracterização térmica de amostra. Nos primeiros casos (4.3.1A, 4.3.1B e 4.3.1C) assumimos que a amostra é boa condutora de calor quando comparado ao gás, e é má condutora quando comparada ao material do suporte de amostra.

O caso 4.3.1A é muito importante já que o sinal PA depende exponencialmente dos parâmetros da amostra.

$\mathrm{O}$ caso 4.3.1B não fornece informações sobre a amostra, mas pode servir para normalização dos demais casos, já que os parâmetros do gás e do suporte aparecem em todas as 
expressões.

O caso 4.3.1C, por sua vez, fornece informações térmicas da amostra dependendo da relação entre $b_{b}$ e $\sigma_{s} L_{s}$.

Nos casos (4.3.2A e 4.3.2B) consideramos que a amostra é boa condutora de calor quando comparada ao gás e ao suporte. Tanto a situação A quanto a B fornecem informações sobre a amostra. As distinçōes nos dois itens se encontram basicamente no decaimento exponencial e na dependência com a frequência.

Com a normalização do sinal, é possível obter outras grandezas térmicas além da difusividade térmica. A condutividade térmica pode ser obtida através do parâmetro $\mathrm{b}_{\mathrm{b} z}$. Por exemplo, usando o caso 4.3.1A normalizado teremos

$$
V_{N}=2\left(\frac{b_{b s}}{b_{b s}+1}\right) e^{-\sigma_{s} L_{s}}
$$

Portanto, fazendo o ajuste da equação (4.27) aos pontos experimentais normalizados obteremos o valor para $b_{b s}$, do qual extraímos a condutividade térmica através da equação

$$
k_{s}=\frac{k_{b}}{b_{b s}} \sqrt{\frac{\alpha_{s}}{\alpha_{b}}}
$$

Esse método é bastante amplo, uma vez que se escolha um determinado comprimento de onda no qual a amostra seja transparente e o suporte de amostra absorvedor. O sinal fotoacústico é equivalente àquele obtido no método de incidência frontal e traseira [11] já 
mencionado anteriormente.

\section{5 - APLICAÇÃo}

Para demonstrar este método usamos várias amostras de polímeros oticamente transparentes na região visível: (PVDF-(poli)vinilideno de flúor, PMMA-(poli)metil metacrilato, e PVC-(poli) cloreto de vinila. As figuras seguintes mostram as curvas dos sinais PA, amplitudes e fases, normalizados para os polímeros acima mencionados.

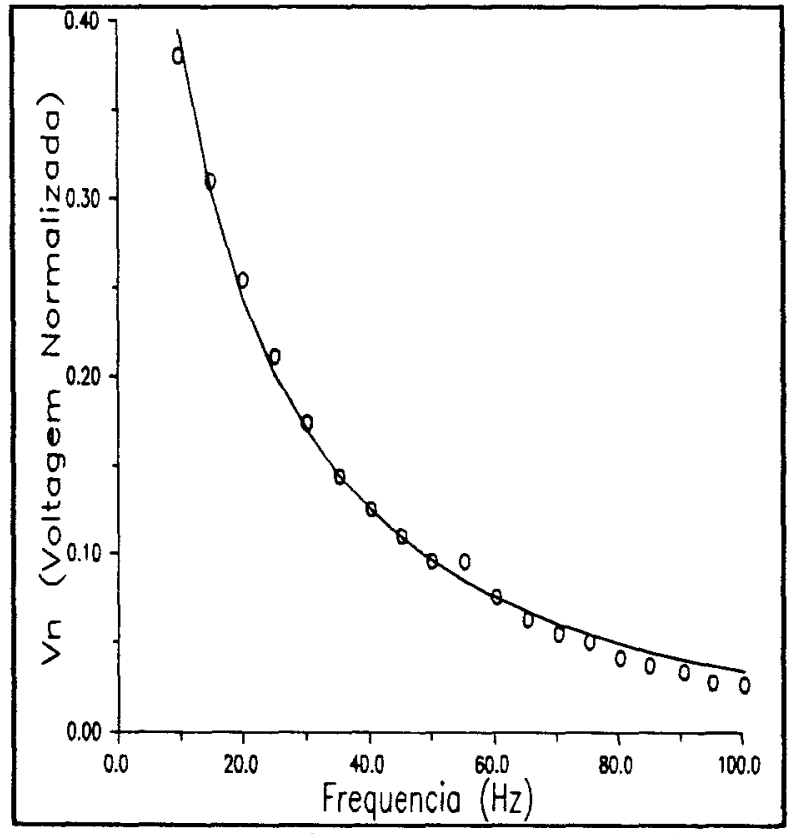

FIG-4.2 - Sinal PA normalizado do filme de PVDF $x$ frequência. Linha cheia - melhor ajuste, (O) pontos experimentais.

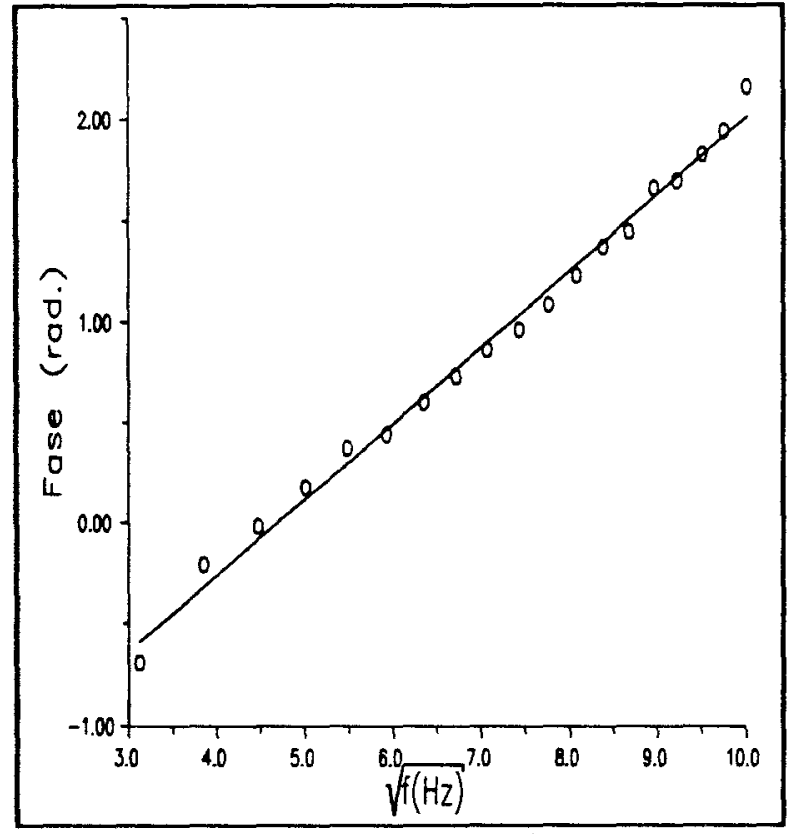

FIG-4.3 - Fase do sinal PA do filme de PVDF $x$ raíz da freq.. Linha cheia-melhor ajuste. (O)-pontos experimentais. 


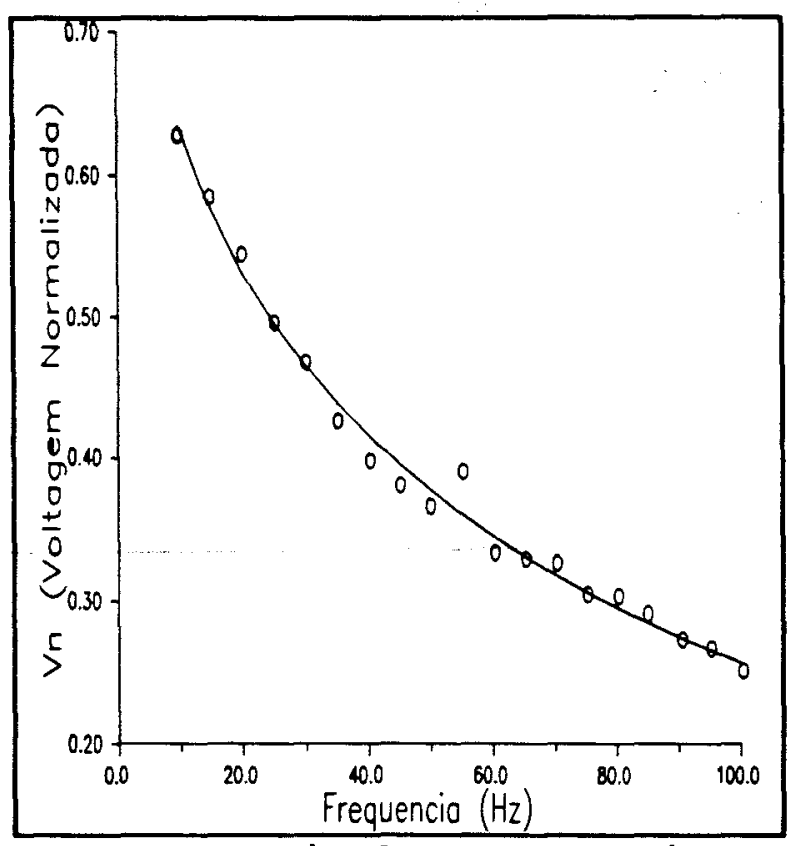

FIG-4.4 - Sinal PA normalizado do filme de PMMA $x$ freq.. Linha cheia-melhor ajuste. (0)pontos experimentais.

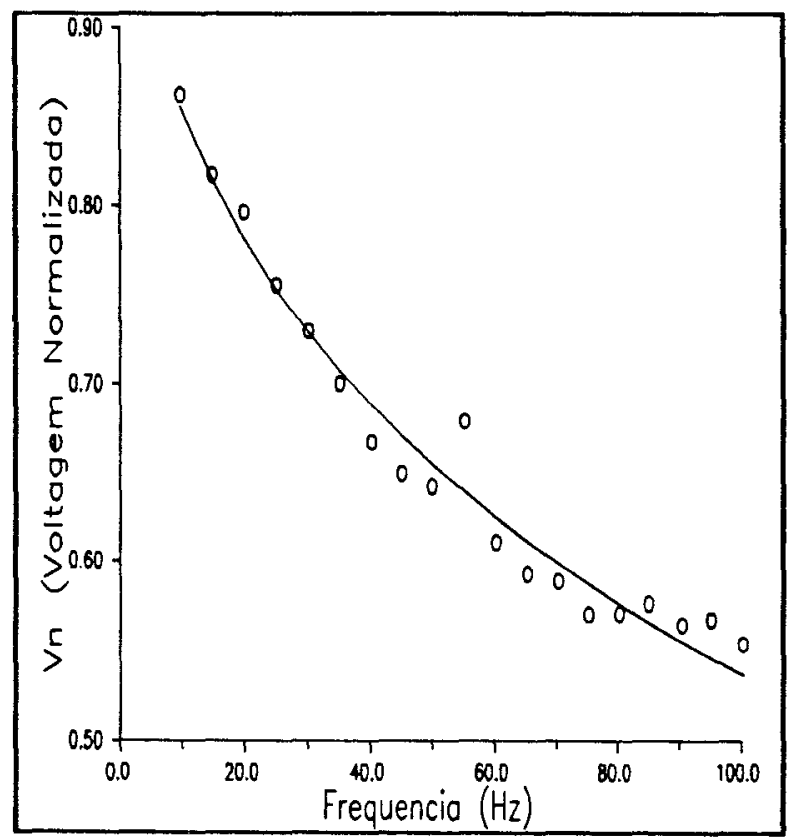

FIG-4.6 - Sinal PA normalizado do filme de PVC x freq.. Curva cheia - melhor ajuste.

(O) -pontos experimentais.

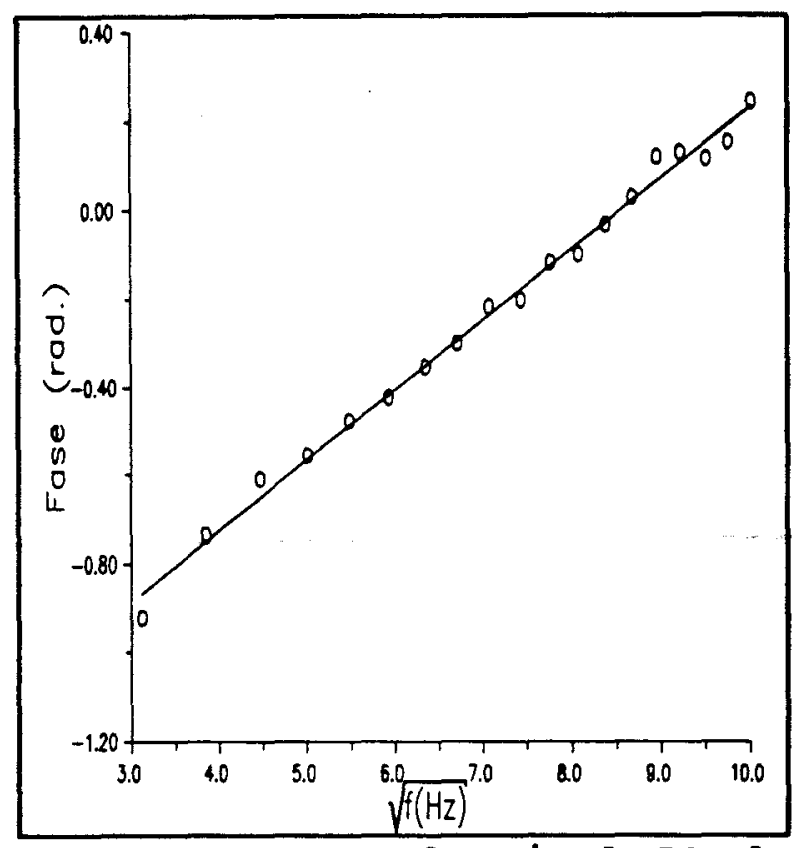

FIG-4.5 - Fase do sinal PA do filme de PMMA $x$ raiz da freq. Linha cheia-melhor ajuste. (0)pontos experimentais.

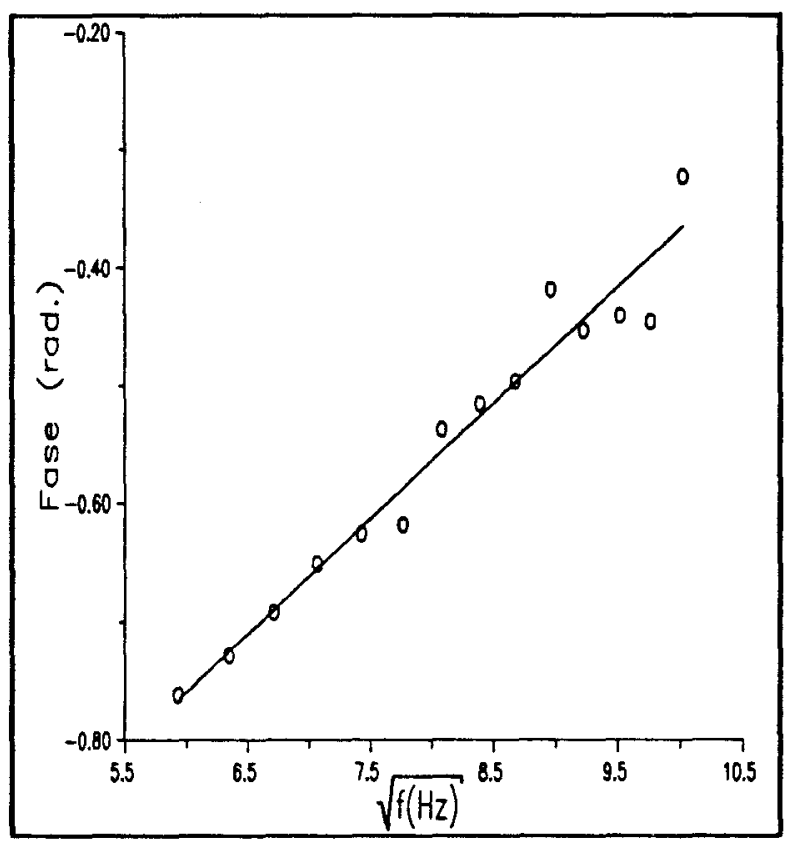

FIG-4.7 - Fase do sinal PA do filme de PVC $x$ raiz da freq.. Linha cheia - melhor ajuste. (O) pontos experimentais. 
A metodologia usada na obtenção do sinal PA dos polímeros foi a seguinte:

1 - as amostras foram cortadas na forma de discos com diâmetro de $8 \mathrm{~mm}$ e uma das faces foi pintada com tinta preta. A face pintada foi colada no suporte (lucite) de amostra com auxílio de graxa de vácuo.

2 - A fonte de luz usada foi um laser de He-Ne. Poderia ter sido usada luz branca de uma lâmpada incandescente.

3 - Usamos um lock-in de duplo canal SR530 e um chopper de frequência variável PAR-194A. Para cada frequência foi anotado a amplitude, fase, canal-x e canal-y.

4 - As medidas foram repetidas para cada amostra. Este procedimento foi usado para testar a reprodutibilidade do sinal e melhor relação sinal/ruído.

5 - Para obter a curva de referência, colocamos um filme fino preto sobre o suporte da amostra, introduzimos na câmara e procedemos da mesma forma como nos itens acima.

6 - Com auxílio do computador realizamos a normalização, os ajustes do modelo aos pontos experimentais e os gráficos mostrados nas figuras anteriores.

Desta forma obtemos os valores de difusividade e condutividade térmicas, os quais estão resumidos na tabela-I juntamente com os valores da literatura. Os valores das difusividades térmicas foram calculados a partir dos parâmetros obtidos nos ajustes das curvas das amplitudes normalizadas e das fases dos sinais. Na tabela as indicações (a) e (f) referem-se aos valores de difusividades térmicas obtidas através das amplitudes e fases, respectivamente. Os valores das condutividades térmicas foram obtidos através da equação (4.28) a partir do conhecimento do parâmetro $b_{b s}$, cujos valores ajustados foram: $b_{b e}(P V D F)=1,52 ; b_{b e}(P M M A)=0,915 e$ 
$b_{b s}(P V C)=1,12$.

Tabela-I

\begin{tabular}{|c|c|c|c|c|}
\hline & $\begin{array}{c}\alpha_{\text {cal }} \\
\left(10^{-8} \mathrm{~m}^{2} / \mathrm{s}\right)\end{array}$ & $\begin{array}{c}\alpha_{\text {lit }} \\
\left(10^{-8} \mathrm{~m}^{2 / \mathrm{a})}\right.\end{array}$ & $\begin{array}{c}\mathbf{k}_{\text {cal }} \\
(\mathrm{W} / \mathrm{mK})\end{array}$ & $\begin{array}{c}\mathbf{k}_{\text {tit }} \\
(\mathrm{W} / \mathrm{mK})\end{array}$ \\
\hline $\begin{array}{c}\mathrm{PVDF} \\
\mathrm{L}_{\mathrm{a}} \cong 50 \mu \mathrm{m}\end{array}$ & $\begin{array}{l}6,14(\mathrm{a}) \\
5,5(\mathrm{f})\end{array}$ & $5,4[18]$ & 0,093 & $0,13[18]$ \\
\hline $\begin{array}{c}\mathrm{PMMA} \\
\mathrm{L}_{\mathrm{a}} \cong 30 \mu \mathrm{m}\end{array}$ & $\begin{array}{l}16,4(\mathrm{a}) \\
11,13(\mathrm{f})\end{array}$ & $11,4[19]$ & 0,25 & $0,193[19]$ \\
\hline $\begin{array}{c}\mathrm{PVC} \\
\mathrm{L}_{\mathrm{s}} \cong 9 \mu \mathrm{m}\end{array}$ & $\begin{array}{l}5,55(\mathrm{a}) \\
2,64(\mathrm{f})\end{array}$ & $5,93[20]$ & 0,12 & $0,15[20]$ \\
\hline
\end{tabular}

Comparativamente, observamos que os valores calculados estão em concordância com os valores da literatura [18-20]. As discrepâncias existentes podem ser devido a diversos fatores, tais como:

a) - imprecisões nas espessuras das amostras;

b) - processo de produção dos polímeros, já que foram usadas amostras comerciais;

c) - possíveis efeitos PA adicionais não previstos no método, tais como expansão térmica e flexão termoelástica, podem ocorrer;

d) - instrumentação, já que foi necessário o uso de uma película da graxa de vácuo para fixar as amostras sobre o seu suporte. Esse suporte é uma peça feita de lucite ou acrílico, nome comercial para o PMMA. Por isso, $b_{b s}$ para o filme de PMMA foi muito próximo de 1 . 


\section{6 - REFERENCIAS}

1 - Cesar, C. L.; Vargas, H.; Mendes Filho, J.; Miranda, L. C. M. - Appl. Phys. Lett. 43, 555(1983).

2 - Swimm, R. T. - Appl. Phys. Lett. 42, 955(1983).

3 - Lachaine, A.; Poulet, P. - Appl. Phys. Lett. 45, 953(1984).

4 - Madhusoodanan, K. N.; Thomas, M. R.; Philip, J. - J. Appl. Phys. 62, 1162(1987).

5 - Zammit, U.; Marinelli, M.; Pizzoferrato, Scudieri, F. e Martellucci, S. - J. Phys. E: Sci Instrum. 21, 935(1988).

6 - Marquezini, M. V.; Cella, N., Mansanares, A. M.; Vargas, H. e Miranda, L. C. M. Meas. Sci. Technol. - 2, 396(1991).

7 - Ferreira, S. O.; Ying An, C.; Bandeira, I. N.; Miranda, L. C. M. e Vargas, H. - Phys. Rev. B 39, 7967(1989).

8 - Perondi, L. F.; Miranda, L. C. M. - J. Appl. Phys. 62, 2955(1987).

9 - Marquezini, M. V.; Dissertação de Mestrado no Instituto de Física Gleb Wataghin UNICAMP - Campinas-SP (1990).

10 - Cella, N. - Tese de Doutorado no Instituto de Física Gleb Wataghin - UNICAMP Campinas-SP (1990).

11 - Pessoa Jr., O.; Patel, N. A.; Vargas, H.; Ghizoni, C. C. e Miranda, L. C. M. - J. Appl. Phys. 59, 1316(1986).

12 - Vargas, H. e Miranda, L. C. M. - Phys. Report - 161, 43(1988).

13 - Marinelli, M.; Murtas, F.; Mecozzi, M. G.; Zammit, U.; Pizzoferrato, R.; Scudieri, F.; Martellucci, S e Marinelli, Marco - Appl. Phys. A 51, 387(1990). 
14 - John, P. K.; Miranda, L. C. M. e Rastogi, A. C. - Phys. Rev. B 34, 4342(1986).

15 - Yacoubi, N. e Alibert, C. - J. Appl. Phys. 69, 8310(1991).

16 - Figari, A. - Meas. Sci. Technol. 2, 656(1991).

17 - Rosencwaig, A. - Photoacoustics and Photoacoustic Spectroscopy - John Wiley \& Sons USA(1980).

18 - Mandelis, A. e Zver, M. - J. Appl. Phys. 57, 4421(1985).

19 - Polymer Handbook - Brandrup, J.; Immergut, E. H. - $2^{2}$ Ed., John Wiley \& Sons _ USA (1975).

20 - Cesar, C. L.; Vargas, H. e Miranda, L. C. M. - J. Phys. D: Appl. Phys. 18, 599(1985). 


\section{CAPITULO v}

\section{MÉTODO SEMI-EMPIRICO PARA A DETERMINAÇÃO DA DIFUSIVIDADE}

TERMTCA

\section{1 - INTRODUÇÃO}

Os fenômenos fototérmicos que ocorrem simultaneamente quando uma amostra é excitada por luz modulada, podem ser detetados de diversas maneiras. Seja por meio fotoacústico, por deflexão fototérmica (efeito miragem) ou por efeito fotopiroelétrico. Esses fenômenos têm a mesma origem física (o aquecimento da amostra pela luz absorvida).

Diversos autores [1-8] têm demonstrado que os modelos para os fenômenos fototérmicos em amostras termicamente espessas e oticamente opacas, apresentam comportamentos diferentes dentro de certos intervalos de frequência de modulação.

Podemos obter importantes informaçōes desses modelos, principalmente daqueles que levam em consideração a deteção traseira $[1,2,5,7,8]$. Quando o fenômeno é de flexão termoelástica, a amplitude do sinal fototérmico depende do inverso da frequềncia de modulação, enquanto a fase do sinal obedece uma relação transcendental [3,5].

No fenômeno de dilatação térmica, a amplitude do sinal fototérmico decresce com $\mathrm{f}^{1}$, enquanto que a fase permanece constante em $-90^{\circ}$ [5].

Entretanto, para o fenômeno dominado pela difusão térmica [7,8], a amplitude do sinal fototérmico, para condição de amostra oticamente opaca e termicamente espessa, decai 
exponencialmente com os parâmetros térmico e geométrico do meio no qual se difunde. A fase obedece a uma relação linear com a raíz quadrada da frequência de modulação, $\mathrm{f}^{\text {th }}$.

Apresentaremos um método muito simples que facilita todo o trabalho de ajuste do modelo teórico às curvas experimentais.

\section{2 - MÉTODO}

Modelos teóricos envolvendo somente o termo de difusão térmica têm sido constantemente desenvolvidos em trabalhos que visam ajustes teórico-experimental. Já o efeito termoelástico é menos considerado, visto que, dependendo das montagens experimentais e do tipo de amostra, nem sempre sua contribuição para o sinal é relevante. Por isso, tomamos como base o efeito da difusão térmica numa amostra oticamente opaca em estudo.

Supondo que um feixe de luz modulada incide sobre a superfície frontal da amostra, a absorção dessa luz gera o calor que se propaga ao longo de sua espessura. A amplitude da onda de temperatura é dada por $[9,10]$,

$$
T(x)=\frac{P_{0}}{\sqrt{f}} e^{-a_{0} x}
$$

onde o coeficiente $\mathbf{P}_{0}$ envolve a intensidade da luz incidente e os parâmetros térmicos difusividade e condutividade, $a_{\mathrm{s}}$ é igual a $\left(\pi \mathrm{f} / \boldsymbol{\alpha}_{\mathbf{s}}\right)^{\text {th }}$, sendo $\mathrm{f}$ a frequência de modulação e $\mathrm{x}$ um ponto no interior da amostra.

Entretanto, pelas condições de contorno, a temperatura e o fluxo de calor na fronteira 
entre dois meios devem ser iguais. Logo, se o detetor se encontra por detrás da amostra, em contato direto, a temperatura decai exponecialmente no seu interior.

Portanto, a temperatura média do detetor é

$$
T_{d} \propto \frac{1}{\sqrt{f}} T_{s}\left(L_{s}\right)
$$

Consequentemente, o sinal fototérmico é expresso por,

$$
S(f)=\frac{A}{f} e^{-a_{s} \sqrt{f}}
$$

onde A é o coeficiente que envolve os parâmetros térmicos dos meios por onde a onda de calor passa. Esse coeficiente depende também, entre outros fatores da geometria da amostra, da temperatura e/ou da pressão ambiente.

O efeito de difusão térmica é o mais simples e muitas vezes ocorre com mais frequência. Por isso, usaremos a equação (5.3) como base para o nosso método.

Suponhamos que exista uma frequência singular, $f_{2}$, tal que

$$
Y=\frac{f_{s}}{f} e^{-a_{s}\left[\sqrt{f}-\sqrt{f_{s}}\right]}
$$

Aplicando o logarítmo natural em $\mathbf{Y}$, obtemos

$$
\log (Y(f))=\log \left(\frac{f_{s}}{f}\right)-a_{s}\left[\sqrt{f}-\sqrt{f_{s}}\right]
$$


e chamando $y=\log (Y(f))$ e reaplicando o logarítmo em $y$, obtemos que

$$
\log (y(f))=\log \left[\log \left(\frac{f_{s}}{f}\right)-a_{s}\left[\sqrt{f}-\sqrt{f_{s}}\right]\right]
$$

Quando $\mathrm{f}<\mathrm{f}_{\mathbf{a}} \mathrm{o}$ valor do $\log (\mathrm{y})$ é um número real, enquanto $\mathrm{f}>\mathrm{f}_{\mathbf{a}} \circ \log (\mathrm{y})$ é um número complexo z $[11,12]$, que pode ser definido por,

$$
\log (z)=\log (r)+i(\theta \pm 2 n \pi)
$$

onde $\mathrm{r}>0$ é o módulo de $\mathrm{z},-\pi<\theta \leq \pi$ é a fase de $\mathrm{z}$ e $\mathrm{n}=1,2, \ldots$ Denomina-se valor principal de $\log \mathrm{z}$ o número definido pela equação (5.7) quando $\mathbf{n}=0$. Assim, o logarítmo complexo possui infinitos valores e não é uma função contínua na origem, portanto, tem uma singularidade nesse ponto e sobre cada ponto do eixo real negativo.

Logo, se $\mathbf{y}(f)=-v$ temos que

$$
\log (-v)=\log (v)+\pi i
$$

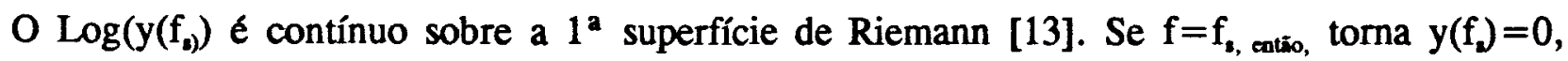
implicando que o $\log \left(y\left(f_{2}\right)\right)$ seja descontínuo.

A equação (5.6) ainda pode ser expressa por,

$$
\log (y(f))=\log \left[\sqrt{\frac{\pi}{f_{c}}}\left(\sqrt{f_{s}}-\sqrt{f}\right)+\log \left[\frac{f_{s}}{f}\right]\right]
$$

Assim, só necessitamos determinar $f_{c}$ já que $f_{\mathfrak{s}}$ é dado pelo $\log (\log$ dos pontos experimentais). 
Da determinação de $\mathrm{f}_{\mathrm{c}}$ encontramos a difusividade térmica, $\alpha$, dada por,

$$
\alpha=f_{c} L^{2}
$$

onde $\mathbf{L}$ é a espessura da amostra.

Também através da fase do sinal fototérmico, para amostra termicamente espessa, é possível aplicar o mesmo procedimento e obter a confirmação do valor de $\alpha$.

\section{3 - CONSIDERAÇÕES GERAIS}

O uso do $\log (\log )$ torna capaz a identificação do fenômeno de difusão térmica envolvido com os demais fenômenos fototérmicos. Quando a equação (5.9) não se ajusta aos pontos experimentais significa que outros fenômenos podem estar ocorrendo simultaneamente.

A eliminação do parâmetro $\mathbf{A}$, a ajustar, também elimina todas as dependências com $\mathbf{o}$ acoplamento térmico, com a geometria da amostra, com a temperatura e pressão do ambiente, entre outros nele contido.

A frequência $f_{s}$ é encontrada com auxilio dos dados experimentais, não sendo um parâmetro a ajustar. Observamos, experimentalmente, que esta frequência depende dos procedimentos experimentais e da amostra. Se uma medida for realizada logo após a amostra ter sido retirada e novamente recolocada na câmara fototérmica, o valor de $\mathrm{f}_{\mathrm{a}}$ poderá não se repetir. Isso nos indica que $f_{\mathfrak{z}}$ é sensível às mudanças experimentais que possam ocorrer ao longo de várias medições. Fatores responsáveis por essas variações podem ser, por exemplo, a diminuição do acoplamento entre amostra-detetor na técnica fotopiroelétrica ou a variação da pressão interna 
da câmara fotoacústica.

A grande vantagem desse método é a extensão em intervalo de frequência no qual pode ser aplicado, sendo independente da região térmica em que se esteja trabalhando. Para demonstrar essa vantagem, usamos o modelo de Mandelis para a espectroscopia fotopiroelétrica [7], que simula uma amostra onde só ocorre difusão térmica. Para isso, usamos parâmetros térmicos do PVDF conhecidos da literatura como parâmetros para a amostra hipotética.

Aplicamos esses parâmetros à expressão de Mandelis e obtemos a curva de resposta amplitude versus frequência. Calculamos o $\log (\log )$ dos pontos dessa curva obtendo $f_{\text {a. }}$ Em seguida, ajustamos a equação (5.9) a esses pontos. As FIG-5.1 e FIG-5.2 mostram esses ajustes para duas espessuras da amostra, $\mathrm{L}=1 \mu \mathrm{m}$ e $\mathrm{L}=70 \mu \mathrm{m}$, respectivamente.

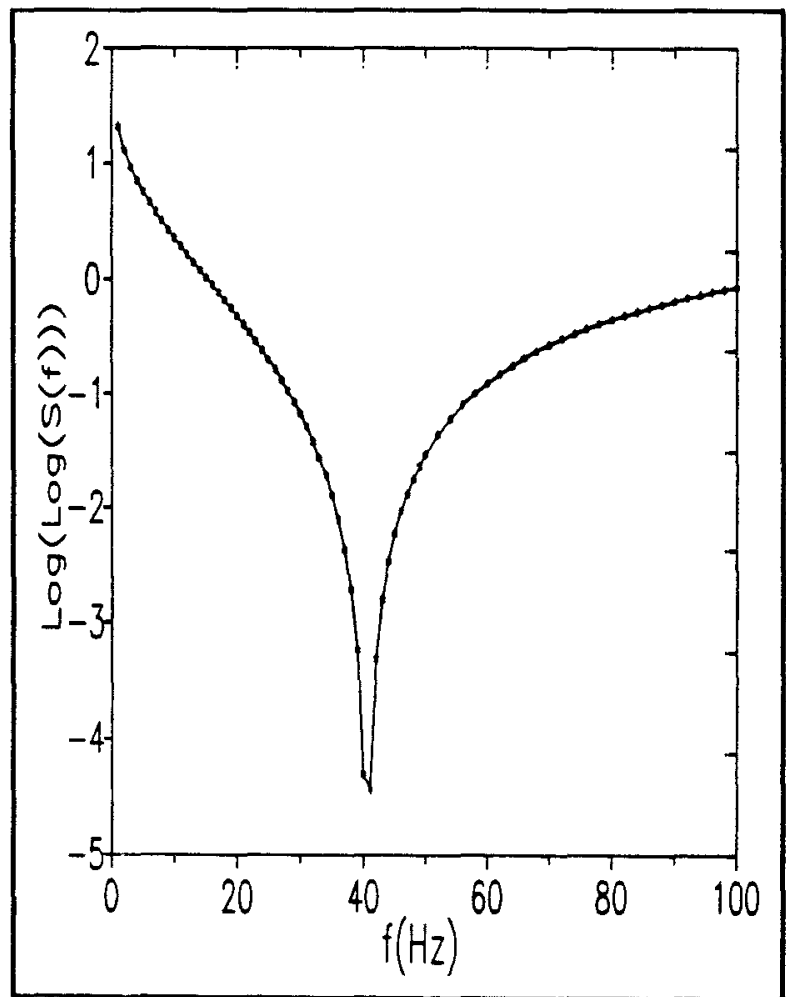

FIG-5.1 - Curva $\log (\log (s))$ da amostra hipotética com espessura de $1 \mu \mathrm{m}$. A curva cheia é o melhor ajuste pela eq.(5.9).

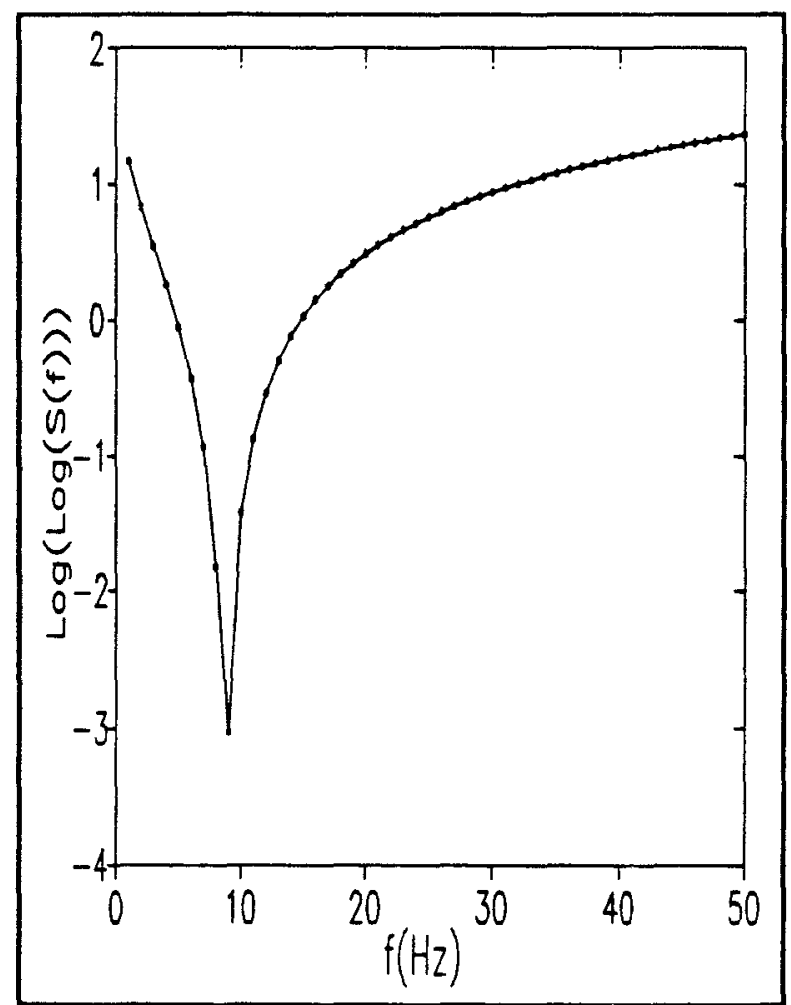

FIG-5.2 - Curva $\log (\log (\mathrm{s}))$ da amostra hipotética com espessura de $70 \mu \mathrm{m}$. Curva cheia é o melhor ajuste pela eq.(5.9). 
O comprimento de difusão térmica variou desde $\mu(1 \mathrm{~Hz})=131 \mu \mathrm{m} \mathrm{a} \mu(100 \mathrm{~Hz})=13,1 \mu \mathrm{m}$.

A amostra com $1 \mu \mathrm{m}$ de espessura, nesse intervalo de frequência, é considerada termicamente fina. Mesmo sob esta condição a equação (5.9) se ajustou muito bem. Para a amostra com $70 \mu \mathrm{m}$ de espessura, podemos verificar que ela se encontra numa região de transição entre termicamente fina para espessa. Ainda nessa condição a equação (5.9) fez excelente ajuste. Portanto, independentemente da região de frequência que se esteja trabalhando, a equação (5.9) sempre se ajustará aos pontos experimentais.

Uma outra vantagem deste método é a rapidez com que a identificação e a determinação da difusividade térmica é realizada, pois não necessita de algorítimos especiais computacionais para realizar os ajustes.

\section{4 - APLICAÇÕES}

Para ilustrar experimentalmente a utilidade desse método, usaremos o Poli(3 Butiltiofeno), P3BT, como amostra sob análise. Duas técnicas foram usadas com a mesma amostra: a técnica fotopiroelétrica e a fotoacústica com câmara aberta (OPC) $[14,15]$.

As FIG-5.3 e FIG-5.4 mostram as curvas experimentais e os ajustes da equação (5.9). Podemos observar na FIG-5.3 que o ajuste foi excelente (desvio=0,00582 e correlação=0,99999), enquanto que na FIG-5.4 o ajuste não teve tal precisão (desvio $=0,01901$ e correlação $=0,99938)$. 


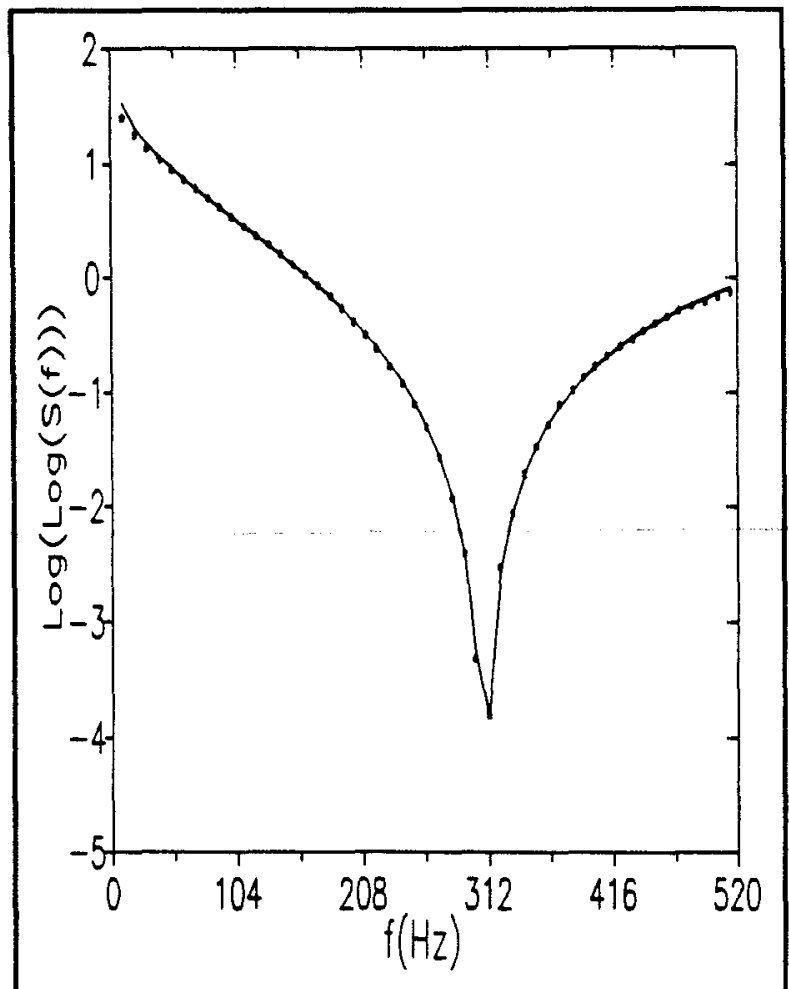

FIG-5.3 - Curva Log(Log) dos pontos experimentais obtidos pela técnica fotopiroeletrica e - ajuste pela equação (5.9), para o filme de P3BT.

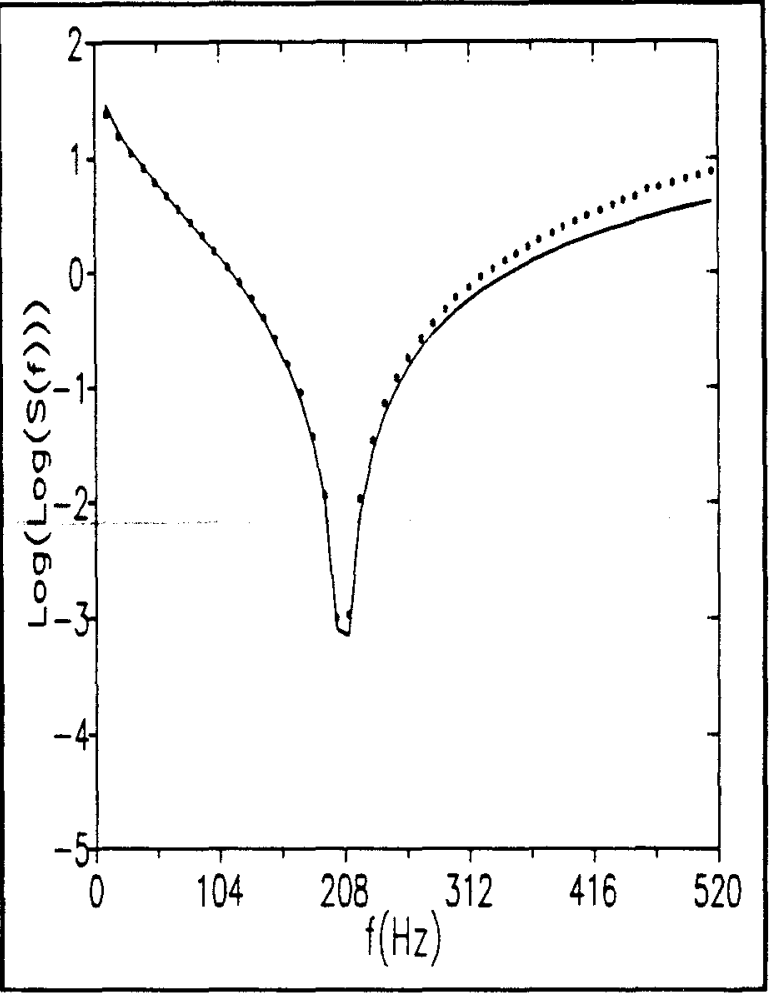

FIG-5.4 - Curva Log(Log) dos ponto experimentais obtido por fotoacústica-OPC e o ajuste pela equação (5.9), para ofilme de P3BT.

Observamos na FIG-5.4 que houve outro tipo de fenômeno juntamente com a difusão térmica. Consideramos que se trata do efeito termoelástico. Devido a isto, obtemos que o valor da difusividade térmica foi diferente daquele obtido pelo pontos na FIG-5.3. Para os dados obtidos pelas técnicas fotopiroelétrica e fotoacústica (OPC), a difusividade térmica é $\alpha=20,22 \times 10^{-8} \mathrm{~m}^{2} / \mathrm{s}$ e $\alpha=9,8 \times 10^{-8} \mathrm{~m}^{2} / \mathrm{s}$, respectivamente.

Nas ref.3 e 4 , os autores alertam para os erros introduzidos na determinação da difusividade quando ocorre o efeito termoelástico. Portanto, demonstramos a eficiência de um simples método para identificação e caracterização térmica de amostras em filmes finos. 


\section{S.5 - REFERENCIAS}

1 - Adams, M. J.; Kirkbright, G. F. - Analyst., 102, 281(1977).

2 - Jackson, W.; Amer, N. M. - J. Appl. Phys., 51, 3343(1980).

3 - Rousset, G.; Lepoutre, F.; Bertrand, L. - j. Appl. Phys., 54, 2383(1983).

4 - Charpentier, P.; Lepoutre, F. e Bertrand, L. - J. Appl. Phys., 53, 608(1982).

5 - Perondi, L. F. e Miranda, L. C. M. - J. Appl. Phys., 62, 2955(1987).

6 - Vargas, H. e Miranda, L. C. M. - Phys. Report, 161, 43(1988).

7 - Mandelis, A.; Zver, M. M. - J. Appl. Phys., 57, 4421(1985).

8 - John, P. K.; Miranda, L. C. M. e Rastogi, A. C. - Physical Rev. B, 34, 4342(1986).

9 - Carslaw, H. S. e Jaeger, J. C. - Condution of Heat in Solids - $2^{2}$ Ed., Oxford University Press (1959) Great Britain.

10 - White, R. M. - J. Appl. Phys, v34, 3559(1963).

11 - Erwin, K. - Matemática Superior, Livros Técnicos e Científicos Editora S. A. - v.4, (1976).

12 - Arfken, G. - Mathematical Methods for Physicists, $2^{2}$ edição, Academic Press, USA(1970).

13 - Churchill, R. V. - Variáveis Complexas e suas Aplicações, McGraw Hill do Brasil, Ltda (1978).

14 - Marquezini, M. V.; Corrêa da Silva, Edson - Dissertação de Mestrado, Inst. de Física "Gleb Wataghin" - UNICAMP-SP (1990).

15 - Cella, N. e Vargas, H. - Tese de Doutorado, Inst. de Física "Gleb Wataghin" - UNICAMPSP (1990) 


\section{CAPftulo VI}

\section{DETERMINAÇÃO DE PARÂMETROS TÉRMICOS E ÓTICOS DO FILME \\ DE POLI(3-BUTIL-TIOFENO) POR ESPECTROSCOPIA FOTOPIROELÉTRICA}

\section{1 - INTRODUÇÃO}

Na década de 1960 a física do estado sólido foi marcada, entre outras coisas, pela descoberta de materiais sintéticos de alta condutividade elétrica - $\left.>1(\Omega \mathrm{cm})^{-1}\right)$ - hoje denominados de metais sintéticos. Os primeiros compostos moleculares encontrados, que possuem condutividades metálicas, foram o tetraciano e tetraoxalatoplatinato, também conhecidos como sais Krogman [1]. Outros compostos inorgânicos foram produzidos, entre eles encontramse os polímeros inorgânicos.

O primeiro polímero inorgânico descoberto foi o poli(sulfonitrilo), cuja compactação policristalina apresentou alta condutividade no trabalho de Chapman, o qual concluiu que esse material era um semicondutor [2].

Após esses anos, grandes avanços vem ocorrendo com polímeros orgânicos. Em 1971, Shirakawa e Ikeda publicaram seus estudos espectroscópicos com filmes de poli-acetileno [3]. O interesse em poli-acetileno cresceu a partir de 1977 quando Shirakawa e Chiang doparam um filme desse polímero com $\mathrm{AsF}_{5}$, obtendo assim uma condutividade elétrica de $56(\mathrm{n} \mathrm{cm})^{-1}[4,5]$. Infelizmente, esse polímero apresenta instabilidade na presença do ar.

Nos anos seguintes novos polímeros condutores foram descobertos, mas todos, a 
exemplo do poli-acetileno, eram insolúveis, com exceção do poli(p-fenileno sulfídrico), o qual era solúvel numa mistura de $\mathrm{AsF}_{5} / \mathrm{AsF}_{3}$ [6]. Anos depois, duas novas famnlias de polímeros condutores foram descobertas: politiofenos e polipirróis. Recentemente, diversas famílias de polímeros condutores vêm sendo descobertas e estudadas por diversas técnicas físicas.

O interesse gerado na pesquisa desses polímeros, apelidados de Polímeros Condutores, é movido, principalmente, pela perspectiva de ampla aplicação tecnológica. Além das áreas de transporte e armazenamento de energia, a aplicação na microelétrônica tem se mostrado promissora. Transistor por Efeito de Campo (FET) com polímeros condutores tem demonstrado excelentes características corrente-tensão. Acredita-se que os polímeros condutores solúveis são melhores candidatos aos novos dispositivos da microeletrônica [7-11].

Devido ao grande interesse nas propriedades elétricas desses polímeros, o estudo de suas propriedades térmicas tem sido pouco realizado até agora. O conhecimento das propriedades térmicas dos materiais também são fundamentais para o seu desenvolvimento tecnológico, já que o calor gerado nos dispositivos eletro-eletrônicos necessita ser dissipado garantindo a sua estabilidade.

Dentre os diversos polímeros condutores da familia do poli-tiofeno, o Poli(3ButilTiofeno) - P3BT tem sido sintetizado no Laboratório do Grupo de Eletretos e estas amostras foram usadas neste trabalho. Após a síntese, passamos a determinar suas propriedades térmicas (difusividade e condutividade térmicas) e óticas (coeficiente de absorção e "gap" ótico) usando a técnica espectroscópica fotopiroelétrica [12]. 


\section{2 - O POLI(3-BUTILTIOFENO)}

O monômero 3-butiltiofeno foi preparado pela doutoranda A. Pawlicka usando o método de Grignard acoplando brometo de 1-butilmagnésio com 3-bromotiofeno. A reação foi realizada em éter dietílico usando cloreto de \{1,3-bis (difenilfosfino) propano\} níquel II $\mathrm{Ni}(\mathrm{dppp}) \mathrm{Cl}_{2}$ - como catalizador. A polimerização foi obtida através da oxidação química do monômero com $\mathrm{FeCl}_{3}$ e o P3BT mostrou boa solubilidade em THF, $\mathrm{CHCl}_{3}$, e $\mathrm{CH}_{2} \mathrm{Cl}_{2}$. O filme com boas propriedades morfológicas foi preparado por evaporação do solvente e as

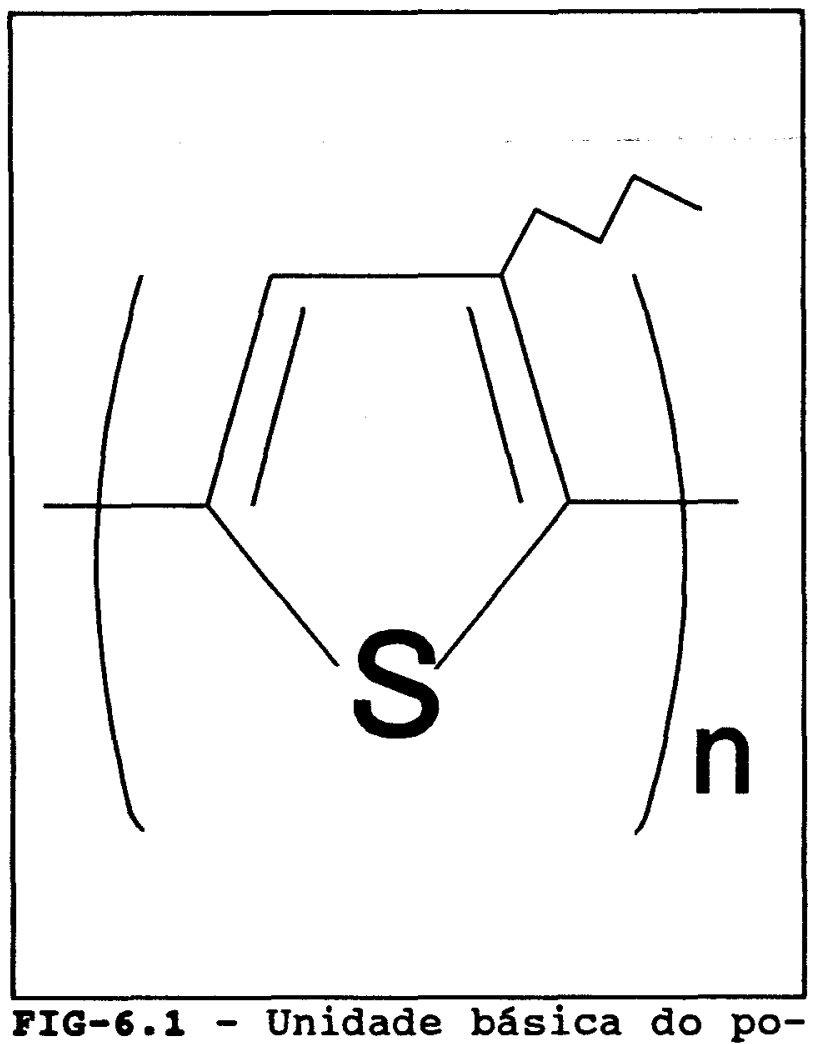
limero P3BT.

espessuras das amostras usadas variaram de 10 a $12 \mu \mathrm{m}$.

A condutividade elétrica intríseca do filme gira em torno de $10^{-7}(\Omega \mathrm{cm})^{-1}$, sendo medido pelo método Montgomery [13], não mostrando nenhuma anisotropia. A densidade de massa foi obtida da razão entre a massa e o volume de um pedaço do filme, obtendo $1 \mathrm{~g} / \mathrm{cm}^{3} \mathrm{com}$ a precisão de 5\%. A FIG-6.1 mostra a unidade monomérica deste polímero. 


\section{3 - PROCEDIMENTOS EXPERIMENTAIS}

Apresentaremos duas maneiras nas quais foram realizadas as medidas fotopiroelétricas dos filmes de P3BT e discutiremos os efeitos fototérmicos envolvidos nas medidas. Pela análise e resultados dos dois procedimentos, procuramos apresentar qual deles é o melhor na obtenção de informaçōes óticas e térmicas das amostras estudadas.

\subsection{1 - Medidas PPES do P3BT com Câmara PPE fechada}

A amostra foi colocada sobre a superfície enegrecida (pintada de preto) do filme de PVDF, usado como detetor piroelétrico, com auxflio de um filme muito fino de graxa de vácuo se fez o acoplamento entre a amostra e o detetor. Em seguida, uma janela de vidro BK7 foi usada para nivelar a superfície da amostra e uniformizar o contato amostra-detetor. Sobre a janela foi colocada a tampa, a qual produzia uma leve pressão sobre o conjunto janela-amostradetetor. Dessa forma obtemos um bom contato térmico entre amostra e detetor, o que é um requisito importante nessa técnica.

Devido às diferenças nas amplitudes dos sinais piroelétricos das câmaras detetoras, usamos só um feixe do cabo de fibra ótica para obtermos os espectros, apesar do espectrômetro fotopiroelétrico ser de duplo feixe. As intensidades e as fases dos sinais PPES da amostra foram aquisicionados pelo microcomputador através da conexão RS232 com o lock-in SR530, mantendo fixa a frequência de modulação durante a varredura do comprimento de onda no monocromador.

Depois de obtermos os sinais espectrais da amostra, a retiramos da superfície do detetor, e então repetimos o mesmo procedimento para obtermos os sinais espectrais da referência. A referência é obtida passando uma fina camada de tinta preta sobre a superfície do detetor, (filme 
de PVDF).

Após a obtenção dos dados, usamos um programa matemático para realizar todos os cálculos e obtermos os espectros da amostra (FIG-6.2 e FIG-6.3). Essa etapa foi necessária porque só usamos um feixe do espectrômetro fototérmico.

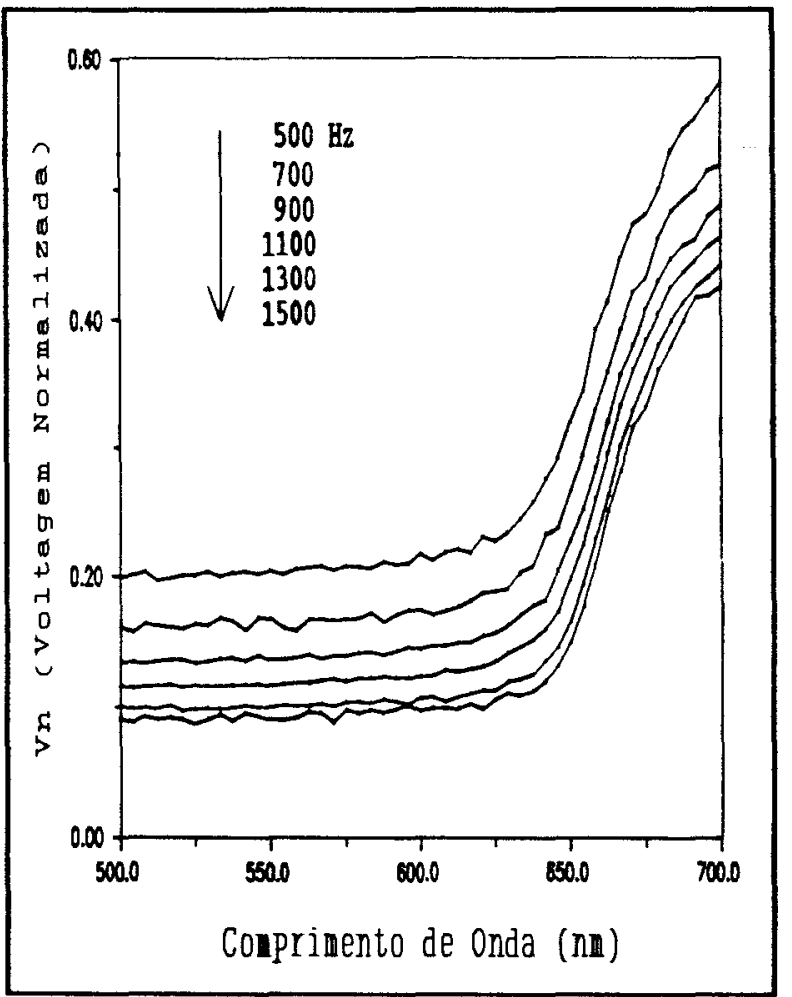

PIG-6.2 - Espectros normalizados do filme de P3BT em diversas frequências de modulação.

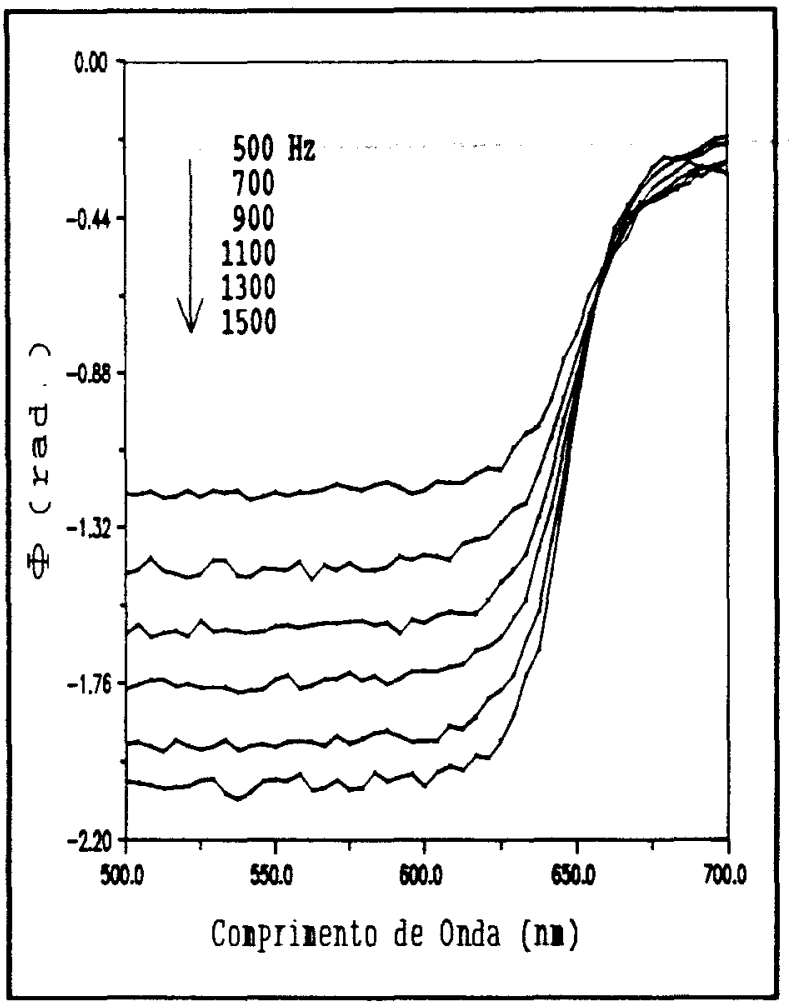

FIG-6.3 - Fases dos sinais PPES do filme de P3BT em diversas frequências.

As FIG-6.2 e FIG-6.3 mostram os espectros do P3BT obtidos através das amplitudes e das fases normalizadas dos sinais PPES, respectivamente, em diversas frequências de modulação.

A normalização foi obtida através da razão entre o sinal PPES da amostra pelo da referência. Podemos notar que a amplitude normalizada, Vn, e a fase, $\Phi$, são funções da frequência de modulação e do comprimento de onda da luz. Os espectros são similares ao espectro de transmissão UV-visível da amostra. Na região de baixa absorção, cerca de $700 \mathrm{~nm}$, 
o sinal fotopiroelétrico é gerado pela absorção da luz que atinge o detetor dando origem a alto sinal normalizado.

Para comprimento de onda menor do que $630 \mathrm{~nm}$, os espectros PPES são considerados fotopiroeletricamente saturados [14]. Portanto, a amplitude normalizada é baixa já que todo calor é gerado pela amostra. Esse, por sua vez, deve atravessar a amostra até atingir o detetor e dar origem à voltagem piroelétrica.

A dependência de Vn com a frequência de modulação foi, praticamente, a mesma tanto em baixo como em alto comprimento de onda. Isso ocorre devido ao conjunto amostra-detetor ser formado por polímeros.

Na FIG-6.3, a variação da fase com o comprimento de onda é similar àquela da amplitude. Na região transparente onde a geração de calor é devido, predominantemente, à absorção de luz pelo detetor, a fase é próxima de zero. Isso é devido ao fato do centróide de calor se encontrar próximo da fronteira entre amostra-detetor. À medida que a absorção da amostra cresce, o centróide de calor se desloca para o interior da amostra em direção à superfície frontal provocando o aumento da fase. Quando $\beta>\beta_{\mathrm{c}}$ a fase tornou-se constante, significando que a absorção ocorre na superfície frontal da amostra.

A dependência de $\Phi$ com a frequência de modulação torna-se mais abrupta quando se transiciona da região transparente para a região opaca. Essa transição ocorre à medida que a frequência aumenta. Na região de alta absorção - região saturada - o aumento da frequência de modulação faz o comprimento de difusão térmica da amostra, $\mu_{s}$, decrescer. Logo o fluxo de calor leva mais tempo para atravessar a amostra e atingir o detetor.

Na região transparente, a fase se aproxima de zero com o aumento da frequência de 
modulação. Em alta frequência o $\mu_{\text {a }}$ está mais próximo da fronteira, enquanto em baixa frequência $\mu_{\text {s }}$ distancia da fronteira. $\AA$ medida que $\beta$ cresce, a amostra passa a contribuir na geração de calor. Portanto, há um ponto de cruzamento em aproximadamente $660 \mathrm{~nm}$.

\subsection{2 - Medidas PPES do P3BT com Câmara PPE aberta}

Essas medidas foram realizadas com a câmara PPE sem a janela de BK7. As obtenções dos espectros seguiram o mesmo procedimento realizados no item anterior. As FIG-6.4 e FIG6.5 mostram as amplitudes e fases como função da frequência de modulação e do comprimento de onda.

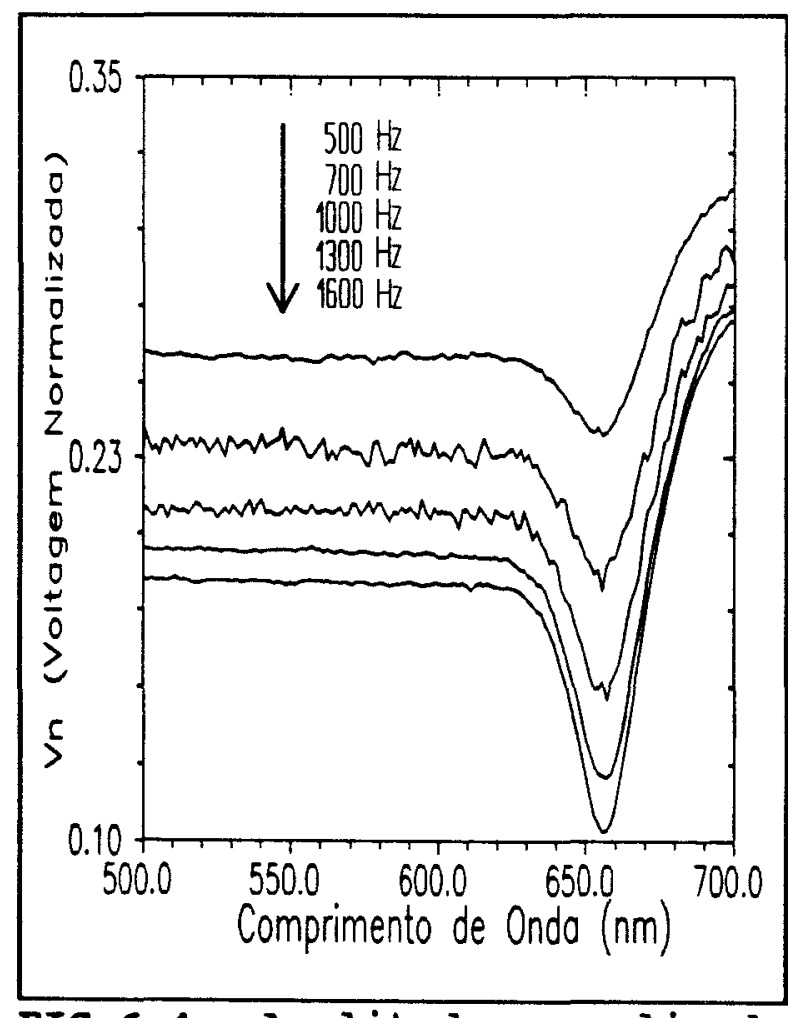

FIG-6.4 - Amplitude normalizada do sinal PPES do filme de P3BT obtido com câmara PPE aberta.

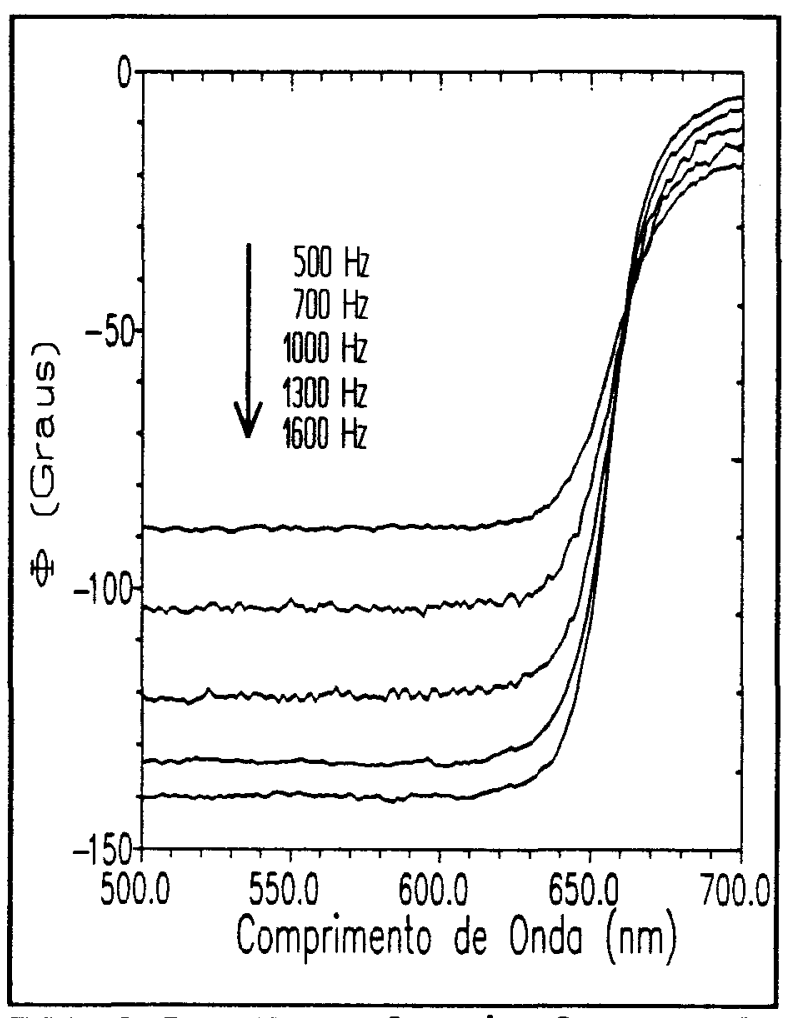

FIG-6.5 - Fase do sinal PPES do filme de P3BT obtido com cámara aberta. 
Notamos que as amplitudes normalizadas, nesse caso, diferem das amplitudes do caso anterior por uma deformação ocorrendo na curva antes da região de saturação. Ainda podemos observar que o ponto de mínimo dessas curvas acontece nas proximidades de $660 \mathrm{~nm}$. Portanto, este mínimo é próximo do ponto de inversão visto nas fases, no caso anterior. Além disso, a deformação fica mais acentuada a medida que a frequência de modulação cresce.

Acreditamos que esse mínimo na curva de voltagem é devido ao efeito termoelástico associado ao fenômeno de difusão térmica $[15,16]$. O efeito termoelástico, sendo originado pela expansão térmica ou pelo gradiente de temperatura na amostra. Esse último efeito tende a dilatar a região iluminada gerando uma flexão termoelástica. Assim sendo, esse deslocamento é transmitido ao detetor, no qual é convertido em sinal elétrico através de sua propriedade piezoelétrica [17].

O efeito de flexão termoelástica é caracterizado por ocorrer em frequência de modulação acima da frequência característica, $f>f_{c}$, e a fase versus $f^{\text {th }}$ não se comporta linearmente como é o caso na difusão térmica [15-18].

As FIG-6.6 e FIG-6.7 mostram a variação da amplitude e fase normalizadas e respectivos ajustes por retas, como é esperado quando o efeito de difusão térmica é dominante em amostra termicamente espessa. As retas se ajustam muito bem aos pontos em baixas frequências, demonstrando que o efeito termoelástico passa a ser dominante em alta frequência.

A formação dos espectros deformados pode, portanto, ser explicada da seguinte forma: para comprimento de onda acima de $660 \mathrm{~nm}$ o sinal piroelétrico é devido à absorção da luz pelo detetor, assemelhando-se aos espectros de transmissão ótica. Quando a amostra passa a absorver significativamente, parte do calor gerado nela se propaga em direção ao detetor, mas é atenuado 
no seu interior.

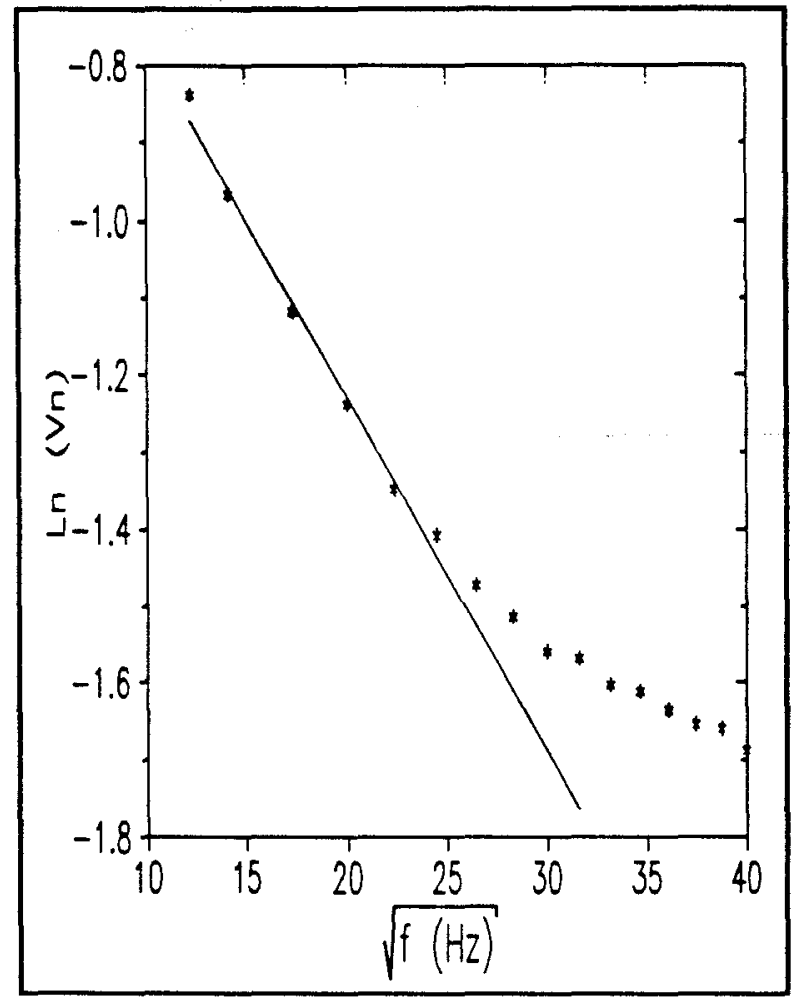

PIG-6.6 - Variação das amplitudes dos sinais PPES do filme de P3BT com a frequência de modulação na região saturada obtidas com a câmara aberta.

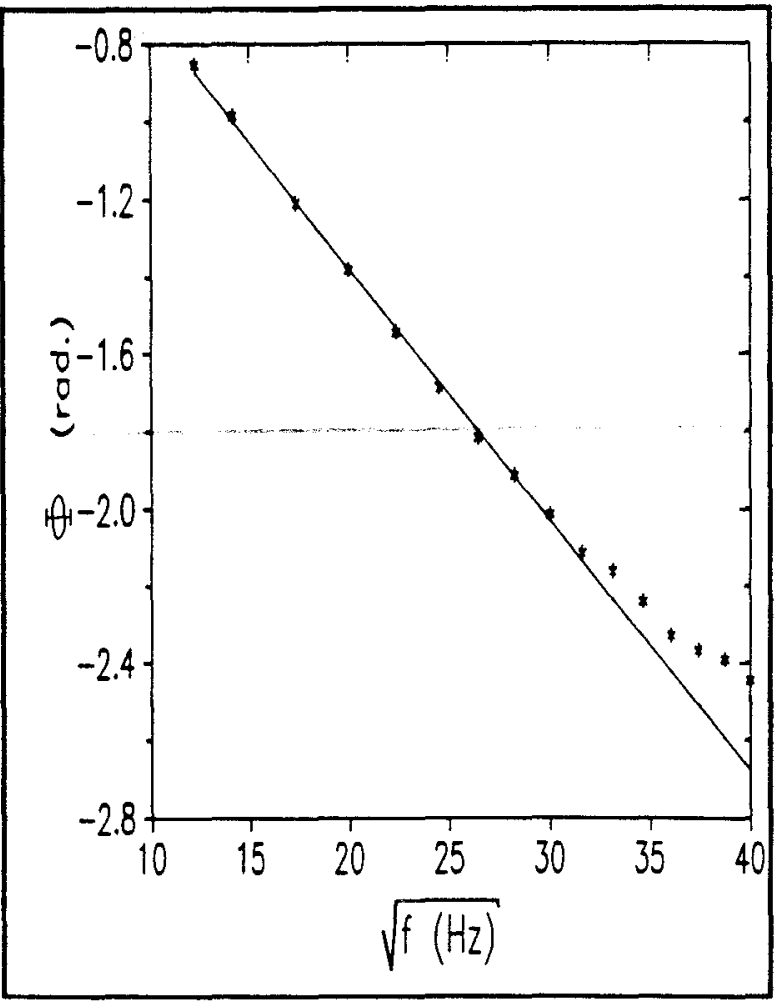

FIG-6.7 - Variação da fase PPES do filme de P3BT com a frequência de modulação na região saturada obtido com a cámara aberta.

A diferença de temperatura entre as superfícies frontal e traseira provoca a flexão da amostra, a qual por sua vez, passa a ser o efeito dominante na geração do sinal elétrico comparativamente ao efeito de difusão térmica. Assim, o sinal normalizado começa a crescer até que a saturação seja atingida. Podemos notar que o comprimento de onda no qual se inicia a saturação é o mesmo do caso anterior. Isto significa que a saturação fotoacústica, devido ao efeito termoelástico, coincide com a saturação fotopiroelétrica.

O efeito termoelástico foi minimizado quando colocamos uma janela transparente sobre 
a amostra. Enquanto isto, as fases não apresentam tais deformações, assemelhando-se àquelas do caso anterior. Podemos observar que há o ponto de cruzamento das curvas de fase no mesmo comprimento de onda.

\section{4 - DETERMINAÇÃO DA DIFUSIVIDADE E CONDUTIVIDADE TÉRMICAS}

Para determinar as grandezas térmicas usamos a teoria fotopiroelétrica desenvolvida por Mandelis [14] et al. Optamos pelo uso dessa técnica por ser mais conveniente nos estudos de filmes finos e por apresentar uma grande relação sinal/ruído, já que se trata de uma medida direta da temperatura média da amostra.

Considerando que o detetor seja termicamente espesso e oticamente opaco $\left(\exp \left(-\beta_{\mathrm{p}} \mathrm{L}_{\mathrm{z}}\right)=0\right.$ e $\left|r_{p}\right|>>1$ ), obtemos a equação,

$$
\begin{gathered}
V=A\left[( \frac { \eta _ { s } b _ { p s } } { k _ { p } \sigma _ { p } ^ { 2 } ( r _ { s } ^ { 2 } - 1 ) } ) \left[2\left(b_{s g} r_{s}+1\right)-\left[\left(r_{s}+1\right)\left(b_{s g}+1\right) e^{\sigma L_{s}}+\left(r_{s}-1\right)\left(b_{s g}-1\right) e^{-\sigma L_{s}} e^{-\beta s L_{s}}\right]+\right.\right. \\
\left.+\left(\frac{\eta_{p} e^{-\beta_{s} L_{s} b_{p s}}}{k_{p} \sigma_{p}^{2}}\right)\left[\left(b_{s g}+1\right) e^{\sigma L_{s}}+\left(b_{s g}-1\right) e^{-\sigma L_{s}}\right]\right] \div\left[\left(b_{s g}+1\right)\left(b_{p s}+1\right) e^{\sigma L_{s}}+\left(b_{s g}-1\right)\left(b_{p s}-1\right) e^{-\sigma L_{s}}\right]
\end{gathered}
$$

Na região saturada a amostra é altamente absorvedora, isto é $\exp \left(-\beta_{\mathrm{a}} \mathrm{L}_{\mathrm{z}}\right) \cong 0$, logo, $\left|r_{a}\right|>>1$ e bgs, no caso da câmara fechada, é o parâmetro de acoplamento entre a janela e a amostra. Assim, a equação (6.1) é simplificada para 


$$
V=A\left[\frac{2 \eta_{g} r_{s} b_{p s}}{k_{p} \sigma_{p}^{2}\left(r_{s}^{2}-1\right)}\right]\left[\frac{\left(b_{s g} r_{s}+1\right)}{\left(b_{s g}+1\right)\left(b_{p s}+1\right) e^{\sigma L_{s}}+\left(b_{s g}-1\right)\left(b_{p s}-1\right) e^{-\sigma, L_{s}}}\right]
$$

onde $A=\left(\mathrm{pI}_{\delta} / \epsilon \epsilon_{\partial}\right)$.

A voltagem de referência, $V_{R}$, é obtida considerando que a camada preta sobre a superfície seja termicamente fina, isto $e, \exp \left( \pm \sigma_{R} L_{R}\right) \cong 1$ e que $b_{R g} r_{R}>>1$, assumindo que $\eta_{R}=1$. Logo obtemos que

$$
V_{R}=\frac{A}{k_{p} \sigma_{p}^{2}}\left[\frac{1}{b_{g p}+1}\right]
$$

sendo o valores das difusividades e condutividades térmicas para o detetor e janela, $\alpha_{\mathrm{PVDF}}=5,4 \times 10^{-8} \mathrm{~m}^{2} / \mathrm{s}, \mathrm{k}_{\mathrm{PVDF}}=0,13 \mathrm{~W} / \mathrm{mK}[14] ; \alpha_{\mathrm{BK} 7}=51,7 \times 10^{-8} \mathrm{~m}^{2} / \mathrm{s}$ e $\mathrm{k}_{\mathrm{BK} 7}=1,114 \mathrm{~W} / \mathrm{mK}$ [19], temos que $b_{\mathrm{gp}}=2,769$, o qual não pode ser desprezado.

A voltagem normalizada, $V_{n}=V_{g} / V_{R}$, é dada por

$$
\begin{gathered}
V_{n}=\left[\left(\frac{\eta_{s} r_{s}}{\left(r_{s}^{2}-1\right)}\right)\left[2\left(b_{g s}+r_{s}\right)-\left[\left(r_{s}+1\right)\left(b_{g s}+1\right) e^{\sigma L_{s}}-\left(r_{s}-1\right)\left(b_{g s}-1\right) e^{-\sigma L_{s}}\right] e^{-\beta L_{s}}\right]+\right. \\
\left.+\left[\left(b_{g s}+1\right) e^{\sigma L_{s}}-\left(b_{g s}-1\right) e^{-\sigma L_{s}}\right] e^{-\beta_{s} L_{s}}\right] \times\left[\frac{b_{g s}+b_{p s}}{\left[\left(b_{g s}+1\right)\left(b_{p s}+1\right) e^{\sigma L_{s}}-\left(b_{s g}-1\right)\left(b_{p s}-1\right) e^{-\sigma g L_{s}}\right]}\right]
\end{gathered}
$$


enquanto que a voltagem normalizada na região de saturação é

$$
V_{n}=2 \eta_{s}\left[\frac{\left(b_{g s}+b_{p s}\right)}{\left(b_{g s}+1\right)\left(b_{p s}+1\right) e^{\sigma L_{s}}-\left(b_{g s}-1\right)\left(b_{p s}-1\right) e^{-\sigma L_{s}}}\right]
$$

onde consideramos que $\left|r_{2}\right|>>b_{g}$.

A equação da fase na região saturada obtida de $V_{n}$ é dada por

$$
\Phi=-\operatorname{arctg}\left[\frac{\left(b_{g s} b_{p s}+1\right) \cosh \left(a_{s} L_{s}\right)+\left(b_{g s}+b_{p s}\right) \operatorname{senh}\left(a_{s} L_{s}\right)}{\left(b_{g s}+b_{p s}\right) \cosh \left(a_{s} L_{s}\right)+\left(b_{g s} b_{p s}+1\right) \operatorname{senh}\left(a_{s} L_{s}\right)} \operatorname{tg}\left(a_{s} L_{s}\right)\right]
$$

Através dos ajustes das equações (6.5) e (6.6) aos pontos experimentais obtemos simultaneamente a difusividade e condutividade térmicas. A condutividade térmica será obtida através do valor de $b_{p s}$ ou de $b_{\mathrm{g} z}$ por

$$
b_{i \neq i}=\frac{k_{i}}{k_{* i}} \sqrt{\frac{\alpha_{* i}}{\alpha_{i}}}
$$

onde $\mathrm{i}=\mathbf{s}$, p ou $\mathrm{g}$.

Portanto, duas situaçōes para o P3BT serão analisadas e caracterizadas termicamente: não dopado e dopado.

\subsection{1 - P3BT não dopado}

As FIG-6.8 e FIG-6.9 mostram a variação das amplitudes e fases normalizadas com a frequência de modulação. Cada ponto na curva é a média dos pontos da região saturada de cada 
espectro. Esses espectros foram obtidos como descrito na seção 6.3.1. A curva contínua é o melhor ajuste obtido com as equações (6.5) e (6.6).
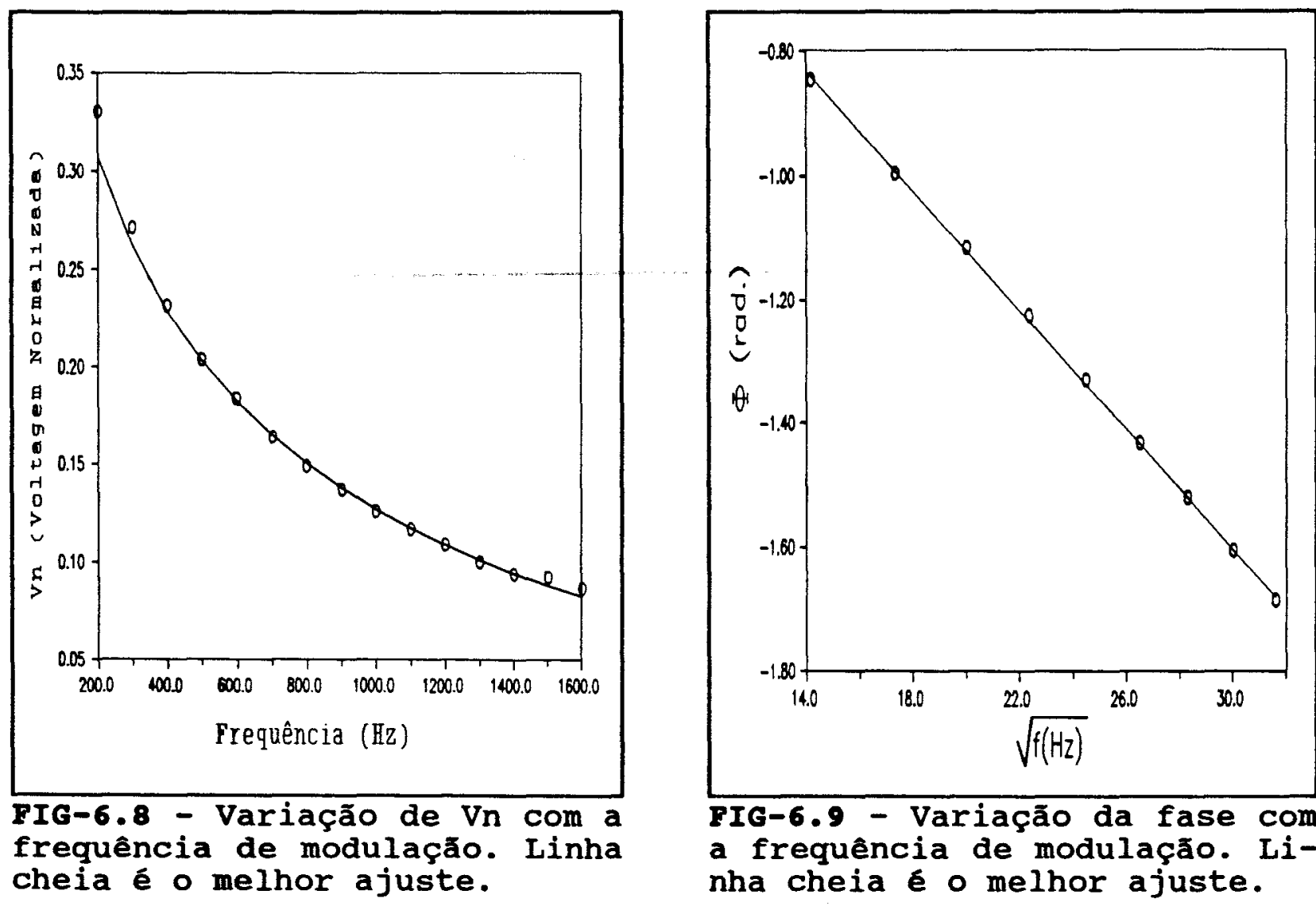

PIG-6.9 - Variação da fase com a frequência de modulação. Linha cheia $e$ o melhor ajuste.

Desses ajustes obtemos que $b_{p s}=1,1$ e $b_{\mathrm{gs}}=3,05$ enquanto que

$$
\alpha_{\mathrm{P} 3 \mathrm{BT}}=16,93 \times 10^{-8} \mathrm{~m}^{2} / \mathrm{s} \quad \text { e } \quad \mathrm{k}_{\mathrm{P} 3 \mathrm{BT}}=0,21 \mathrm{~W} / \mathrm{mK} .
$$

O calor específico para o P3BT foi obtido de $\rho \mathrm{c}=\mathrm{k}_{\downarrow} / \alpha_{\mathrm{s}}$ e o valor que encontramos é $\mathrm{c}=1,24 \mathrm{~J} / \mathrm{gK}$ para o filme de $12 \mu \mathrm{m}$. Os ajustes das variações da amplitude e da fase deram, aproximadamente, os mesmos resultados. 


\subsection{2 - P3BT dopado}

No processo de síntese e polimerização do P3BT são usadas diversas substancias que deixam resíduos os quais servem de dopantes para o polímero. As amostras usadas nas nossas medidas foram dopadas com $\mathrm{FeCl}_{3}$ e apresentaram baixos níveis de dopagens, isto foi verificado por comparação com o filme de P3BT não dopado. O filme de P3BT dopado foi conseguido por evaporação do solvente, obtendo espessuras que variaram de $18-26 \mu \mathrm{m}$.

Quando o P3BT está dopado o sinal fotopiroelétrico é saturado, não permitindo a obtenção de espectro ótico do filme, porém foi possível obter a variação da amplitude e da fase versus frequência de modulação. As FIG-6.10 e FIG-6.11 apresentam estas curvas.

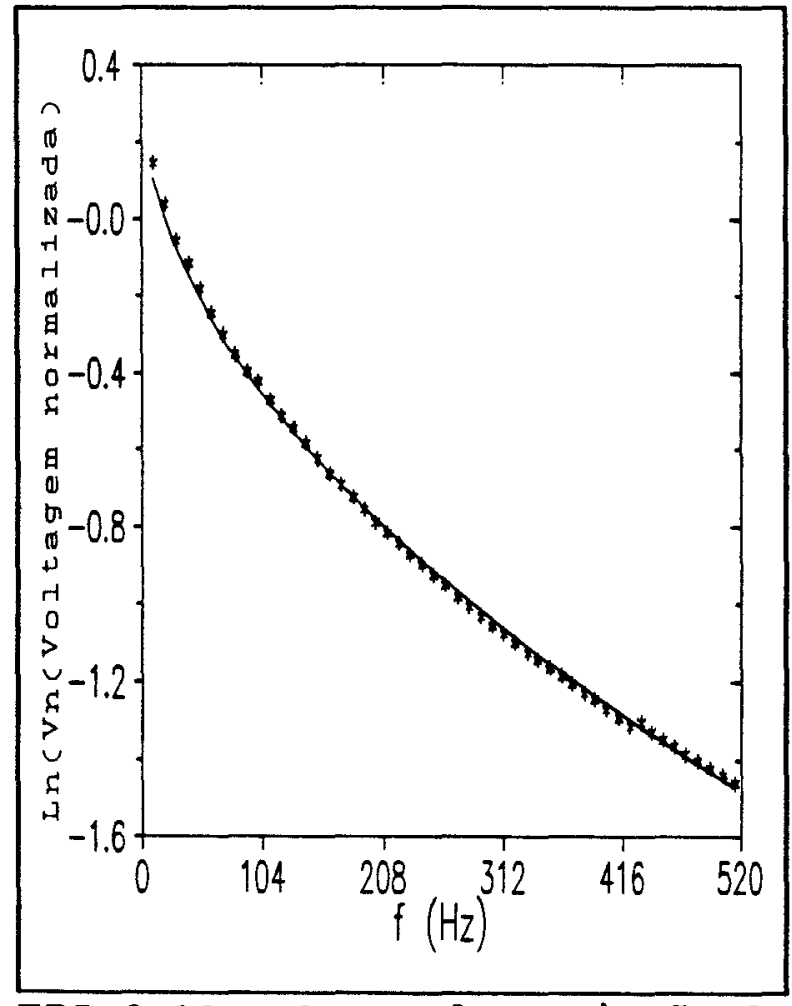

FIG-6.10 - Curva da variação da amplitude do sinal PPES do filme de P3BT dopado. Curva cheia melhor ajuste.

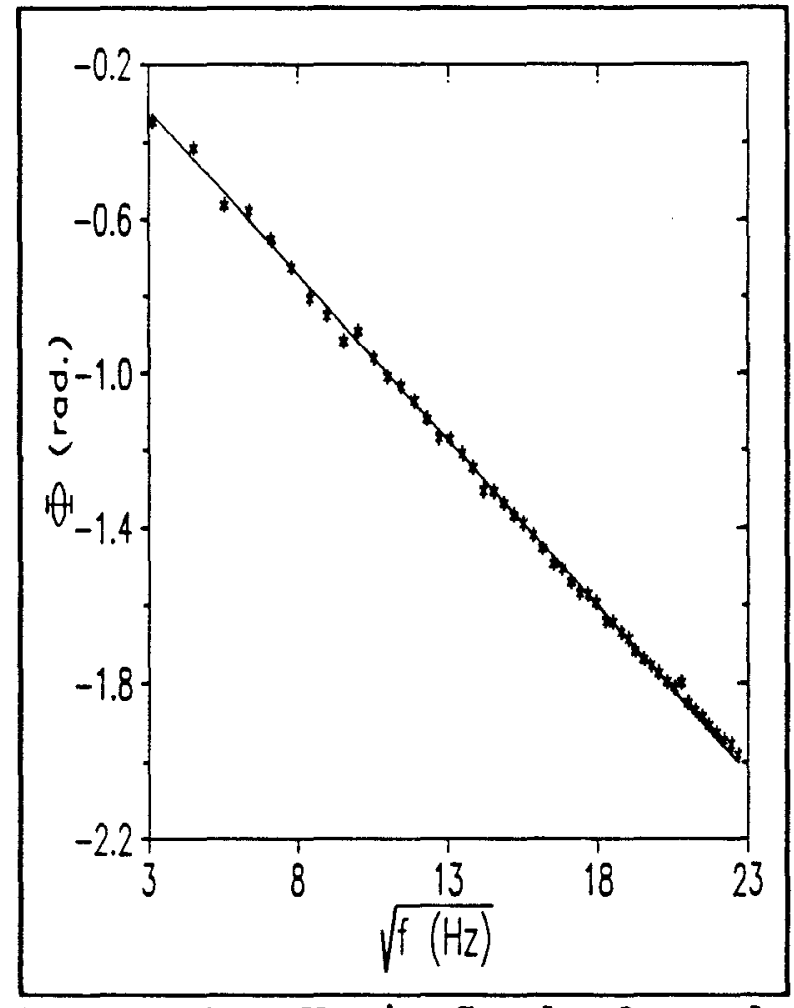

FIG-6.11 - Variação da fase do sinal PPES versus raiz da frequência. Filme de P3BT dopado. Linha cheia é o melhor ajuste. 
Os pontos foram obtidos da seguinte forma: sobre o detetor piroelétrico (detetor preto) foi colocado uma janela de vidro e entre eles colocamos um película de graxa de vácuo para eliminar bolhas de ar e melhorar a aderência das superfícies. Para assegurar o bom acoplamento entre as superfícies usamos a tampa da câmara a qual fêz uma leve pressão sobre a janela de vidro.

Usamos luz branca no sistema ótico de medida descrito no capítulo II para excitar a tinta preta. As voltagens dos sinais fotopiroelétricos foram lidas nos displays do lock-in SR530 e anotados o R(módulo), a fase $(\theta)$ e as componentes $\mathrm{X}$ ( em fase) e $\mathrm{Y}$ (quadratura) em cada frequência de modulação.

Em seguida, retiramos a janela e colocamos a amostra a qual com auxillio da película de graxa de vácuo foi fixada à superfície detetora. Sobre a amostra colocamos a janela de vidro e a tampa da câmara fêz uma leve pressão.

O mesmo procedimento de leitura dos sinais fotopiroelétricos, descritos anteriormente, foi realizado. Com auxílio de um programa matemático realizamos as normalizações e ajustamos as equações (6.5) e (6.6) aos pontos das amplitudes e fases normalizadas, respectivamente.

Destes ajustes encontramos os seguintes valores para a difusividade e condutividade térmicas:

$$
\begin{aligned}
& \alpha_{\mathrm{P} 3 \mathrm{BT} \text { dopado }}=20,6 \times 10^{-8} \mathrm{~m}^{2} / \mathrm{s} \text { com } b_{\mathrm{ps}}=0,916 \text { e b } \mathrm{b}_{\mathrm{gs}}=2,54 \\
& \mathrm{k}_{\mathrm{P3BTdopado}}=0,277 \mathrm{~W} / \mathrm{mK} .
\end{aligned}
$$

Usamos o filme de espessura igual a $20 \mu \mathrm{m}$. Os valores da difusividade térmica obtidos pelos ajustes da amplitude e da fase são praticamente os mesmos. 
Dos dados acima obtemos que a capacidade térmica do polímero dopado é $1.39 \mathrm{~J} / \mathrm{cm}^{3} \mathrm{~K}$ que é $12 \%$ a mais da capacidade térmica do polímero não dopado. Estes dados comprovam a capacidade da técnica de monitorar a dopagem dos polímeros condutores.

\section{5 - DETERMINAÇÃo DAS GRANDEZAS ÓTICAS}

Além das grandezas térmicas é possível determinar as grandezas óticas, tais como: coeficiente de absorção e "gap" ótico. Para isso, usamos um dos espectros, mostrados na FIG6.2 , obtidos com câmara a fechada.

Vimos que na região transparente o sinal fotopiroelétrico é devido à luz que atinge o detetor, portanto temos que $r_{\mathbf{s}}<1$. Isto leva o primeiro termo do segundo membro da equação (6.4) ser menor do que o segundo termo. Assim, simplificamos para

$$
V_{n}=\left[\frac{\left[\left(b_{g s}+1\right) e^{\sigma L_{s}}-\left(b_{g s}-1\right) e^{-\sigma L_{s}}\right]\left(b_{g s}+b_{p s}\right)}{\left(b_{g s}+1\right)\left(b_{p s}+1\right) e^{\sigma L_{s}}-\left(b_{g s}-1\right)\left(b_{p s}-1\right) e^{-\sigma_{s} L_{s}}}\right] e^{-\beta_{s} L_{s}}
$$

Logo, a equação (6.8) é composta por uma parte que depende da frequência de modulação e outra do coeficiente de absorção. Então, podemos expressá-la por

$$
V_{n}(\beta)=A(f) e^{-\beta_{s} L_{s}}
$$

Aplicando -Log à equação (6.9) obtemos que

$$
\beta_{s} L_{s}=\log (A(f))-\log \left(V_{n}\right)
$$


Uma expressão similar é encontrada na ref. 20 e é independente da frequência de modulação, porém nem sempre isto se verifica.

Na FIG-6.12 mostramos a aplicação da equação (6.10) ao espectro de P3BT obtido na frequência de modulação de $500 \mathrm{~Hz}$. Nessa figura também apresentamos a determinação do "gap" ótico através das interseção das duas retas, isto é, no cotovelo da curva $[20,22]$ as quais são os melhores ajustes nas duas regiões.

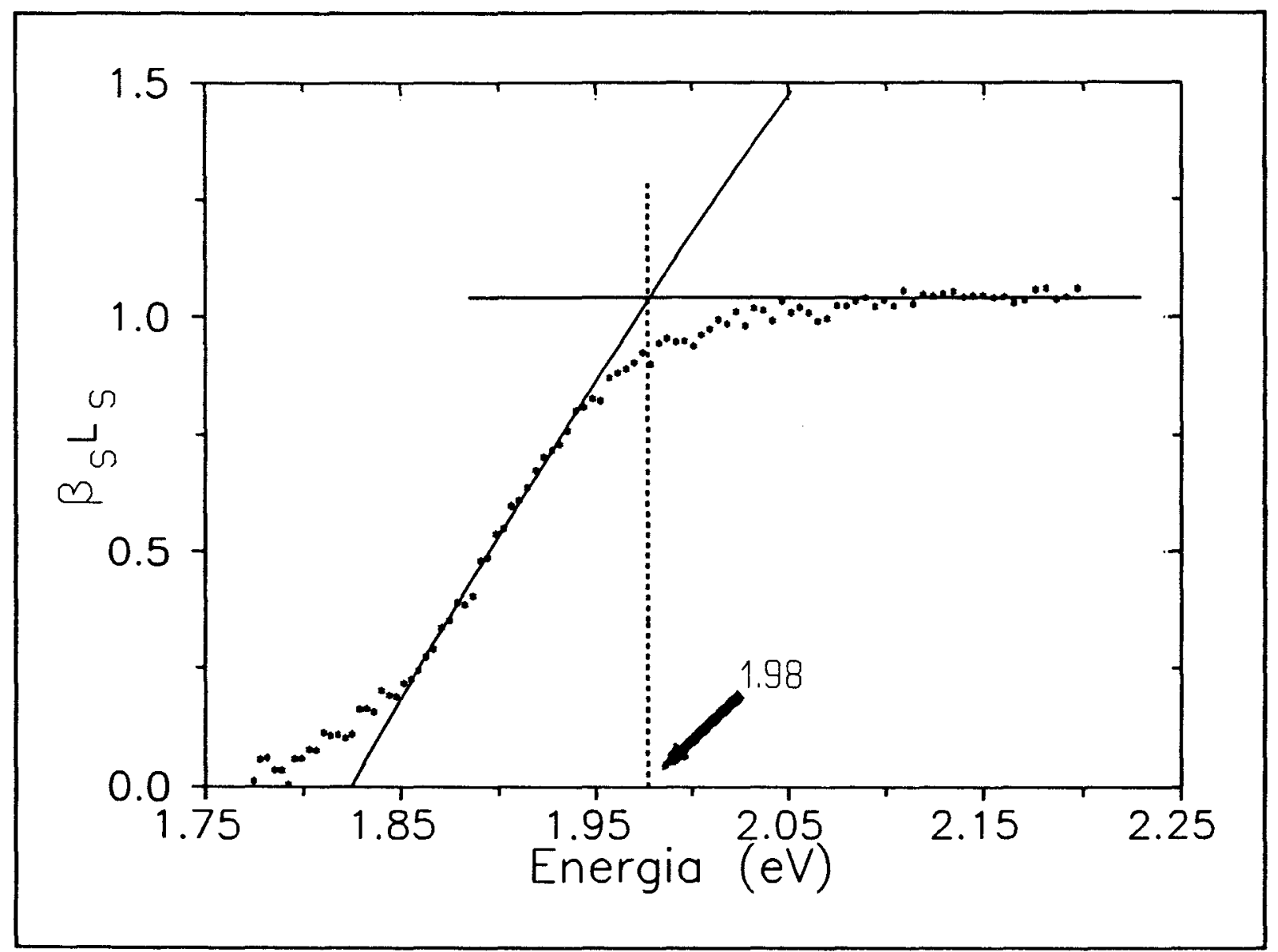

FIG-6.12 - $\beta_{\mathrm{g}} \mathrm{L}_{\mathrm{g}}$ versus energia (eV) obtido do espectro de P3BT na frequência de $500 \mathrm{~Hz}$. 
O valor para o "gap" ótico determinado desse modo foi aproximadamente

$$
\mathrm{E}_{\mathrm{z}}=1.98 \mathrm{eV} \text {. }
$$

Este valor está em concordância com os valores obtidos para outros membros da famflia politiofeno: Poli(3-metiltiofeno), P3MT, com 1,95eV a 2,0 eV por fotocondutividade [23], por luminescência e pela técnica de reflexão [23,24], Poli(3-otiltiofeno); P3OT, 2-2,1eV por absorção [25]. Constata-se que a família Poli(tiofeno) tem "gap" entre 2-2,5eV [26].

O valor do "gap" ótico também pode ser determinado pelas curvas da fase na FIG-6.3 ou na FIG-6.5, através do processo da interseção das duas retas, já utilizado na FIG-6.12. O valor obtido é $E_{z}=1,95 e V$, o qual está de acordo com aquele obtido da curva de $\beta_{2} L_{3}$.

O coeficiente de absorção ótico pode ser determinado pelo ajuste da equação (6.1) às curvas da FIG-6.2 supondo que as bandas de absorção se comportam como funções gaussianas, deste modo estimamos que $\beta \cong 4 \times 10^{7} \mathrm{~m}^{-1}$.

Da FIG-6.12 podemos estimar $\beta_{c}$, sabendo-se que este é o coeficiente de absorção no início de saturação [20]. O valor que obtemos para $\beta_{\mathrm{c}}$ na frequência de modulação de $500 \mathrm{~Hz}$ para o filme de $12 \mu \mathrm{m}$ é de $\beta_{\mathrm{c}}=9 \times 10^{5} \mathrm{~m}^{-1}$.

Ainda da equação (6.10) encontramos que $\log (A(f))=0,53$, o qual foi obtido dos pontos experimentais e usado para obter a FIG-6.12, enquanto que o valor calculado é 0,71 . A discrepância entre esses valores está, possivelmente, na reflexão da superfície da amostra a qual não foi levada em consideração na equação (6.1) e nos possíveis erros instrumentais.

Isto demonstra que esta técnica e as simplificações do modelo de Mandelis realizadas para obter a equação (6.10) constituem um método eficiente e simples no estudos de filmes de polímeros condutores. 


\section{6 - REFERENCIAS}

1 - Ku, C. C.; Liepins, R. - Electrical Properties of Polymers (Chemical Principles) - Hanser

Publishers, Munich - FRG - 1987.

2 - Chapman, D.; Warn, R. J.; Fitzgerald, A. G.; Yoffe, A. D. - Tans. Faraday Soc. 60, 294(1964).

3 - Shirakawa, H.; Ikeda, S.- Polym. J. 2, 231(1971).

4 - Shirakawa, H.; Louis, E. J.; MacDiarmid, A. G.; Chiang, C. K.; Heeger, A. J. - J. Chem. Soc. Chem. Commin. 578(1977).

5 - Chiang, C. K.; Fincher Jr, C. R.; Park, W. Y.; Heeger, A. J.; Hirakawa, H.; Louis, E. J.;

Gau, S. C. e MacDiarmid, A. G. Phys. Rev. Lett. 39, 1098(1977).

6 - Frommer, J. E. - Accounts Chem. Res., 19, 2(1986).

7 - Miyauchi, S.; Dei, T.; Tsubata, I.; Sorimachi, Y. - Synthetic Metals, 41-43, 1155(1991).

8 - Horowitz, G.; Fichou, D.; Peng, X. e Garnier, F. - Synthetic Metals, 41-43, 1127(1991).

9 - Tsumura, A.; Fuchigami, H. e Koezuka, H. - Synthetic Metals, 41-43, 1181(1991).

10 - Miyauchi, S.; Goto, Y.; Tsubata, I. e Sorimachi, Y. - Synthetic Metals, 41-43, 1051(1991).

11 - Voss, K. F.; Braun, D. e Heeger, A. J. - Synthetic Metals, 41-43), 1185(1991).

12 - Melo, W. L. B.; Pawlicka, A.; Sanches, R.; Mascarenhas, S. e Faria, R. M. - J. Appl. Phys. (submetido).

13 - Montgomery, H. C. - J. Appl. Phys., 42, 2971(1971).

14 - Mandelis, A. e Zver, M. M. - J. Appl. Phys. 57, 4421(1985).

15 - Rousset, G.; Lepoutre, F.; Bertrand, L. - J. Appl. Phys., 54, 2383(1983).

16 - Charpentier, P.; Lepoutre, F.; Bertrand, L. - J. Appl. Phys., 53, 608(1982). 
17 - Jackson, W. e Amer, A. N. - J. Appl. Phys., 51, 3343(1980).

18 - Perondi, L. F. e Miranda, L. C. M. - J. Appl. Phys., 62, 2955(1987).

19 - Optical Glass - SCHOTT - Jena ${ }^{\mathrm{ER}}$ GlasWerk Schott \& Gen. - Mainz - RFA (1980).

20 - Christofides, C.; Mandelis, A.;Ghandi, K.; Wagner, R. - Rev. Sci. Instrum. 61, 2360(1990).

21 - Kitamura, M.; Ogawa, T. e Arai, T. - J. Phys. Soc. of Japan 52, 2561(1983).

22 - Rosencwaig, A. - Photoacoustics and Photoacoustic Spectroscopy - Chemical Analysis 57, cap.14, John Wiley \& Sons USA(1980).

23 - Stöckert, D; Kessel, R. e Schultze, J.W. - Synthetic Metals, 41-43, 1295(1991).

24 - Renkuan, Y.; Cheng, G.; Youdou, Z.; Xuechu, S.; Wengao, T. e Ginley, D. S. - Synthetic Metals, 41-43, 543(1991).

25 - Inganās, O e Gustafsson, G. - Synthetic Metals, 37, 195(1990).

26 - Handbook of Conducting Polymer - Ed. por A. T. Skotheim, Marcel Dekker New York (1986). 


\section{CAPItULO VII \\ CONCLUSÕES}

Vimos nos capítulos anteriores alguns modelos e métodos aplicados ao fenômeno fototérmico. Os modelos que desenvolvemos apresentaram bom acordo com os dados experimentais e com a literatura. Vamos apresentar as conclusões separadamente para cada assunto.

\section{1 - DO MODELO PPESR}

O fenômeno descrito pelo modelo fotopiroelétrico por reflexão concordou com a experiência em laboratório, além de especificar três regiões distintas nas quais ficam bem caracterizadas as condições de opacidade e transparência térmicas. Observamos que a amostra se torna termicamente espessa para $f>f_{c}$, onde antes se considerava que fosse para a frequência crítica, $f>f_{c r}$.

O requisito da amostra oticamente transparente não é essencial, como vimos nas medidas com a pastilha de silício. Portanto, este modelo pode ser usado para qualquer tipo de amostra. Aplicamos também a técnica na determinação da difusividade térmica do filme de P3BT dopado e obtivemos excelente resultado, o qual concordou com o obtido pelo modelo de Mandelis, pois essa amostra é oticamente opaca. Além disso, o contato térmico entre as superfícies da amostra e do detetor foi mais eficiente já que não havia a camada de tinta preta. Essa camada nem 
sempre fica uniformemente distribuida. Por esta razão, é que conseguimos obter os sinais fotopiroelétricos versus frequência de modulação, mais estáveis e, portanto, mais precisos do que aqueles obtidos com a superfície preta.

A espectroscopia realizada com esse modelo torna-se equivalente a espectroscopia fotoacústica tendo a vantagem de ser uma técnica de câmara aberta, com medida direta da temperatura. Outras vantagens que são obtidas com essa técnica por reflexão é a independência com o termo do detetor e a determinação da região de transição, fator importante na caracterização térmica.

\section{2 - MODELO FOTOACÚSTICO PARA AMOSTRAS TRANSPARENTES}

Apesar deste modelo ser similar aos de outros pesquisadores, apresentamos neste trabalho um novo tratamento que simplifica os resultado e facilita sua aplicação na caracterização térmica de amostras transparentes.

Esse tratamento traz ainda a vantagem, no aspecto experimental, de ser aplicável a qualquer tipo de câmara fotoacústica convencional.

\section{3 - MÉTODO SEMI-EMPÍRICO PARA DETERMINAÇÃo DA DIFUSIVIDADE TÉRMICA}

Este método tem como base as observaçōes feitas em diversos modelos fototérmicos que consideram apenas a difusão térmica como fenômeno dominante. 
Através de uma expressão simples e racional, verificamos que seu campo de ação abrange amostras tanto termicamente fina como espessa, e seu resultado é comparado aos obtidos por expressões mais complexas. Sua aplicação em amostras reais, quando a difusão térmica é dominante, mostrou ser de grande utilidade e eficiência. Através dos ajustes da expressão do método aos pontos experimentais foi possível verificar a região de frequência de modulação onde, possivelmente, outro efeito ocorreu, tal como flexão termoelástica.

O uso do $\log (\log )$ nos possibilitou ter mais sensibilidade na análise dos sinais fototérmicos.

\section{4 - ESTUDO DO P3BT}

O P3BT foi estudado basicamente pela técnica fotopiroelétrica com a qual obtivemos informações térmicas de interesse: difusividade e condutividade térmicas.

Foi possível observar que esta técnica pode monitorar a dopagem dos filmes de polímeros condutores através de suas propriedades térmicas.

Foi obtido a partir da curva de absorção, o valor do "gap" ótico, representando a transição $\pi-\pi^{*}$, através da análise das curvas $V_{n}$ e fase versus comprimento de onda, respectivamente.

Também, foi possível observar a existência de outro efeito fototérmico, tal como a flexão termoelástica, ocorrendo simultaneamente ao de difusão térmica. Esse efeito foi minimizado quando colocamos uma janela transparente sobre a amostra, diminuindo a possibilidade de seu deslocamento . 


\section{5 - SUGESTÕES AOS USUÁRIOS DAS TÉCNICAS FOTOTÉRMICAS}

Relacionamos abaixo algumas sugestões para usuários das técnicas fotoacústica e fotopiroelétrica:

1 - equilibrio dos sinais elétricos, quando se usa dois feixes óticos, no caso de equipamento de duplo feixe;

2 - evitar diferença de volume nas câmaras fotoacústicas a qual produz erros na linha de base do espectro;

3 - procurar a melhor frequência de modulação para minimizar a deformação no espectro fototérmico;

4 - o uso da técnica fotopiroelétrica, quando possível, para caracterização térmica de amostra;

5 - procurar normalizar os sinais fototérmicos versus frequência de modulação;

6 - comparar os resultados obtidos pela amplitude com os da fase;

7 - usar a técnica fotopiroelétrica por reflexão para caracterização térmica de amostra não totalmente opacas;

8 - sempre que possível, obter os sinais fototérmicos em fase e em quadratura;

9 - procurar ajustar as curvas pelo método $\log (\log )$;

10- ter muito cuidado com perda de calor quando a amostra é espessa; 


\section{6 - TRABALHOS FUTUROS}

Para os trabalhos futuros, pretendemos continuar nos estudos de polímeros condutores na forma de filmes e também de pastilhas de pó prensado. Pretendemos estudar a anisotropia térmica dos polímeros e o efeito de compactação das pastilhas dos polímeros nas grandezas térmicas.

Dados preliminares, não mostrados no texto, apresentaram valores de difusividade térmica mais alta do que a do filme. Observamos que estes valores dependem do processo de compactação, isto é, o valor de pressão aplicada e atmosfera envolvente. Para uma pastilha de $350 \mu \mathrm{m}$ de espessura obtida com uma pressão de $12000 \mathrm{libras} / \mathrm{cm}^{2}$ e baixo vácuo, conseguimos determinar que a difusão térmica é de $\cong 200 \times 10^{-8} \mathrm{~m}^{2} / \mathrm{s}$.

Pretendemos concluir os estudos da degradaçao do pó de óxido de neodímio $\left(\mathrm{Nd}_{2} \mathrm{O}_{3}\right)$ usando a câmara fotoacústica combinada para verificar se há liberação de oxigênio no interior da câmara e sua respectiva variação de temperatura.

Desejamos continuar aplicando estas técnicas em outros materiais de interesse científicos e tecnológicos.

111 